\title{
Localization and Function of RNases in Bacillus subtilis
}

\author{
Dissertation \\ for the award of the degree \\ "Doctor rerum naturalium" \\ of the Georg-August-Universität Göttingen
}

\author{
within the doctoral program \\ Molecular Biology \\ of the Georg-August University \\ School of Science (GAUSS)
}

submitted by

Nora Cascante Estepa

from Soria (Spain) 


\section{Thesis Committee}

Prof. Dr. Jörg Stülke

(Institute of Microbiology and Genetics, Department of General Microbiology)

Prof. Dr. Markus Bohnsack

(Institute of Molecular Biology, Department of Molecular Biology)

Prof. Dr. Ivo Feussner

(Albrecht-von-Haller Institute for Plant Sciences, Department of Plant Biochemistry)

\section{Members of the Examination Board}

Prof. Dr. Jörg Stülke

(Institute of Microbiology and Genetics, Department of General Microbiology)

Prof. Dr. Markus Bohnsack

(Institute of Molecular Biology, Department of Molecular Biology)

Prof. Dr. Ivo Feussner

(Albrecht-von-Haller Institute for Plant Sciences, Department of Plant Biochemistry)

Prof. Dr. Stefanie Pöggeler

(Institute of Microbiology and Genetics, Department of Genetics of Eukaryotic Microorganisms)

PD Dr. Wilfried Kramer

(Institute of Microbiology and Genetics, Department of Molecular Genetics)

Dr. Fabian Commichau

(Institute of Microbiology and Genetics, Department of General Microbiology) 
Herewith I declare, that I prepared the Doctoral Thesis "Localization and Function of RNases in Bacillus subtilis" on my own and with no other sources and aids than quoted.

Göttingen, 21st December 2016 



\section{Acknowledgements}

In the first place I would like to express my sincere gratitude to my supervisor Prof. Dr. Jörg Stülke for this opportunity and for the guidance throughout these years. Besides my supervisor, I would like to immensely thank Prof. Dr. Markus Bohnsack and Prof. Dr. Ivo Feussner for being part of my Thesis Advisory Committee, and for their insightful comments during the committee meetings. I thank Prof. Dr. Stefanie Pöggeler, Prof. Dr. Heike Krebber, and Dr. Fabian Commichau for taking part in the Examination Board.

I would like to thank Achim Dickmanns, Johannes Arens, and Piotr Neumann for the work performed on PNPase, as well as Prof. Dr. Ficner for the opportunity of working together with his group in that project.

I would also like to express my gratitude to Prof. Dr. Diederichsen for the possibility of performing experiments in his department. Thank you to Daniel Frank for his technical support in managing the HPLC, and for his infinite patience.

During my secondment in Amsterdam I had an amazing time and I would like to thank Prof. Dr. Leendert Hamoen for the opportunity of spending two months in his lab. Also I would like to thank Laura C. Bohórquez for helping me in the lab and in the city, and for the nice time that I had there. iGracias! Of course, I also want to thank the rest of the Hamoen's lab for the nice environment and for making me feel very welcome. Also, thank you to Henrik Strahl for the very interesting talks that we had and for the brief time we worked together on RNase $\mathrm{Y}, \mathrm{I}$ learnt a lot during this time.

Thank you to the fellows and all the members of the AMBER Consortium. I really had a very nice time in all the meetings, courses, conferences, and, of course, the free time that we spent together. Also thank you to the EU FP7 Marie Curie Initial Training Network on Molecular Bacteriology for financial support.

I would like to thank the Molecular Biology program of the University of Göttingen for this amazing opportunity, and especially to Kerstin Grüniger and Dr. Steffen Burkhardt for their organization and their constant support.

I am very grateful to all the members of the AG. Stülke, AG. Commichau, and AG. Hoppert (past and present), for the great time that I had these years and for the nice working environment. Especially, I would like to thank Christina Herzberg, who was there from the very beginning, and taught me everything. Also for the conversations that we shared while filling tip boxes, that made it much less boring ;). Very especial thanks to Jan Kampf and Daniel Reuß, as well as Ingrid Quintana and Blanca Rincón for the nice conversations, meals, and kitchen times. 
You cheered me up in difficult moments. Also, thanks to Raphael Michna, Bingyao Zhu, and Martin Weiß for awesome times in the Nerd office.

I also want to thank my students Cedric Blötz, Larissa Krüger, and Jonas Jennrich for showing me how much I like teaching. Also Katrin Gunka for joining the RNA team, I wish we could have worked longer together.

Quiero agradecer el apoyo de mi familia, de mi hermano Mario, mis padres y Ricardo por apoyarme incondicionalmente y por siempre preguntarme sobre la tesis y escucharme con paciencia. También a Nicolás Lemus por tantas conversaciones y momentos desesperados que al final acaban con una sonrisa ;).

And last but, of course, not least, thanks to Mike, that was the one that really was there for me every day, in the best and worst moments, and that patiently listened to me and helped me. And also thank you for surviving me writing the thesis. 


\section{Table of contents}

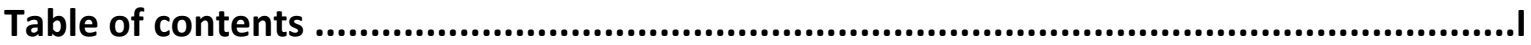

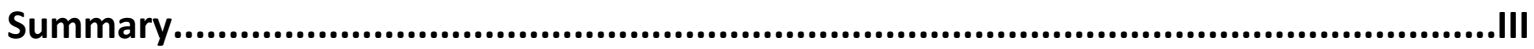

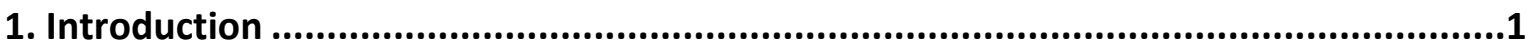

1.1. RNA processing in bacteria: maturation and decay ..........................................................1



1.3. The RNA degradosome in Escherichia coli ......................................................................4

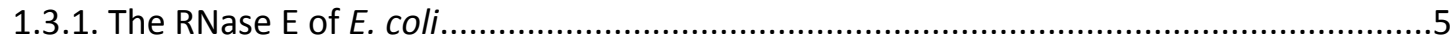

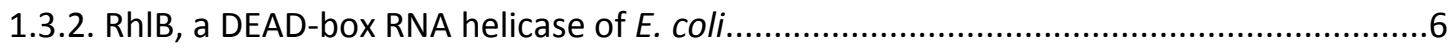

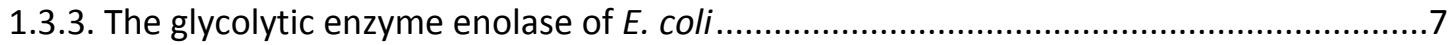

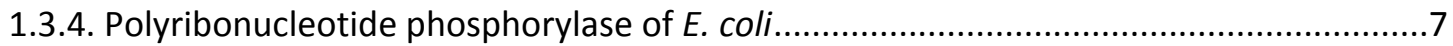

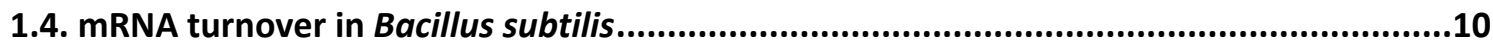

1.5. The RNA degradosome of Bacillus subtilis ......................................................................11

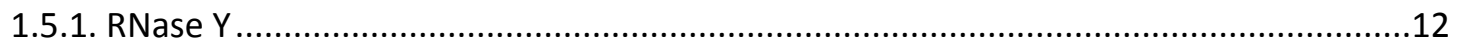

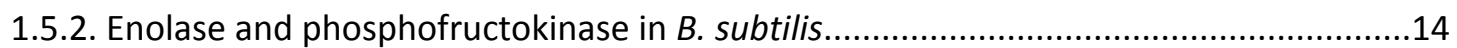

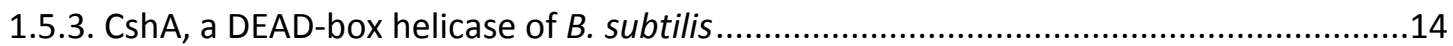

1.5.4. The polynucleotide phosphorylase of $B$. subtilis ......................................................15

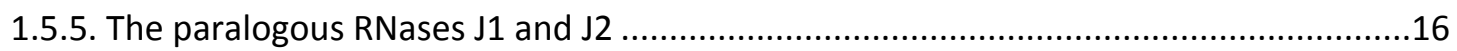

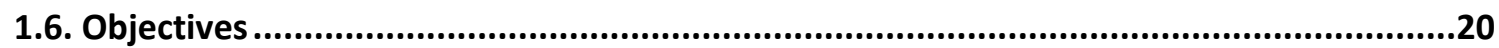

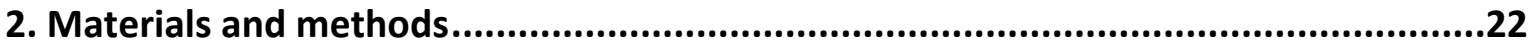

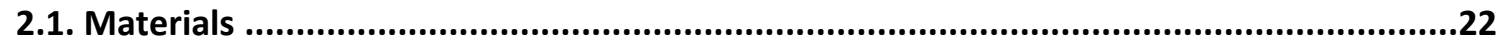

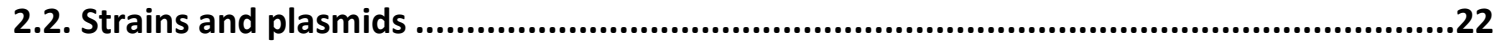

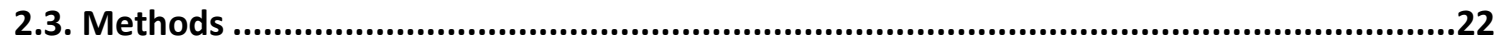

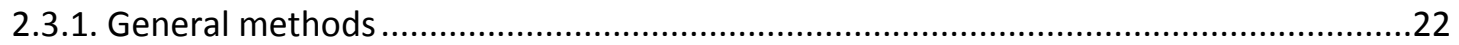

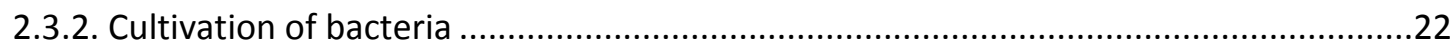

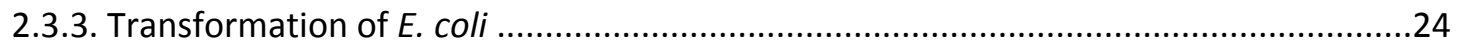

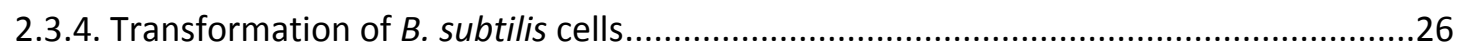

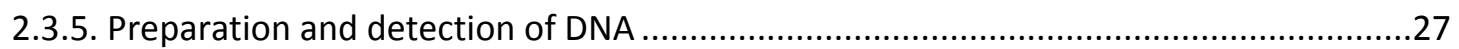

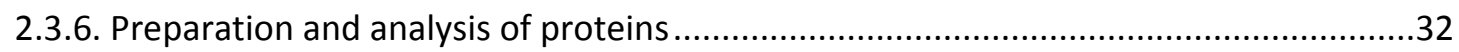

2.3.7. Light and fluorescence microscopy ...........................................................................

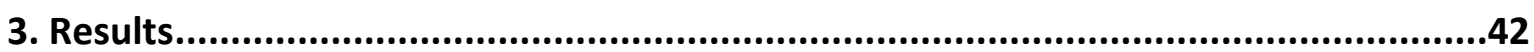

3.1. Localization of components of the RNA-degrading complex of $B$. subtilis .......................42

3.1.1. Functionality of the proteins fused to GFP in vivo......................................................42 
3.1.2. Localization of the proteins fused to GFP within the $B$. subtilis cell

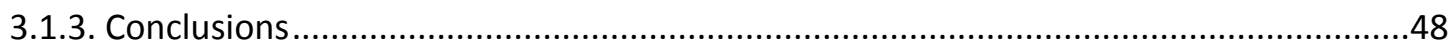

3.2. In vivo interaction of the paralogous RNases $\mathrm{J1}$ and J2 ........................................49

3.2.1. RNases J1 and J2 interact in vivo through the C-terminal domain ..........................49

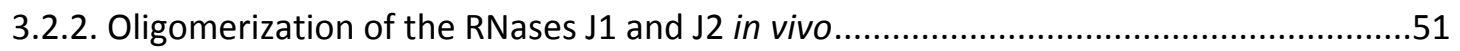

3.2.3. Localization of the RNases J1 and J2 in different deletion mutants ..........................54

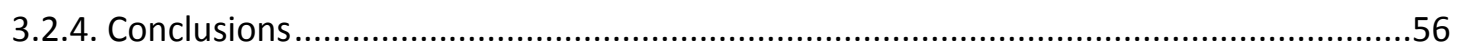

3.3. In vitro activity of the enzyme PNPase of Bacillus subtilis ..........................................57

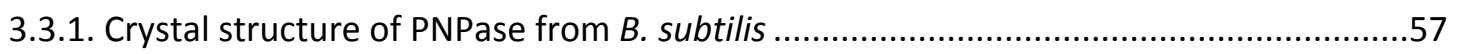

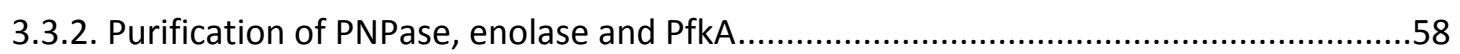

3.3.3. Degradation activity of PNPase in vitro ............................................................61

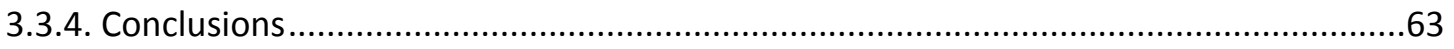

4. Discussion..............................................................................................64

4.1. The RNA degradosome of $B$. subtilis, does it exist? ..............................................64

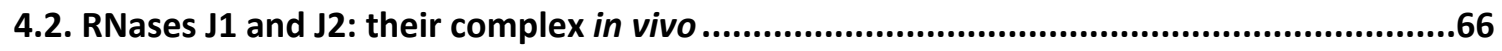

4.3. The degradation activity of PNPase in vitro ...................................................69

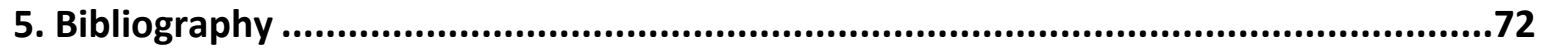

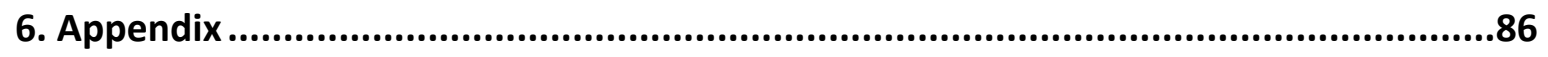

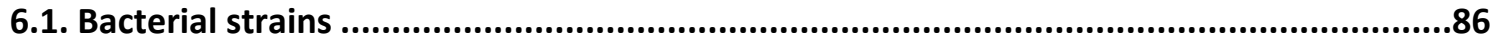

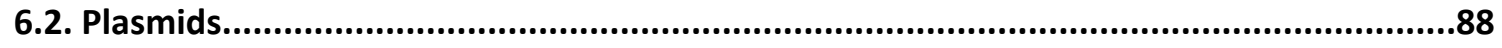

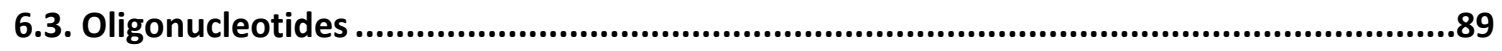

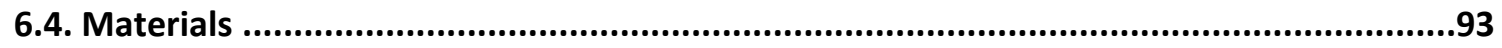

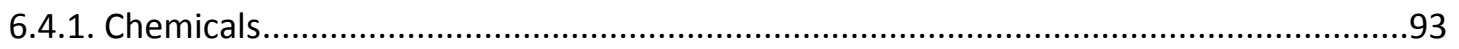

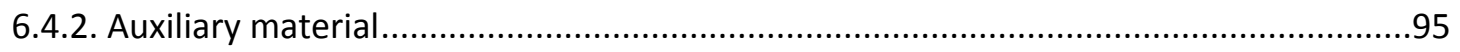

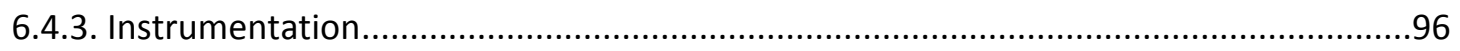

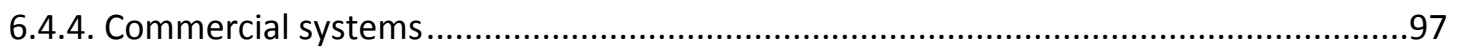

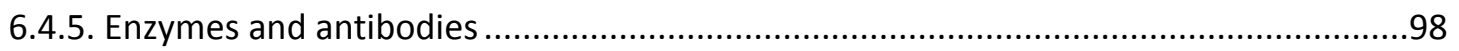

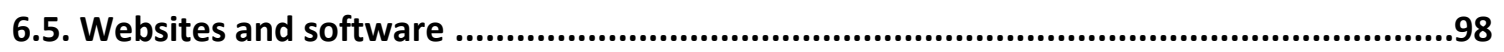

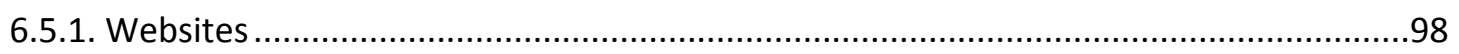

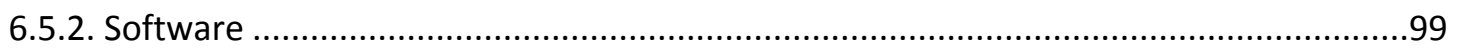

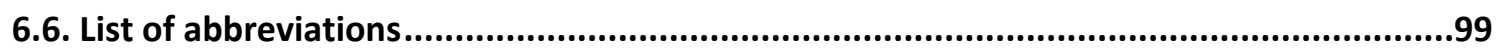

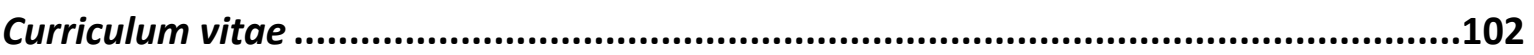




\section{Summary}

The ability to adapt to changing environmental conditions is essential for every organism to survive. In bacteria, this adaptation relies on the control of the mRNA synthesis, stability, and turnover, which allows the expression of different sets of proteins as a response to the external conditions. In many bacteria, the enzymes responsible for the degradation of the mRNA interact to form multi-enzyme complexes, the RNA degradosomes. In the Gram-positive model organism Bacillus subtilis, several binary interactions were detected amongst RNA-related proteins in vivo, and it has been hypothesized that an RNA-degrading complex exists in this organism. These interactions involved the endoribonuclease RNase $\mathrm{Y}$, the RNA helicase CshA, the exoribonucleases RNase J1 and PNPase, and the glycolytic enzymes enolase and phosphofructokinase. Moreover, the paralogue of RNase J1, RNase J2 was shown to only interact with RNase J1. However, some of these interactions could not be reproduced and the complex could never be purified as a whole, questioning the possibility of its existence. In this work, I have studied the subcellular localization of the components of the RNA degradosome of $B$. subtilis. The differential localization of each protein rules out the existence of a stable RNA degradosome. Furthermore, I have studied the interaction and oligomerization between the paralogous RNases $\mathrm{J} 1$ and $\mathrm{J} 2$ in vivo, and analyzed the importance of the $\mathrm{C}$-terminal domain for this interaction. The results confirm the interaction of the RNases J1 and J2 through the C-terminal domain, and show that they oligomerize as dimers and tetramers. However, it is possible that the tetramers can only be formed in the presence of RNA. Moreover, it seems that the RNase J2 cannot interact with RNA on its own.

Although the enzymes of the putative RNA degradosome have been extensively studied, many questions regarding activity and regulation remain open. Amongst them, the enzyme PNPase is one of the best studied, since PNPase from Escherichia coli has been studied for many decades. It has been shown that ATP, c-di-GMP and citrate, amongst others, can regulate its activity. However, the regulation of the PNPase from B. subtilis is not known. In this work, I have studied the effect of citrate, c-di-GMP and c-di-AMP, as well as enolase and phosphofructokinase, on the RNA degradation activity of PNPase. None of these metabolites and enzymes seems to have an effect on this activity.

Altogether, these findings contribute to a better understanding of the complex picture of RNA degradation, while opening ways for further investigations. 



\section{Introduction}

It is essential for any organism to establish a dynamic equilibrium that allows the proper interplay and regulation of the different molecular mechanisms. This should permit the maintenance of the homeostasis as well as enable the organism to be able to swiftly respond to sudden environmental changes. To achieve this, the organisms need to have access to a different set of proteins for every specific condition, to ensure the possibility of accommodating their internal molecular mechanisms to the new environment. This is achieved by the control of the gene expression. This can be exerted at several levels; however, the protein levels are ultimately dependent on, not only the amount of mRNA, but also of other RNA species, such as rRNA, tRNA and non-coding regulatory RNAs. The RNA turnover relies on transcriptional and posttranscriptional regulation; however, its stability and functionality are dependent on the latter. This regulation, that occurs after the RNA has been synthesized, is what is referred to as RNA processing.

RNA processing exists and is essential in every domain of life (archaea, bacteria and eukarya). It is a general name that describes very different mechanisms that modulate the gene expression, such as capping, splicing, nuclear export, polyadenylation, editing, maturation or decay. These are regulated all together to ensure that a proper amount of functional RNA species is provided at all times.

\subsection{RNA processing in bacteria: maturation and decay}

The ability to adapt to external changes is especially important in bacteria, since they are often subject to extreme environmental variations (in temperature, salt concentration, nutrient availability, presence of antibiotics), for example in the change from saprophyte to pathogenic. In prokaryotes, however, the majority of the RNA processing events are minor or non-existing, so they rely almost exclusively on RNA maturation and degradation to exert the post-transcriptional control of the gene expression.

Maturation occurs in rRNA and tRNA species, which are synthesized as precursor molecules that need to undergo several modifications to become fully functional. These include base modification and nucleolytic cleavage. Prokaryotic ribosomes (70S) are complex ribonucleoproteins composed of the large (50S) and the small (30S) subunits. The proteins serve as a scaffold for the proper organization of the complex, whereas the RNAs possess catalytic activity. There are three rRNA molecules within the ribosome: $5 \mathrm{~S}$ and $23 \mathrm{~S}$ in the large subunit and $16 \mathrm{~S}$ in the small subunit. They are encoded in a single operon that is present several times in the 
genome, depending on the microorganism, for example, seven times for Escherichia coli (Deutscher, 2009) and ten for B. subtilis (Loughney et al., 1982; Stewart et al., 1982; Jarvis et al., 1988). The ribosomal RNAs are transcribed together in one molecule, consequently, a downstream processing is necessary to obtain the mature forms that can be assembled into the ribosomal subunits. This maturation processing is very conserved amongst bacteria, although the mechanisms through which they are performed differ substantially (Arraiano et al., 2010).

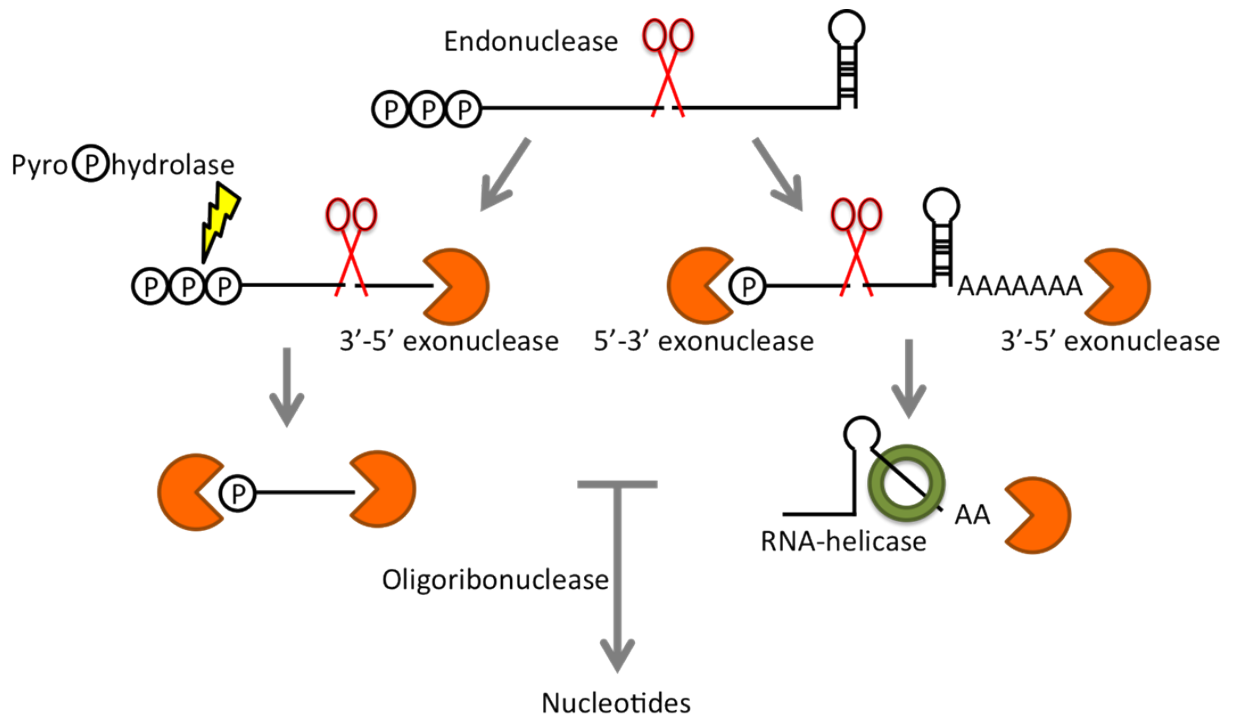

Figure 1. Pathways for RNA degradation in bacteria. Messenger RNAs are generally protected in both ends to prevent their fast degradation. They possess a triphosphorylated 5' end and secondary structures at the 3', as well as in the body of the transcript. The degradation of an mRNA can occur starting with an endonucleolytic cleavage or by exonucleolytically processing the extremes of the transcripts. However, for the latter, other enzymes have to take part in surpassing the protection of the ends. Pyrophosphohydrolases can remove the phosphates at the $5^{\prime}$ and RNA helicases, with the help of poly(A)-polymerases can overcome the secondary structures. Once the protections have been removed or the transcript has been cut in the body by an endonuclease, the degradation of the transcript is very fast, and the pool of nucleotides is restored with the help of oligoribonucleases.

Once the ribosomes are correctly assembled, the tRNAs act as adaptors for decoding the information on the mRNAs in the process of translation. Transfer RNAs are also often encoded in operons, so they must undergo nucleolytic processing similar to ribosomal RNA. Once the single tRNAs have been released, further processing is required (like base modification or CCA signal at $3^{\prime}$ end) for the mature form to be able to fold properly and to be recognized for specific aminoacylation (Hartmann et al., 2009). Incorrect folding implies rapid decay, less fidelity of aminoacylation and less efficiency in the binding to ribosomes. Altogether, the proper regulation of the rRNA and tRNA post-transcriptional modification is mandatory for an appropriate protein synthesis. Nonetheless, quality control mechanisms exist to eliminate defective species that threaten the accuracy of the process. Nucleolytic processing is responsible for the degradation of 
rRNAs and tRNAs when needed, sometimes after addition of a destabilising poly(A) tail (in the case of tRNAs) (Arraiano et al., 2010).

The turnover of the messenger RNAs is also a highly regulated process and a crucial event for the control of the gene expression. It is necessary for the rapid adaptation of the organism to the environment (Wilusz and Wilusz, 2004), as well as for the maintenance of the pool of ribonucleotides that have to be available for incorporation in newly synthesized molecules. It is, thus, essential to have the mechanisms for mRNA degradation under strict control (Laalami et al., 2014). However, the only way of efficiently regulating the degradation of mRNA is to control the steps for the initial cleavage, which commits the molecule to decay (Górna et al., 2012). There are three theoretical ways of initiating the degradation of the mRNA molecules: an endonucleolytic cleavage or an exonucleolytic cleavage from the $5^{\prime}$ or $3^{\prime}$ end (Laalami et al., 2014) (Figure 1). The decay of mRNA has been extensively studied especially in the Gram-negative model organism $E$. coli, where the processes and enzymes involved are well characterized (Carpousis, 2002; Marcaida et al., 2006; Bandyra et al., 2013). For many years it was assumed that these mechanisms and enzymes for mRNA degradation in other bacteria would be very similar to the ones previously described for $E$. coli (Deutscher, 2015). Surprisingly, new functional studies as well as the sequencing of the whole genome of the Gram-positive model organism Bacillus subtilis (Kunst et al., 1997) proved that what was known for the Gram-negative could not be fully extended to B. subtilis (Deutscher, 2015). The study of the mechanisms for the decay of mRNA in B. subtilis revealed major differences in the enzymes taking part in this process (Górna et al., 2012; Deutscher, 2015). The search for homologues of the known enzymes was not fruitful, and it seemed that, while the processes were conserved, the players were not (Laalami et al., 2013; Bandyra et al., 2013).

\section{2. mRNA turnover in Escherichia coli}

The pathways for the degradation of mRNA in bacteria have been studied for many years and continue to be extensively studied. Almost every year a review is published that gathers the recent discoveries on the topic (Condon, 2007; Arraiano et al., 2010; Condon and Bechhofer, 2011; Bechhofer, 2011; Lehnik-Habrink et al., 2012; Laalami et al., 2014; Hui et al., 2014; Deutscher, 2015; Mohanty and Kushner, 2016). The decay of mRNA has been mostly studied in the Gram-negative model organism E. coli. It is generally accepted that the degradation of the mRNA can occur following two different pathways: the direct entry pathway and the $5^{\prime}$ enddependent pathway. In the direct entry, the transcript, protected with a triphosphate at the $5^{\prime}$ end is attacked by a single endonucleolytic cut by the endonuclease RNase E. Subsequently, the 
two fragments that are released are differentially processed. The upstream fragment is degraded by 3'-5' exonucleases, like RNase II, PNPase or RNase R. The downstream fragment, unprotected of the $5^{\prime}$ triphosphate, can now be recognized by the $5^{\prime}$ sensor of RNase E. The $5^{\prime}$ end is bound in a pocket of RNase $\mathrm{E}$ and the fragment is cleaved several times, releasing fragments that are degraded by $3^{\prime}-5^{\prime}$ endonucleases. The small fragments that are released are then further degraded to monomers by the oligoribonuclease, restoring like this the pool of ribonucleotides. The second pathway depends on the phosphorylation of the $5^{\prime}$ end. The pyrophosphohydrolase $\mathrm{RppH}$ is responsible for cleaving the $5^{\prime}$ triphosphate structure that protects the transcript. Once the $5^{\prime}$ is unprotected, the RNase $\mathrm{E}$ is able to bind the transcript and perform several cleavages, releasing several fragments that are degraded by $3^{\prime}-5^{\prime}$ exonucleases as described above. In the case of secondary structures, the transcript can be polyadenylated by a poly(A) polymerase, allowing the $3^{\prime}-5^{\prime}$ exoribonucleases to re-engage until the fragments have been processed to ribonucleotides. Furthermore, the RNA helicases can help in the process of degrading fragments with secondary structures. A general overview of the process can be seen in Figure 1.

It can be appreciated that the decay of mRNA transcripts is not dependent on one single enzyme, but is a collaboration of several activities. Interestingly, it has been shown for E. coli and other prokaryotes that the RNases associate with other RNA-related activities to form active complexes, the RNA degradosome. The RNA degradosome of $E$. coli is described below.

\subsection{The RNA degradosome in Escherichia coli}

The RNA degradosome is a multi-enzyme complex formed by RNA-related proteins and whose function is the processing and degradation of RNA. The complex is formed around a central endonuclease, RNase E, which interacts with the $3^{\prime}-5^{\prime}$ exoribonuclease PNPase (Carpousis et al., 1994; Braun et al., 1996), the DEAD-box RNA helicase RhIB (Py et al., 1996), and the glycolytic enzyme enolase (Miczak et al., 1996; Py et al., 1996). The complex exists associated to the membrane through the N-terminal domain of the RNase E (Liou et al., 2001; Strahl et al., 2015). Furthermore, the complex has been reconstituted in vitro (RNase E, PNPase, and RhlB), where it forms spontaneously and is active as the native complex (Coburn et al., 1999). The complex with its four subunits could also be reconstituted by another group (Worrall et al., 2008). Moreover, the interactions of the proteins within the RNA degradosome have also been studied in vivo and the distances between subunits could be measured by fluorescence microscopy (DomínguezMalfavón et al., 2013). Interestingly, the complex has also been shown associated to the RNase II (Lu and Taghbalout, 2014) and the chaperone DnaK (Miczak et al., 1996), although the latter interaction seems to occur when the degradosome forms abnormally under stressful conditions 
(Regonesi et al., 2006). This, however, shows that the complex can interact with more proteins in a dynamic manner. A general study of these interaction partners was performed by proteomics and several partners could be identified for the wild type degradosome (Mauri and Dehò, 2008). The role of this minor interactions and their relevance was assessed by Kaberdin and Lin-Chao, 2009. A study of the function of the RNA degradosome in vivo found out that the four integral members of the complex are necessary for proper mRNA turnover in E. coli but that the complex acted upon some specific transcripts while others were not affected. It was proposed that there are structural or biochemical determinants that selectively target some transcripts over other (Bernstein et al., 2004).

The individual proteins of the RNA degradosome are described below.

\subsubsection{The RNase $\mathrm{E}$ of $E$. coli}

The endoribonuclease RNase E belongs to the RNase E/G family, which is present throughout the bacterial domain (proteobacteria, actinobacteria, firmicutes, and in some cyanobacteria). RNase $E$ is the central endoribonuclease. It does not only affect the global RNA stability and decay, but is responsible for the processing of RNA precursors of rRNA (Apirion, 1978; Roy and Apirion, 1983; Bouvet and Belasco, 1992; Ow and Kushner, 2002). It was discovered as the enzyme responsible for the cleavage between the $26 \mathrm{~S}$ and the $5 \mathrm{~S}$, although the gene could only be later identified (Apirion, 1978). Interestingly, the gene rne turned out to be identical to the ams (altered $\underline{m} R N A$ stability), the long-time known responsible for the global altered stability of the mRNAs (Mudd et al., 1990; Taraseviciene et al., 1991). Although RNase E shows no sequence specificity for its cleavages, it preferentially cuts in A/U-rich unpaired regions (Bouvet and Belasco, 1992; Carpousis, 2007). Furthermore, it is sensitive to the phosphorylation state of the 5' end, cutting preferentially when the $5^{\prime}$ is monophosphorylated (Mackie, 1998).

The enzyme is divided into two major domains: the N-terminal or catalytic domain, and the Cterminal or scaffolding domain (Figure 2). The crystal structure of the $\mathrm{N}$-terminal domain is available, and it has shed some light on the preferences of the enzyme for its cleavage (Callaghan et al., 2005a; Koslover et al., 2008). Furthermore, this catalytic domain is responsible for the tetramerization of the enzyme. For this oligomerization and for the functionality of the catalytic domain, the protein must be bound to zinc and magnesium ions (Callaghan et al., 2005b). The Cterminal domain is predominantly disordered, and it harbours several micro-domains, that interact with the members of the RNA degradosome: enolase, RhIB, and PNPase (Callaghan et al., 2004; Bouvier and Carpousis, 2011). It also contains two RNA-binding domains (Taraseviciene et al., 1995; Leroy et al., 2002) and an amphipathic $\alpha$-helical membrane domain that associates the 
multi-protein complex to the cell membrane (Khemici et al., 2005; Khemici et al., 2008; Strahl et al., 2015). This helix is conserved in homologues of RNase E of $\beta$ - and $\gamma$-proteobacteria, and its deletion causes slow growth in E. coli (Khemici et al., 2008; Aït-Bara et al., 2014).

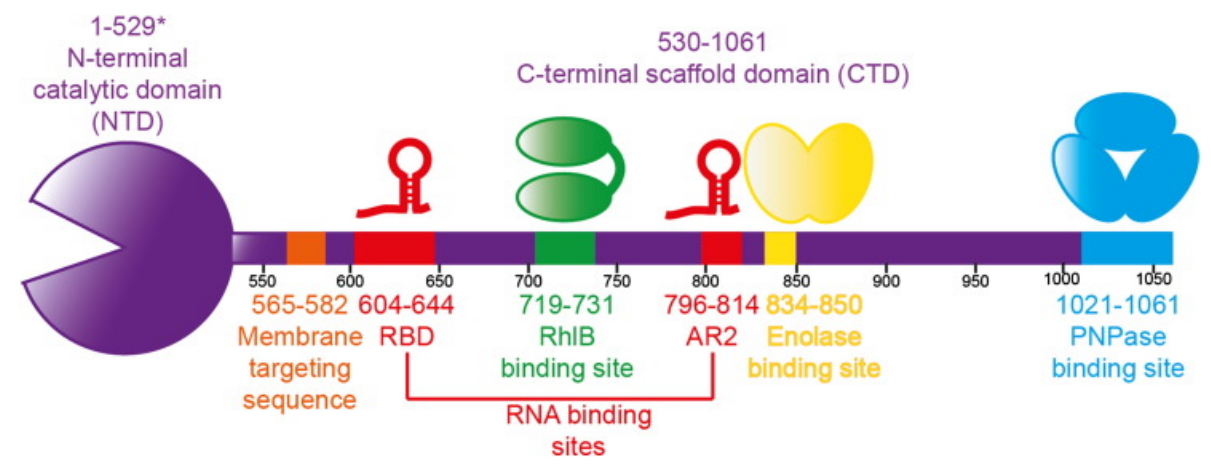

Figure 2. Domain organization of the endoribonuclease RNase E. From Bandyra et al., 2013. RNase E possesses tow distinct domains: the catalytic $\mathrm{N}$-terminal domain and the unstructured $\mathrm{C}$-terminal domain. The catalytic domain contains the active site and allows the enzyme to tetramerize, as a dimer of dimers. The unstructured C-terminal domain contains several micro-domains, and serves as a scaffold for interacting proteins of the RNA degradosome. The canonical interaction partners Rhlb, PNPase, and enolase are depicted. Furthermore, the C-terminal domain contains two RNA binding sites (red) and an amphipathic $\alpha$-helix that associates the enzyme to the membrane (orange).

\subsubsection{RhIB, a DEAD-box RNA helicase of $E$. coli}

RhlB is an ATP-dependent RNA helicase that belongs to the DEAD-box RNA helicase family (Kalman et al., 1991), and it is one of 5 members of this family present in E. coli (Worrall et al., 2007). RhIB is, however, the only helicase to have been found associated with the RNA degradosome. The presence of an RNA helicase within this RNA-degrading complex suggests that it is necessary for the proper degradation of structured RNA by the exo- and endonucleases, PNPase and RNase E (Py et al., 1996). In the degradosome, RhIB interacts with the essential scaffolding protein RNase E. This interaction is necessary for the activity of RhIB, and increases the ATPase activity of RhIB by an order of magnitude (Chandran et al., 2007; Worrall et al., 2007). Furthermore, it has been seen that RraA, a regulator protein of E. coli, binds RhIB and RNase E, inhibiting the activity of the helicase and, indirectly, the activity of PNPase in the complex (Górna et al., 2010; Pietras et al., 2013). However, several reports suggest that a mini-degradosome can be formed by the polynucleotide phosphorylase PNPase and the helicase RhIB. It was shown that RhIB interacts with PNPase in vivo and in vitro, but not with enolase, another member of the degradosome. The RhIB-PNPase complex is also active, without the interaction to RNase E (Liou et al., 2002). Furthermore, it was proved that a loss of interaction between RhlB and PNPase but not of RhIB with RNase E greatly affects the expression of genes involved in the cysteine metabolism, and increases the response to oxidative stress (Tseng et al., 2015). These studies confirm that 
RhIB and PNPase can be active on their own and not necessarily being part of the RNase E-based RNA degradosome.

For extensive reviews on DEAD-box RNA helicases in RNA degradosomes and involved in RNA metabolism consult (Carpousis et al., 2008; Hardwick and Luisi, 2013).

\subsubsection{The glycolytic enzyme enolase of $E$. coli}

Enolase is a metallo-enzyme that catalyses the conversion of 2-phosphoglycerate into phosphoenolpyruvate, in the penultimate step of glycolysis. It is universally conserved and present in the three domains of life, as is glycolysis. Although the enolase of $E$. coli has been characterized for many decades (Spring and Wold, 1971), the knowledge of its relationship with RNA metabolism is more recent (Miczak et al., 1996). Enolase is part of a multi-protein RNAdegrading machine, the RNA degradosome, and interacts directly with the core of the complex, RNase E (Chandran and Luisi, 2006). Although the presence of enolase within this complex has been known for a number of years (Miczak et al., 1996), the function of the glycolytic enzyme in such remains obscure. It is known, however, that the interaction of enolase with the degradosome is essential for the degradation of the glucose transporter mRNA ptsG under conditions of phosphosugar stress (Morita et al., 2004) and that the disruption of its interaction with RNase E affects the global mRNA turnover in E. coli (Bernstein et al., 2004). Nonetheless, it is yet unclear what is the role of the enzyme in the degradation of mRNA. It has been proposed that enolase could have a structural or allosteric role within the degradosome, connecting the RNA degradation with the central carbon metabolism pathways (Kühnel and Luisi, 2001). It has been shown, however, that a reconstitution in vitro of the RNA degradosome without the presence of enolase possesses activity like a wild type degradosome (Coburn et al., 1999).

\subsubsection{Polyribonucleotide phosphorylase of $E$. coli}

Polyribonucleotide phosphorylase (PNPase) was first identified as an RNA polymerase. The studies on PNPase from Azotobacter vinelandii granted in 1959 the Nobel Prize in Physiology or Medicine to Severo Ochoa, shared with Arthur Kornberg, "for their discovery of the mechanisms in the biological synthesis of ribonucleic acid and deoxyribonucleic acid". Many studies were performed in the following decades to elucidate the mechanism of action and regulation of the protein in vitro. The results from these studies have been reviewed by Littauer and GrunbergManago in 1999. The enzyme requires magnesium and catalyses the phosphorolytic cleavage of RNA molecules utilizing inorganic phosphate ( $\mathrm{Pi}$ ). This reaction is reversible, and thus the enzyme can use NDPs to synthesize RNA, releasing a Pi moiety (see Figure 3). In 1963, it was first 
discovered to play a role in the degradation of an mRNA from E. coli (Andoh et al., 1963; Sekiguchi and Cohen, 1963). This required Pi, which was calculated to be in the cell at a concentration of 30 mM (Andoh et al., 1963). PNPase is a 3'-5' exoribonuclease, which means that it degrades RNA from the 3' end. In E. coli, a second 3'-5' exoribonuclease exists, RNase II, which also catalyzes the degradation of RNA molecules, although in a hydrolytic manner. Interestingly, it was shown that 90\% of the RNA degradation in E. coli was performed hydrolytically, making PNPase not likely a major player in the RNA turnover in this organism (Deutscher and Reuven, 1991). Furthermore, studies of both RNases in vivo showed that the activity of neither of these enzymes could participate in the rate-limiting step of RNA degradation (Belasco and Higgins, 1988). It was later proposed that the enzyme responsible for the rate-determining step of RNA decay was the newly discovered endoribonuclease, RNase E (Babitzke and Kushner, 1991).



Figure 3. Reaction catalysed by PnpA. PNPase catalyses the reversible reaction of phosphorolytic cleavage of RNA. The enzyme needs a divalent cation as cofactor $\left(\mathrm{Mg}^{2+}\right.$ or $\mathrm{Mn}^{2+}$, for example) and inorganic phosphate to produce a nucleophilic attack on the RNA strand. As a result, one molecule of NDP is produced and the RNA molecule is shortened by one monomer. In the appropriate conditions the enzyme can elongate an RNA molecule by incorporating NDPs and releasing inorganic phosphate.

Further studies were performed to elucidate the role of this enzyme in vivo. It was shown that polyadenylation was required for the processive degradation by PNPase (Xu and Cohen, 1995). Moreover, even though the responsible enzymes (PAPI and PAPII) for polyadenylation in E. coli had been identified (Sarkar, 1997), it was discovered that PNPase possessed poly(A)polymerase activity (Mohanty and Kushner, 2000), that could account for the residual polyadenylation in the absence of the PAPs. Interestingly, the PNPase from spinach chloroplasts could also function as 
exonuclease and poly(A) polymerase (Yehudai-Resheff et al., 2001). It was later demonstrated, however, that the polymerization activity of PNPase in E. coli is not relevant in vivo (Jarrige et al., 2002). Furthermore, it was discovered that PNPase was necessary for the survival of the organism at cold temperatures, and that the exonucleolytic function and not the polymerization activity was critical in these conditions (Matus-Ortega et al., 2007; Awano et al., 2008). Although PNPase has a clear and important role in the RNA metabolism, it is obvious that, since others can replace the activity of the enzyme within the cell, PNPase is yet another player in the complex picture of RNA degradation. Interestingly, the enzyme has been shown to be regulated by several metabolites and signalling molecules such as ATP (Del Favero et al., 2008), citrate (Nurmohamed et al., 2011), and c-di-GMP (Tuckerman et al., 2011). The regulation of an RNA-degrading enzyme by such molecules raises interesting questions regarding the relationship between RNA processing and other cellular pathways.

PNPase is also involved in DNA metabolism, as it takes part in DNA repair after damage. It participates in nucleotide excision repair after UV damage (Rath et al., 2012) and it is involved in the protection against oxidative stress (Wu et al., 2009). Furthermore, it has been proved to be involved in the quality control of precursors for rRNA (Cheng and Deutscher, 2003).

The crystal structure of PNPase has been obtained (Shi et al., 2008; Nurmohamed et al., 2009). The enzyme presents a trimeric, ring-like structure, as was reported for enzymes from other organisms in previous studies (Portier, 1975a; Portier, 1975b; Symmons et al., 2000; Jarrige et al., 2002; Symmons et al., 2002). The central channel enclosed by the trimeric structure could be a means for the access of the RNA molecules to the active site of the enzyme. A close-up of the structure pointed to a role of the helical domain in catalytic activity, and unravelled the residues participating in the coordination of divalent metal ions, which are conserved amongst PNPases (Nurmohamed et al., 2009). PNPase has a subdomain organization composed of two RNase PHlike sub-domains, surrounding an $\alpha$-helical domain (Shi et al., 2008). Crystallographic studies in Streptomyces antibioticus suggest that only the most C-terminal PH domain is catalytically active (Symmons et al., 2000). At the C-terminal end the protein contains two RNA-binding domains KH and S1. They have been proposed to be the RNA binding surface that confers processivity to the enzyme (Jarrige et al., 2002; Stickney et al., 2005), but they do not participate in the catalysis (Stickney et al., 2005; Briani et al., 2007). A study of 55 sequences of bacterial PNPases has shown that the protein is highly conserved, except the $\alpha$-helical domain (Bermúdez-Cruz et al., 2005).

PNPase from $E$. coli has been shown to interact with several proteins in vivo. It was first identified to be present in the ribosomal fraction when this was isolated (Wade and Lovett, 1961). Moreover, it is part of a multi-protein RNA-degrading complex, the RNA degradosome. In the RNA degradosome, PNPase is bound to a characterized micro-domain in the C-terminal domain of 
RNase E (Vanzo et al., 1998), the central endoribonuclease of the RNA degradosome (see 1.3.1). The crystal structure of the E. coli PNPase has been solved bound to the aforementioned microdomain of RNase E (Nurmohamed et al., 2009). This complex comprises the central endoribonuclease RNase E, the DEAD-box RNA helicase RhIB, the glycolytic enzyme enolase, and the exoribonuclease PNPase (see 1.3). Furthermore, it has been reported that PNPase and the RNA helicase RhIB can interact in vivo independent of RNase E (Liou et al., 2002).

An extensive review on the regulation, expression, structure and activity of different PNPases of prokaryotes was recently published (Briani et al., 2016).

\section{4. mRNA turnover in Bacillus subtilis}

Although the pathways for the degradation of mRNA in B. subtilis have been extensively studied, many question marks remain. The mechanisms are very similar to those of the Gramnegative E. coli, however, the players are not well conserved (see 1.2). As for E. coli, the transcripts can be degraded in two pathways, the direct entry and the $5^{\prime}$ end-dependent pathway. In the direct entry a first endonucleolytic cleavage is performed that commits the transcript to degradation, being the rate-limiting step. It is performed by RNase $\mathrm{Y}$, although it can, in a lesser extent be performed by the RNases J1/J2 or another endonuclease (Laalami et al., 2014). Consequently, two fragments are released. The upstream fragment is degraded by the $3^{\prime}-5^{\prime}$ exonuclease polynucleotide phosphorylase ( $\mathrm{PnpA})$; the downstream fragment is degraded by the $5^{\prime}-3^{\prime}$ exonuclease RNase J1/J2. The latter was the first enzyme to be found that could degrade RNA in the 5'-3' direction in prokaryotes (Mathy et al., 2007). Alternatively, the protection of the triphosphate at the $5^{\prime}$ end can be removed by a pyrophosphohydrolase ( $\mathrm{RppH} 1$ or 2). Subsequently, the transcript is sensitive to be attacked by the exonuclease activity of RNase J1/J2. However, RNase J1/J2 has also been shown to cut endonucleolytically close to the $5^{\prime}$ end. Furthermore, RNase Y preferentially cuts RNAs with a monophosphorylated 5' end. This translates on a competition between RNase $\mathrm{Y}$ and both activities of RNase J1/J2 for the degradation of the unprotected transcript (Laalami et al., 2014). The smaller fragments generated by the consecutive action of several RNases are further degraded to ribonucleotides by oligoribonucleotides. Interestingly, no poly(A) polymerase has been identified in $B$ subtilis. However, there is evidence that the intermediates of degradation are polyadenylated. It is not clear, nonetheless, whether the polyadenylation is this organism contributed to the degradation of structured mRNAs. The existence of RNA helicases may be critical for the degradation of highly structures transcripts. A simplified overview of the degradation of mRNAs in bacteria is depicted in Figure 1. 
As for E. coli, many of the RNases and RNA-related proteins have been shown to interact amongst each other, in a putative RNA degradosome (see 1.3). These interactions and their relevance are described below.

\subsection{The RNA degradosome of Bacillus subtilis}

To increment the effectivity of a pathway, proteins can arrange in multi-enzyme complexes. Many of the activities that in B. subtilis take part in the degradation of RNA have been shown to interact amongst each other. They have been proposed to form an RNA-degrading complex, similar to the well-studied RNA degradosome of E. coli (see 1.3).

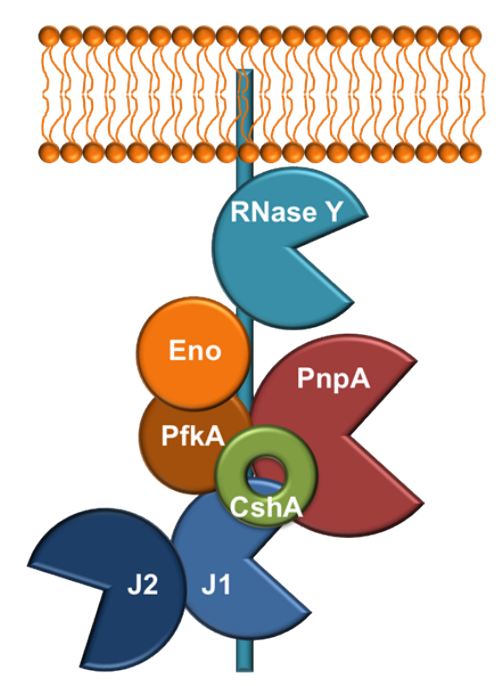

Figure 4. RNA degradosome of Bacillus subtilis. Interaction of proteins to form the RNA-degrading machine, the degradosome, following experiments from Commichau et al., 2009 and Lehnik-Habrink et al., 2010. RNase $Y$ is the protein that attaches the complex to the membrane through its $\mathrm{N}$-terminal membrane domain. The rest of the proteins interact amongst each other and with RNase $\mathrm{Y}$ at its scaffolding C-terminal unstructured domain.

The interactions were initially found by bacterial two-hybrid $(\mathrm{B} 2 \mathrm{H})$, as binary protein-protein interactions (Commichau et al., 2009). The model for the degradosome represented in Figure 4, is a complex of the exonuclease PNPase, the RNases $\mathrm{J} 1$ and $\mathrm{J} 2$, and the glycolytic enzymes enolase and PfkA, interacting with the unstructured $\mathrm{C}$-terminal domain of RNase $\mathrm{Y}$. RNase $\mathrm{Y}$ serves as a scaffolding protein, that attaches the putative RNA degradosome to the cell membrane thanks to its membrane-spanning $\alpha$-helix at its $\mathrm{N}$-terminal end (see 1.5.1). CshA was later identified as the DEAD-box RNA-helicase attached to the complex, as an analogy to RhlB in the E. coli RNA degradosome. Interestingly, among these RNA-related enzymes two glycolytic enzymes could be found, enolase and phosphofructokinase (PfkA or PFK). This is the case as well for enolase in the E. coli RNA degradosome. The interactions could later be reproduced by crosslinking in vivo pull- 
down experiments (Lehnik-Habrink et al., 2011a). Some of the binary interactions could also be analysed in vitro (enolase-RNase $Y$ and PNPase-RNase $Y$ ), although some could no be detected (PfkA-PNPase, PfkA-RNase J1, and RNase J1-RNase Y) (Newman et al., 2012). Furthermore, the interaction of PNPase and RNase Y could be reproduced in vivo by a different group (Salvo et al., 2016). However, the existence of this complex in B. subtilis is still under debate, since it could never be isolated as a whole. Furthermore, in vivo pull-down experiments of RNase J1 indicate that RNase J2 is most likely the major interacting protein, forming a complex of their own (Mathy et al., 2010), with no sign of additional interactions.

\subsubsection{RNase $Y$}

RNase $Y$ is encoded in $B$. subtilis by the gene $y m d A$, later re-named to rny (Commichau et al., 2009). The protein is an endoribonuclease that not only is involved in the processing of many individual transcripts (Commichau et al., 2009; Shahbabian et al., 2009; Lehnik-Habrink et al., 2011b; Noone et al., 2014), but also is of great importance for the general mRNA decay in this organism (Durand et al., 2012; Laalami et al., 2013). RNase $Y$ is, however, sensitive to the phosphorylation state of the transcript, and it is not able to cut endonucleolytically when the $5^{\prime}$ is triphosphorylated (Shahbabian et al., 2009). RNase $\mathrm{Y}$ is highly conserved in bacteria, especially in firmicutes. In the bacterial groups that do not contain a homologue of RNase $\mathrm{Y}$ it is likely to find a member of the E/G or the J RNases, although some exceptions exist that contain none of these known RNases (Commichau et al., 2009).

RNase $Y$ has been shown to play an important role in global mRNA decay in $B$. subtilis. There is evidence that this enzyme is responsible for the initial step, the rate-limiting step, of the decay, and that a depletion affects the expression of $25 \%$ of the genome (Durand et al., 2012). In other studies, however, the effect of the depletion of RNase $Y$ seems to be not as strong. Moreover, among the transcripts found to be affected in both studies, only $10 \%$ overlap (Laalami et al., 2013). It seems that the level of depletion and the conditions in which the experiments are performed highly affect the outcome. Furthermore, similar studies with the depletion of RNase $\mathrm{J} 1$, that also possesses endonuclease activity, show that this enzyme also greatly affects the global mRNA decay. Therefore, the possibility of RNase J1 being responsible for the initial step of mRNA decay cannot be completely excluded (Durand et al., 2012). Interestingly, it has been shown that RNase Y plays a role in biofilm formation (Lehnik-Habrink et al., 2011b; Lehnik-Habrink et al., 2011a). The rny gene is encoded in a bi-cistronic operon with $y m d B$, a gene encoding a phosphodiesterase that is involved in bi-stability and biofilm formation in B. subtilis (Diethmaier et al., 2011). 
Since the discovery of the enzyme it has been thought that the enzyme was essential, meaning it cannot be deleted from the genome (Hunt et al., 2006; Commichau et al., 2009; Shahbabian et al., 2009; Lehnik-Habrink et al., 2011b). Indeed, the depletion of the enzyme caused a strong phenotype with slower growth, elongated and anucleate cells and mini-cells. In 2013, the gene could, however, be completely knocked-out of the genome, showing an even more severe phenotype. The mutant strain is defective in competence and sporulation, hypersensitive to antibiotics and shows strong defects in cell morphology (Figaro et al., 2013).

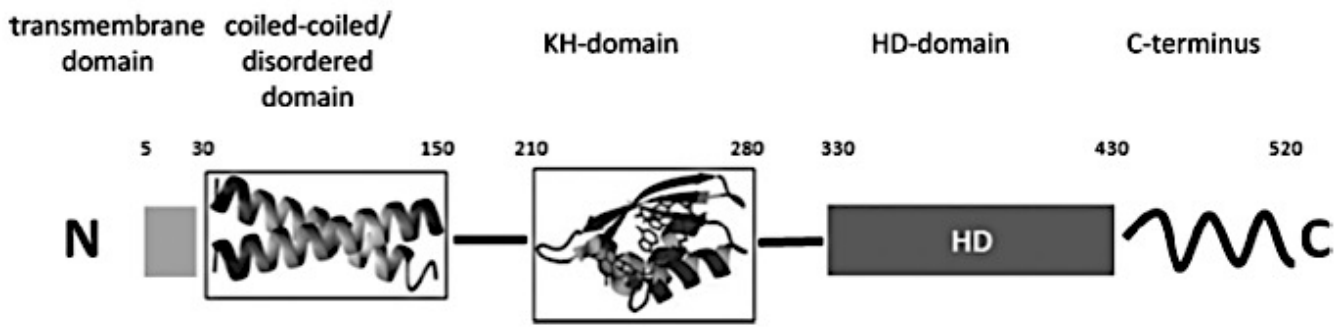

Figure 5. Domain organization of the RNase $\mathrm{Y}$ endoribonuclease. From Lehnik-Habrink et al., 2011a. RNase $\mathrm{Y}$ is composed of five domains. From $\mathrm{N}$-terminal to $\mathrm{C}$-terminal: membrane-spanning $\alpha$-helix, coil-coiled of unknown function, $\mathrm{KH}$ domain for RNA binding, HD domain with the active site and unstructured C-terminal domain of unknown function.

Structurally, the enzyme is composed of several domains (see Figure 5). It possesses a HD domain (His Asp) that is responsible for the enzymatic catalysis. This domain is highly conserved in the superfamily of metal-dependent phosphohydrolases (Aravind and Koonin, 1998). Indeed, it has been shown that the enzyme requires magnesium to perform the catalytic activity, although it can be replaced by manganese and zinc ions (Shahbabian et al., 2009). Furthermore, it contains a $\mathrm{KH}$ domain (ribonucleoprotein $\mathrm{K}$ homology) that is the RNA-binding domain and is typically found in RNases (Aravind and Koonin, 2001). Additionally, it contains two domains of unknown function, the coil-coiled domain and the unstructured but conserved C-terminal domain (Lehnik-Habrink et al., 2011a). A membrane-spanning $\alpha$-helix is found at the $\mathrm{N}$-terminal end of the protein (Shahbabian et al., 2009; Lehnik-Habrink et al., 2011a). This membrane anchor is fundamental to the enzyme. Releasing RNase $Y$ from the membrane results in reduced viability and hindered protein-protein interactions (Lehnik-Habrink et al., 2011a). Interestingly, it was recently found that in the Gram-positive Staphylococcus aureus the membrane localization of RNase $Y$ is essential for growth. Furthermore, the membrane-anchor seems to be necessary to bring related proteins to the proximity of the membrane (Khemici et al., 2015). Furthermore, the localization pattern at the membrane is influenced by the dissipation of the membrane potential (Strahl et al., 2014). 
In B. subtilis, RNase has been found to interact with several proteins from the RNA metabolism as well as from the carbon metabolism, namely glycolysis (Commichau et al., 2009). Indeed, it has been proposed as a scaffold for RNA-related proteins in a degradosome-like complex. The interactions involved in the formation of this RNA-degrading machine have been previously described (see 1.5).

\subsubsection{Enolase and phosphofructokinase in B. subtilis}

Enolase and phosphofructokinase (PFK) are enzymes from the glycolysis, a pathway that is conserved amongst bacteria, eukaryotes and archaea. Furthermore, enolase is one of the few enzymes that is universally conserved (Commichau et al., 2009). The essentiality of these enzymes has been an extensive field of study. Enolase has been reported as essential (Kobayashi et al., 2003) although the eno gene, could also be deleted in several studies (Leyva-Vazquez and Setlow, 1994; Commichau et al., 2013). The mutant is, however, not able to grow in LB complex medium. PFK was also considered essential for many years (Kobayashi et al., 2003) although deletion mutants have been isolated, with slower growth in sporulation medium or minimal media with glucose as a single carbon source (Muñoz-Márquez and Ponce-Rivas, 2010; Commichau et al., 2013). Even though some results seem contradictory, it is important to consider that, as metabolic enzymes, the growth media and the conditions in which the mutants were obtained greatly influence the possibility of deleting their respective genes.

Enolase and PFK have, interestingly, been associated with the RNA-degrading machinery in $B$. subtilis. This is of great importance, since enolase is an integral member of the E. coli RNA degradosome (see 1.3.3). Enolase has been shown to interact in vivo by bacterial two-hybrid assays (B2H) and crosslinking with RNase $Y$ and the RNA helicase CshA (Commichau et al., 2009; Lehnik-Habrink et al., 2010; Lehnik-Habrink et al., 2011a). PFK has been shown in the same experiments with CshA, RNase Y, PNPase and RNase J1 (Commichau et al., 2009; Lehnik-Habrink et al., 2010; Lehnik-Habrink et al., 2011a). However, the interaction between PFK and PNPase, and PFK and RNase J1 could not be confirmed in vitro, unlike the interaction enolase-RNase $\mathrm{Y}$, that was confirmed by surface-plasmon resonance (SPR) (Newman et al., 2012).

\subsubsection{CshA, a DEAD-box helicase of $B$. subtilis}

CshA in encoded by the $y d b R$ gene, later renamed to $\operatorname{csh} A$ (cold shock helicase-like protein A) (Hunger et al., 2006). It has been characterized as an ATP-dependent RNA binding protein, with RNA-dependent ATPase activity (Ando and Nakamura, 2006) that is able to destabilize RNA duplexes (Hunger et al., 2006). Furthermore, it is one out of four members of the DEAD-box RNA 
helicase family, present in B. subtilis (Redder and Linder, 2012). The expression of cshA is increased 2.6-fold as a response to cold shock, and it has been related to the cold-shock proteins (CSPs) (Beckering et al., 2002; Hunger et al., 2006). Furthermore, the deletion of this gene leads to growth defect and altered morphology at temperatures under $22^{\circ} \mathrm{C}$ (Ando and Nakamura, 2006; Lehnik-Habrink et al., 2013). Another group, however, could not see a cold sensitivity in the mutant (Hunger et al., 2006). CshA has been shown to be the most abundant helicase in $B$. subtilis and to be able to interact with ribosomal proteins. Interestingly, the protein is located to the same area as the ribosomes (Hunger et al., 2006), and its deletion leads to a defect in ribosome biosynthesis, as shown by a reduced number of them within the cell (Lehnik-Habrink et al., 2013). Moreover, CshA has been proposed as the functional homologue of RhIB in E. coli as it is able to interact with several RNases, in a putative RNA degradosome (Lehnik-Habrink et al., 2010). The Cterminal domain of CshA is necessary for interaction with these proteins and for its own dimerization. It can interact in vivo under crosslinking conditions with RNase $\mathrm{Y}$, PNPase, the glycolytic enzymes enolase and PfkA and RNase J1. Furthermore, it was shown by differential centrifugation that CshA is mostly attached to the membrane fraction (Lehnik-Habrink et al., 2010).

\subsubsection{The polynucleotide phosphorylase of $B$. subtilis}

Polynucleotide phosphorylase, or PNPase in $B$. subtilis, is a $3^{\prime}$ to $5^{\prime}$ exoribonuclease that catalyses the phosphorolytic attack on RNA, releasing a molecule of NDP. Moreover, the reaction is reversible and the enzyme is able to polymerize RNA, liberating a molecule of inorganic phosphate. It is encoded by the pnpA gene, formerly comR (it is involved in the expression of late competence genes (Luttinger et al., 1996). The enzyme is 50\% identical and $67 \%$ similar to the homologue of E.coli. Interestingly, the global mRNA decay in B. subtilis is mostly depending on a phosphorolytic activity, in contrast to E. coli that relies on a hydrolytic RNA degradation (Deutscher and Reuven, 1991). It is, therefore, likely that the PNPase in B. subtilis is one of the major activities in RNA metabolism. It has been speculated, however, that this effect could be artifactual, since the exonucleolytic activity of the, by the time unknown, RNase J1/J2 (see 1.5.5) could have been overlooked by using a 5' triphosphorylated transcript (Laalami et al., 2014). This would explain why the deletion of PNPase is not only viable but does not show a strong general effect on the gene expression (Luttinger et al., 1996). Nonetheless, a deletion strain of PNPase presents reduced competence, elongated filamentous cells and cold-sensitivity at $16^{\circ} \mathrm{C}$ and $23^{\circ} \mathrm{C}$ (Luttinger et al., 1996), but shows a relatively normal growth in other conditions (Wang and Bechhofer, 1996). The phenotype of long chained cells could be explained by a decrease in the 
expression of sigma D and the effect on the downstream genes (Liu et al., 2014). The enzyme was first confirmed as a polynucleotide phosphorylase upon in vitro activity assays, where it was able to cleave single-stranded RNA dependent on Pi (Mitra et al., 1996). Furthermore, the enzyme shows a similar processing function of the PNPase of E. coli (Wang and Bechhofer, 1996). In vivo the enzyme is required for the decay of specific transcripts, and can be stalled by secondary structures of the RNA (Bechhofer and Wang, 1998; Farr et al., 1999). Moreover, the enzyme has been shown to be involved in DNA metabolism, since it can degrade single-stranded DNA under conditions where manganese is available and the concentration of $\mathrm{Pi}$ is low. Interestingly, under high concentrations of $\mathrm{Pi}$, the enzyme preferentially degrades RNA, suggesting a dual function depending on the status of the cell (Cardenas et al., 2009). Since the enzyme catalyses a reversible reaction, its polymerization as well as its degradation activity have been shown to be involved in DNA repair mechanisms, regulated by RecN and RecA, respectively (Cardenas et al., 2011). Furthermore, its polymerization activity has led to the investigation of whether PNPase is the missing poly(A) polymerase of $B$. subtilis, since in E. coli PNPase accounts for the residual polyadenylation after deletion of the main PAP (see 1.3.4). However, two activities able to polyadenylate in the absence of PNPase have been found, although they could not be identified (Sarkar et al., 1997). Furthermore, a comparison of polyadenylation in B. subtilis in the presence and absence of PNPase proved that the polyadenylation profile was similar in both situations, ruling out the possibility that PNPase is the major poly(A) polymerase of this organism (CamposGuillén et al., 2005). In the meantime, the enzyme responsible for addition of poly(A) tails in $B$. subtilis remains unknown (Mohanty and Kushner, 2010).

\subsubsection{The paralogous RNases J1 and J2}

RNase J1 and J2 are two paralogous enzymes with a $49 \%$ sequence identity and $70 \%$ sequence similarity. They are encoded by the genes $r n j A(y k q C)$ and $r n j B(y m f A)$, respectively. They were first identified as members of the $\beta$-CASP protein family (metallo- $\beta$-lactamaseassociated CPSF Artemis SNM1/PSO2), as they contain the characteristic $\beta$-lactamase and $\beta$-CASP domains that name the family. These proteins contain three conserved motifs ( $A, B$, and $C)$ that are necessary for the enzyme's activity and that were predicted to be present in both paralogues, RNase $\mathrm{J} 1$ and J2. This family is present in all three domains of life (eukaryota, bacteria, and archaea) and its members are involved in DNA and RNA metabolism. However, all archaeal and bacterial members of this family have only been described to be active on RNA (Callebaut et al., 2002). 
RNases $\mathrm{J} 1$ and $\mathrm{J} 2$ were first identified in $B$. subtilis as functional homologues of the wellstudied endoribonuclease RNase E from E. coli, since they were able to cleave the thrS leader sequence from $B$. subtilis at the same place where RNase E can also process it. This discovery was a breakthrough because RNases $\mathrm{J} 1$ and $\mathrm{J} 2$ were the first proteins from the $\beta$-CASP family from prokaryotes demonstrated to take part on the RNA metabolism (Even et al., 2005). Furthermore, these enzymes seemed to have sensitivity to the phosphorylation state of the $5^{\prime}$ end of the transcript, showing a preference for monophosphorylated over triphosphorylated substrates. Interestingly, RNase $\mathrm{J} 2$ has an unexpected substitution in the conserved motif $\mathrm{C}$, that seems to not affect its endoribonucleolytic activity (Even et al., 2005). Further studies implicated RNase J1 in the maturation of the 5' end of the 16S rRNA form B. subtilis (Britton et al., 2007; Mathy et al., 2007) but it was discovered that this processing occurred 5'-3' exonucleolytically (Mathy et al., 2007). This was a major discovery since this activity had never been seen in prokaryotes and it was thought to only exist in eukaryotes. This activity seemed to be sensitive to the phosphorylation state of the $5^{\prime}$ end, and was also present in RNase J2, although much weaker: RNase J2 had a 100 times lower catalytic constant that RNase J1/J2 (Mathy et al., 2010). Since the first discovery of these enzymes, they have been shown to affect the expression of many transcripts. RNase J1 was proven to be responsible for the degradation of the destabilized glmS mRNA after metabolite-induced ribozyme-dependent self-cleavage (Collins et al., 2007). It was also shown to endonucleolytically process the ermC mRNA (Yao et al., 2008) although the 5'-3' exoribonucleolytic activity of RNase J1 could also take part in this degradation (Yao et al., 2009). Furthermore, RNase J1 was found to be responsible for the turnover of the trp leader RNA, which was processed both endo- and exonucleolytically (Deikus and Bechhofer, 2007; Deikus et al., 2008; Deikus and Bechhofer, 2011) and of the hbs transcript (Daou-Chabo et al., 2009). Moreover, RNase J1 is responsible for the decay of the RNAs from the toxin/antitoxin systems bsrE/SR5 and bsrG/SR4 in B. subtilis (Müller et al., 2016; Jahn and Brantl, 2016). Although these enzymes affected many individual transcripts, the complete picture of their activity in the cell was missing. A proteome and transcriptome analysis performed on the single and double mutants showed that a great amount of transcripts were affected by the lack of the enzymes, but much more in the double mutant than in the single mutants (Mäder et al., 2008). A deeper analysis of individual transcripts confirmed the -omics analysis. Moreover, an analysis by tiling microarrays was performed that demonstrated that 25 to $30 \%$ of the transcripts in the cell were affected by a more than 30-fold depletion of RNase J1 (Durand et al., 2012).

RNase J1 was described as essential in a study where the essentiality of several genes was evaluated (Hunt et al., 2006). The depletion of this enzyme caused an elongated phenotype and affected distribution of nucleoids, even with the presence of anucleate cells. This phenotype is 
similar to a mutant with blocked DNA replication. However, in a more recent study a deletion mutant of RNase J1 was obtained. As was observed for the depletion of RNase J1, the cells were filamentous and curly, although the phenotype could not be rescued by addition of magnesium. This filamentous phenotype could be explained by an 11-fold stabilization of the $m r e B H$ transcript (Durand et al., 2012). An increase in the expression of MreB has been shown to produce similar spirals in B. subtilis (Kawai et al., 2009; Figaro et al., 2013). It also showed other interesting phenotypes like hypersensitivity to antibiotics, cold-sensitivity (even at room temperature), and impaired competence (Figaro et al., 2013). Interestingly, a double RNase J1/J2 mutant was also viable. The deletion of RNase $\mathrm{J} 2$ has been shown to increase fitness under low-pressure conditions. An evolutionary experiment under these conditions has also shown a 9-nucleotide inframe deletion that also confers increased fitness compared with the parental strain (Waters et al., 2015). Although RNase J1 was shown to not be essential, the importance of the enzyme for the cell is undeniable. However, it is still unclear which function of the enzyme is responsible for the severe phenotype of RNase J1 deletion mutant. Both RNase J1 and RNase J2 have endonuclease activity, but the exonuclease activity of RNase J2 is very weak. Since the deletion of RNase $\mathrm{J} 2$ shows no clear phenotype it has been proposed that the most important activity is the 5'-3' exonucleolytic (Condon, 2010; Durand et al., 2012). Indeed, a double RNase J1 and PNPase ( $3^{\prime}-5^{\prime}$ exoribonuclease) mutant was not possible to be obtained (Figaro et al., 2013). This could be explained by a recent discovery that the bacterium relies on the $5^{\prime}-3^{\prime}$ exonuclease activity for the turnover of 3' processing fragments, if such activity is present in the cell (DiChiara et al., 2016). Interestingly, many other $\beta$-CASP family members have both activities (Dominski et al., 2013; Clouet-d'Orval et al., 2015) but little is known about how these activities are related. The first crystal structure of an RNase J was obtained from Thermus thermophilus, which is $61 \%$ similar to either RNase J1 or J2 (Li de la Sierra-Gallay et al., 2008). The enzyme possessed, as expected, the $\beta$-lactamase and $\beta$-CASP domains, as well as a C-terminal domain.

The catalytic site was defined by the presence of two zinc ions, coordinated in an octahedral environment. These were located in the cleft between the $\beta$-lactamase and the $\beta$-CASP domains. However, this depicted one only active site for a dual activity. Nonetheless, the confirmation that the active site was responsible for both activities was confirmed by the mutation of the amino acids responsible for the coordination of the zinc ions, which severely impaired the exo- and the endonucleolytic activities. Soon after, the paradox of one active site-two functions could be explained, when the crystal structure of B. subtilis RNase J1 was obtained (Newman et al., 2011), as well as the crystal structure of $T$. thermophilus RNase J bound to RNA (Dorléans et al., 2011). The structure of RNase J1 (Figure 6) is very similar to the previous one for T. thermophilus. Interestingly, some key amino acids for the coordination of the zinc ions in the active site are 
missing in the RNase J2 of B. subtilis (Newman et al., 2011). Furthermore, another two amino acids that seem to be important for the correct positioning of RNA are also substituted in RNase J2. These phenomena could explain the loss of exonuclease activity of RNase J2, but they cannot explain why the endonuclease activity is maintained. However, the structural studies from Dórleans and colleagues and Newman and colleagues could provide an explanation for both activities being performed in the same active site. Further crystal structures exist for RNase J from Streptomyces coelicolor and Deinococcus radiodurans (Pei et al., 2015; Zhao et al., 2015).

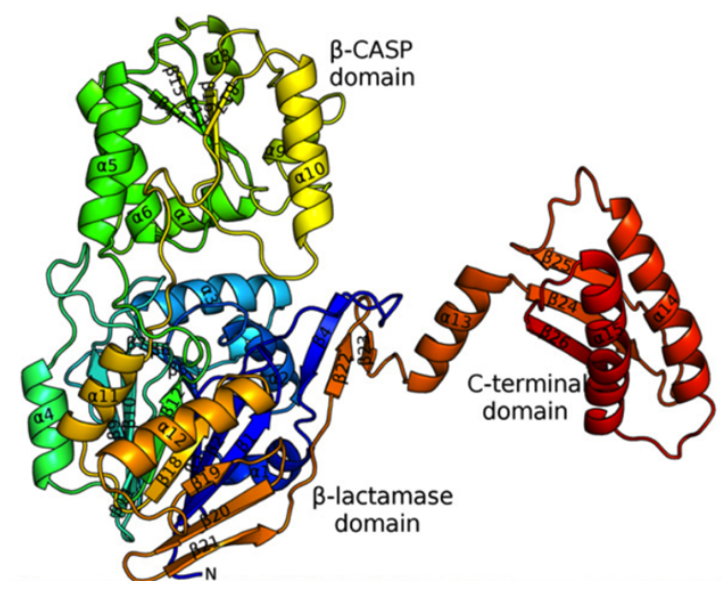

Figure 6. Crystal structure of a monomer of RNase J1. From Newman et al., 2011. The three domains $\beta$-lactamase, $\beta$-CASP, and C-terminal are depicted. The active site localizes in the cleft between the two first, where the zinc ions are coordinated. The C-terminal domain is connected to the other two via the $\alpha 13$ helix. The structure is depicted as ribbons, with a rainbow color-coded from blue in the $\mathrm{N}$-terminal to red in the $\mathrm{C}$-terminal.

RNase J1 and RNase J2 have been shown to form a complex in vivo, that also modifies the individual specificities of the enzymes (Mathy et al., 2010). However, there is still controversy as in what is the oligomeric state of the proteins in vivo. It has been shown in vitro that the proteins are able to form dimers and tetramers, with a 1:1 stoichiometry, although the major form in vivo is still under discussion (Mathy et al., 2010; Newman et al., 2011). It is also not known whether the enzymes interact as heterodimers, which, in turn, interact amongst each other, or as homodimers that interact to form a heterotetramer (see Figure 7). However, after the study of association and dissociation constants it was hypothesized that the homodimers interact to form heterotetramers (Newman et al., 2011). Interestingly, when the proteins are purified independently, the synergistic effect of the complex is no longer visible (Mathy et al., 2010), suggesting that the enzymes can form homodimers and heterodimers with similar stabilities, and that subunit exchange is unlikely.

It is known by structural and functional analysis that the C-terminal domain of RNase J1 (see Figure 6) is necessary for its dimerization and for its activity in vitro. Furthermore, the C-terminal 
domain of other members of the $\beta$-CASP family is important for the modulation of their activity (Li de la Sierra-Gallay et al., 2008). However, the relevance of the C-terminal domain for the in vivo interaction and activity of RNase $\mathrm{J} 1$ and $\mathrm{J} 2$ of $B$. subtilis is not known.

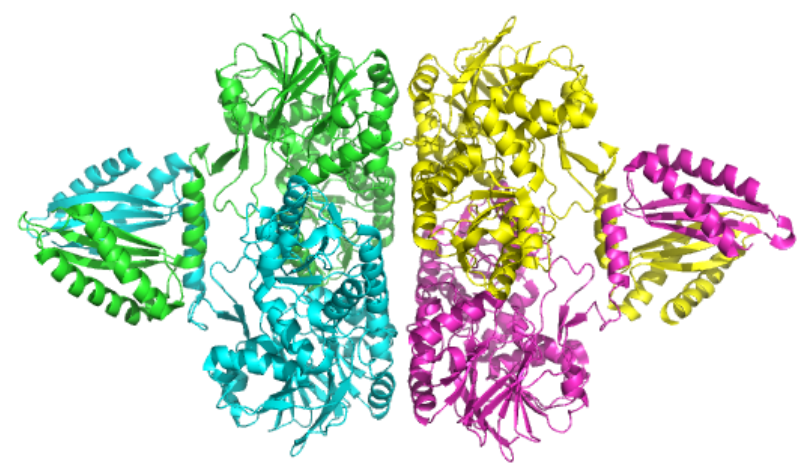

Figure 7. Ribbon representation of the RNase J1 homotetramer. Structure from Newman et al., 2011 (Entry 3ZQ4 in the Protein Data Bank). Each monomer has been coloured differently. The pink and yellow, and the green and blue form both dimers. It is visible the intimate contact of the C-terminal domains in the dimer interface, and the less extensive surface of the tetramer interface.

Furthermore, the subcellular localization of RNase J1 was studied some years ago (Hunt et al., 2006). The enzyme is present in the cytoplasm in a ribosome-like distribution, and this localization was affected by the interruption of transcription by rifampicin (Hunt et al., 2006), as is the case for ribosomes (Mascarenhas et al., 2001). The distribution and effect of rifampicin were recently confirmed in another publication (Cascante-Estepa et al., 2016), also for RNase J2. Interestingly, a complex of RNase J associated with translating ribosomes was observed in Gram-negative bacterium Helicobacter pylori (Redko et al., 2013).

Although these enzymes have been extensively studied in B. subtilis and other organisms, many features remain unknown and many other controversial.

\subsection{Objectives}

The study of the RNA processing in bacteria has been extensive. In B. subtilis, however, much is still not known of this important regulatory mechanism of gene expression. In my thesis I have tried to fill some of those gaps in the story of RNA metabolism in this Gram-positive organism. It has been known for many years that in E. coli there is a complex of RNases and RNA-related proteins, the RNA degradosome that interacts to make the process more efficient. Although many interactions among RNA-related proteins have been detected in B. subtilis, there was no real evidence for the presence of such a complex in vivo. I have analysed the localization of the proteins supposed to be part of this putative degradosome by GFP fusions, to detect possible 
interactions in vivo and common localization patterns. Furthermore, I have studied the localization of the RNases J1 and J2 in the cell by GFP fusions, and the effect of the deletion of one of the paralogues on the localization of the other. Moreover, I have analysed the interaction of these paralogues in vivo and the importance of the C-terminal domain for such interaction. Last but not least, I have studied the activity of the conserved $3^{\prime}-5^{\prime}$ exonuclease polynucleotide phosphorylase in vitro and the possible effectors of this activity, including members of the putative RNA degradosome of $B$. subtilis. 


\section{Materials and methods}

\subsection{Materials}

Materials used in this work such as chemicals, enzymes, oligonucleotides and commercial kits and equipment are listed in the appendix.

\subsection{Strains and plasmids}

A list of the strains and plasmids generated and used in this work can be found in the appendix.

\subsection{Methods}

\subsubsection{General methods}

Some general methods used in this work that are mentioned in the literature are listed in Table 1.

Table 1. General methods

\begin{tabular}{ll}
\hline Method & Reference \\
\hline Absorption measurement & Sambrook et al., 1989 \\
Gel electrophoresis of DNA & Sambrook et al., 1989 \\
Plasmid preparation from E. coli & Sambrook et al., 1989 \\
Ligation of DNA fragments & Sambrook et al., 1989 \\
Determination of protein amounts & Bradford, 1976 \\
Gel electrophoresis of proteins (denaturing) & Laemmli, 1970 \\
Sequencing according to the chain termination method & Sanger et al., 1977
\end{tabular}

\subsubsection{Cultivation of bacteria}

E. coli and B. subtilis were grown in LB medium at $37^{\circ} \mathrm{C}$ or $28^{\circ} \mathrm{C}$ and $200 \mathrm{rpm}$ in tubes and Erlenmeyer flasks. Fresh colonies from plates, glycerol stocks or overnight liquid cultures were used for inoculation. Growth was measured at a wavelength of $600 \mathrm{~nm}$ using a Ultrospec 2100 Pro Spectrophotometer (Amersham Biosciences). 


\section{Bacterial growth media and supplements}

Solutions, buffers and media were prepared with deionized water and autoclaved ( 20 minutes at $121^{\circ} \mathrm{C}$ and 2 bar) (Autoclave LA $2 \times 3 \times 4$, Zirbus Technology $\mathrm{GmbH}$ ). Substances sensitive to high temperatures were sterilized by filtration through a $20 \mu \mathrm{m}$ Filtropur $\mathrm{S}$ plus syringe filter (Sarstedt). E. coli was cultured in Luria Bertani's (LB) medium or agar plates, both supplemented with the necessary antibiotics. B. subtilis was grown in LB medium or SP-agar and LB-agar plates supplemented with appropriate antibiotics. Agar was added to basic media in a concentration of $15 \mathrm{~g} / \mathrm{l}$.

Table 2. Growth media

\begin{tabular}{|c|c|c|}
\hline LB medium & Tryptone & $10 \mathrm{~g}$ \\
\hline \multirow[t]{3}{*}{ (1 I) } & Yeast extract & $5 \mathrm{~g}$ \\
\hline & $\mathrm{NaCl}$ & $10 \mathrm{~g}$ \\
\hline & $\mathrm{dH}_{2} \mathrm{O}$ & add to 1 I \\
\hline SP medium & Nutrient broth & $8 \mathrm{~g}$ \\
\hline \multirow[t]{8}{*}{ (1 I) } & $\mathrm{MgSO}_{4} \cdot 7 \mathrm{H}_{2} \mathrm{O}$ & $0.25 \mathrm{~g}$ \\
\hline & $\mathrm{KCl}$ & $1 \mathrm{~g}$ \\
\hline & $\mathrm{dH}_{2} \mathrm{O}$ & add to $1 \mathrm{I}$ \\
\hline & autoclave; after cooling down addition of & \\
\hline & $\mathrm{MnCl}_{2}(10 \mathrm{~mm})$ & $1 \mathrm{ml}$ \\
\hline & Ferric ammonium citrate (CAF; 2.2 & \\
\hline & $\mathrm{mg} / \mathrm{ml}$ ) & $2 \mathrm{ml}$ \\
\hline & $\mathrm{CaCl}_{2}(0.5 \mathrm{M})$ & $1 \mathrm{ml}$ \\
\hline CE minimal medium & $\mathrm{KH}_{2} \mathrm{PO}_{4}$ & $0.4 \mathrm{~g}$ \\
\hline \multirow[t]{6}{*}{$(100 \mathrm{ml})$} & $\mathrm{K}_{2} \mathrm{HPO}_{4} \cdot 3 \mathrm{H}_{2} \mathrm{O}$ & $1.6 \mathrm{~g}$ \\
\hline & $\left(\mathrm{NH}_{4}\right)_{2} \mathrm{SO}_{4}$ & $0.33 \mathrm{~g}$ \\
\hline & $\mathrm{MnSO}_{4} \cdot 4 \mathrm{H}_{2} \mathrm{O}$ & $0.232 \mathrm{mg}$ \\
\hline & $\mathrm{MgSO}_{4} \cdot 7 \mathrm{H}_{2} \mathrm{O}$ & $12.3 \mathrm{mg}$ \\
\hline & Tryptophan (5 mg/ml) & $1 \mathrm{ml}$ \\
\hline & $\begin{array}{l}\text { Ferric ammonium citrate (CAF; } 2.2 \\
\mathrm{mg} / \mathrm{ml} \text { ) }\end{array}$ & $1 \mathrm{ml}$ \\
\hline
\end{tabular}




\section{Antibiotics}

Antibiotics were prepared as 1000 -fold concentrated stock solutions. Ampicillin, spectinomycin and kanamycin were dissolved in deionized water and chloramphenicol in $70 \%$ ethanol. All solutions were sterile filtrated and stored at $-20^{\circ} \mathrm{C}$. The antibiotics were added to the media before inoculation. The agar media were cooled down before addition of the antibiotics.

Table 3. Antibiotic selection

\begin{tabular}{lr}
\hline Selection in E. coli & \\
\hline Ampicillin & $1 \mu \mathrm{g} / \mathrm{ml}$ \\
\hline Selection in B. subtilis & \\
\hline Spectinomycin & $150 \mu \mathrm{g} / \mathrm{ml}$ \\
Chloramphenicol & $5 \mu \mathrm{g} / \mathrm{ml}$ \\
Kanamycin & $10 \mu \mathrm{g} / \mathrm{ml}$ \\
\hline
\end{tabular}

\section{Storage of bacteria}

E. coli was kept on LB medium agar plates up to 4 weeks at $4^{\circ} \mathrm{C}$. For long-term storage, bacterial stocks were prepared in $10 \%$ DMSO (Roth), and stored at $-80^{\circ} \mathrm{C}$. SP-plates at room temperature were used for the long-term storage of $B$. subtilis, as well as $50 \%$ glycerol stocks prepared from overnight cultures and stored at $-80^{\circ} \mathrm{C}$.

\subsubsection{Transformation of $E$. coli}

\section{Preparation of competent DH5 $\alpha$ cells}

A single colony was inoculated to $20 \mathrm{ml} \mathrm{LB}$ medium and incubated with agitation for 24 hours at $28^{\circ} \mathrm{C}$. A $250 \mathrm{ml}$ culture of $\mathrm{SOB}$ medium was inoculated to an $\mathrm{OD}_{600}$ of 0.1 with the preculture and cells were grown with agitation to an $\mathrm{OD}_{600}$ of 0.5 at $16^{\circ} \mathrm{C}$ (20 hours). The culture was incubated for 10 minutes on ice, and cells were harvested by centrifugation for 10 minutes at $5000 \mathrm{rpm}$ and $4^{\circ} \mathrm{C}$ (Sorvall RC 6+, Thermo Scientific). The pellet was resuspended in $80 \mathrm{ml}$ ice-cold TB and incubated for another 10 minutes on ice, after which the cells were centrifuged for 5 minutes at $5000 \mathrm{rpm}$ and $4^{\circ} \mathrm{C}$. After resuspension of the pellet in $20 \mathrm{ml}$ ice-cold TB, DMSO was 
added to a final concentration of $7 \%(\mathrm{v} / \mathrm{v})$. Aliquots of $0.2 \mathrm{ml}$ were frozen in liquid nitrogen and stored at $-80^{\circ} \mathrm{C}$.

Table 4. Buffers and media for competent E. coli

\begin{tabular}{|c|c|c|}
\hline TB & PIPES & $3.46 \mathrm{~g}$ \\
\hline \multirow[t]{6}{*}{ (1 I) } & $\mathrm{CaCl}_{2} \cdot 2 \mathrm{H}_{2} \mathrm{O}$ & $2.2 \mathrm{~g}$ \\
\hline & $\mathrm{KCl}$ & $18.64 \mathrm{~g}$ \\
\hline & $\mathrm{dH}_{2} \mathrm{O}$ & add to 11 \\
\hline & adjust $p H$ to 6.7 & \\
\hline & autoclave; after coo & \\
\hline & $\mathrm{MnCl}_{2}(1 \mathrm{M}$, sterile $)$ & $55 \mathrm{ml}$ \\
\hline SOB & Tryptone & $20 \mathrm{~g}$ \\
\hline \multirow[t]{7}{*}{ (1 I) } & Yeast extract & $5 \mathrm{~g}$ \\
\hline & $\mathrm{NaCl}$ & $0.58 \mathrm{~g}$ \\
\hline & $\mathrm{KCl}$ & $0.186 \mathrm{~g}$ \\
\hline & $\mathrm{dH}_{2} \mathrm{O}$ & add to $1 \mathrm{I}$ \\
\hline & autoclave; after coo & \\
\hline & $\mathrm{MgCl}_{2}(1 \mathrm{M}$, sterile) & $10 \mathrm{ml}$ \\
\hline & $\mathrm{MgSO}_{4}(1 \mathrm{M}$, sterile) & $10 \mathrm{ml}$ \\
\hline
\end{tabular}

\section{Transformation of $E$. coli competent cells}

The aliquots of $200 \mu \mathrm{l}$ of competent cells were thawed on ice. Alternatively, the freshly prepared competent cells were divided in aliquots to a volume of $200 \mu \mathrm{l}$ and kept on ice. The cells were mixed with 10-100 $\mu \mathrm{g}$ of DNA, and kept on ice for 30 minutes. The samples were subjected to heat-shock for 90 seconds at $42^{\circ} \mathrm{C}$ (ThermoStat Plus, Eppendorf), after which they were put back on ice for an additional 5 minutes. After addition of $800 \mu \mathrm{l}$ of LB medium, the samples were incubated with agitation for an hour at $37^{\circ} \mathrm{C}$. The transformation samples were propagated in LBagar plates supplemented with the appropriate antibiotic, and left to grow overnight at $37^{\circ} \mathrm{C}$. 


\subsubsection{Transformation of $B$. subtilis cells}

\section{Preparation of competent cells}

Competent cells were prepared freshly the same day of the transformation. A colony from an $\mathrm{SP}$-agar plate was inoculated in $4 \mathrm{ml} \mathrm{LB}$ and was incubated overnight at $28^{\circ} \mathrm{C}$ with agitation. With the overnight culture, $10 \mathrm{ml}$ of MNGE supplemented wit $0.1 \%$ CAA were inoculated to an $\mathrm{OD}_{600}$ of 0.1 and grown at $37^{\circ} \mathrm{C}$ with agitation until an $\mathrm{OD}_{600}$ of 1.3 . The culture was diluted with $10 \mathrm{ml}$ of MNGE without CAA and incubated for another hour at $37^{\circ} \mathrm{C}$ with agitation. For transformation, $400 \mu$ l aliquots were used.

\section{Transformation of competent cells}

The aliquots of competent bacteria were mixed with the DNA and incubated for further 30 minutes at $37^{\circ} \mathrm{C}$. Then, $100 \mu \mathrm{l}$ of expression mix were added to the samples and incubated for another hour at $37^{\circ} \mathrm{C}$ with agitation, after which they were propagated in SP-agar or LB-agar plates supplemented with the appropriate antibiotic.

Table 5. Media for transformation of B. subtilis

\begin{tabular}{|c|c|c|}
\hline 10X MN medium & $\mathrm{K}_{2} \mathrm{HPO}_{4} \cdot 3 \mathrm{H}_{2} \mathrm{O}$ & $136 \mathrm{~g}$ \\
\hline \multirow[t]{3}{*}{ (1 I) } & $\mathrm{KH}_{2} \mathrm{PO}_{4}$ & $60 \mathrm{~g}$ \\
\hline & Sodium citrate $\cdot 2 \mathrm{H}_{2} \mathrm{O}$ & $10 \mathrm{~g}$ \\
\hline & $\mathrm{dH}_{2} \mathrm{O}$ & add to $1 \mathrm{I}$ \\
\hline MNGE medium & MN medium (10X) & $1 \mathrm{ml}$ \\
\hline \multirow[t]{7}{*}{$(10 \mathrm{ml})$} & Glucose (20\%) & $1 \mathrm{ml}$ \\
\hline & Potassium glutamate (40\%) & $50 \mu \mathrm{l}$ \\
\hline & $\begin{array}{l}\text { Ferric ammonium citrate (CAF; } 2.2 \\
\mathrm{mg} / \mathrm{ml} \text { ) }\end{array}$ & $50 \mu l$ \\
\hline & Tryptophan (5 mg/ml) & $100 \mu 1$ \\
\hline & $\mathrm{MgSO}_{4}(1 \mathrm{M})$ & $30 \mu \mathrm{l}$ \\
\hline & $\mathrm{dH}_{2} \mathrm{O}$ & add to $10 \mathrm{ml}$ \\
\hline & +/- Casamino acids (CAA; 10\%) & $100 \mu \mathrm{l}$ \\
\hline
\end{tabular}




\begin{tabular}{llr}
\hline Expression mix & Yeast extract $(5 \%)$ & $500 \mu \mathrm{l}$ \\
$(1 \mathrm{ml})$ & Casamino acids (CAA; 10\%) & $250 \mu \mathrm{l}$ \\
& Tryptophan $(5 \mathrm{mg} / \mathrm{ml})$ & $50 \mu \mathrm{l}$ \\
& $\mathrm{dH}_{2} \mathrm{O}$ & $250 \mu \mathrm{l}$ \\
\hline
\end{tabular}

\subsubsection{Preparation and detection of DNA}

\section{Preparation of plasmid DNA from E. coli}

For the isolation of plasmid DNA from E. coli $2 \mathrm{ml}$ of an overnight culture of the desired strains were harvested at $14.500 \mathrm{rpm}$ for 1 minute (Heraeus Fresco 21, Thermo Scientific). After discarding the supernatant the NucleoSpin ${ }^{\circledR}$ Plasmid Kit (Macherey-Nagel) was used to extract the DNA, following the manufacturer's instructions. The plasmid DNA was eluted from the column with deionized water that had been pre-warmed to $70^{\circ} \mathrm{C}$.

\section{Polymerase chain reaction (PCR)}

DNA was amplified by PCR with specific oligonucleotide, using Phusion DNA polymerase (Thermo Scientific) in a thermocycler (SensoQuest). Oligonucleotides were designed using the software Geneious 7.0.2 (Biomatters). All oligonucleotides were purchased from Sigma-Aldrich and are listed in the appendix. The PCR reactions were performed in a total volume of $50 \mu \mathrm{l}$, and 30 cycles of amplification. The PCR reaction and program used are described below (elongation time is specific for every PCR product).

Table 6. Polymerase Chain Reaction (PCR)

\begin{tabular}{lc}
\hline Compound & Volume $(\mu \mathrm{l})$ \\
\hline Template DNA & 1 \\
5X Phusion HF buffer* & 10 \\
dNTP mix (12.5 mM each) & 2 \\
Forward oligo $(5 \mu \mathrm{M})$ & 2 \\
Reverse oligo $(5 \mu \mathrm{M})$ & 2 \\
Phusion polymerase* & 0.5 \\
$\mathrm{dH}_{2} \mathrm{O}$ & 32.5 \\
\hline
\end{tabular}




\begin{tabular}{lcc} 
Step & Temperature $\left({ }^{\circ} \mathrm{C}\right)$ & Time \\
\hline Initial denaturation & 98.5 & $2^{\prime}$ \\
Denaturation & 98.5 & $20^{\prime \prime}$ \\
Annealing & 54 & $30^{\prime \prime}$ \\
Elongation & 72 & variable \\
Final elongation & 72 & $10^{\prime}$ \\
Hold & 4 & hold \\
\hline
\end{tabular}

*Thermo Scientific

\section{Isolation of genomic DNA from B. subtilis}

The genomic DNA was purified from the desired strains using the peqGOLD Bacterial DNA kit (PEQLAB Biotechnologie $\mathrm{GmbH}$ ). For that purpose, a single colony was inoculated to $4 \mathrm{ml}$ of LB medium containing, if necessary, the appropriate antibiotics, and grown overnight at $28^{\circ} \mathrm{C}$ at 200 $\mathrm{rpm}$. The cells $(2 \mathrm{ml})$ were collected by centrifugation for 2 minutes at $14.500 \mathrm{rpm}$. The extraction of the DNA was performed following the manufacturer's instructions. For the elution deionized water pre-warmed to $70^{\circ} \mathrm{C}$ was used.

\section{Agarose gel electrophoresis}

DNA fragments were separated and analyzed in gels prepared from $1 \%(\mathrm{w} / \mathrm{v})$ peqGOLD Universal-Agarose (PEQLAB Biotechnologie $\mathrm{GmbH}$ ) disolved in TAE buffer. For staining of the DNA fragments HD Green Plus DNA stain (INTAS Science Imaging Instruments $\mathrm{GmbH}$ ) was mixed with the dissolved agarose solution $(1 \mu \mathrm{l} / 10 \mathrm{ml}$ ). The DNA samples were mixed with self-made 5 -fold DNA loading dye. After the samples were loaded, $130 \mathrm{~V}$ were applied to the gel until the bromophenol blue had migrated two thirds of the gel. As a molecular weight marker $\lambda$-DNA digested with the restriction enzymes BamHI and EcoRI was used. The DNA was detected and documented via its fluorescence under UV light $(\lambda=254 \mathrm{~nm})$ by GelDoc ${ }^{\mathrm{TM}}$ (BioRad).

Table 7. Materials for agarose gel electrophoresis

\begin{tabular}{llr}
\hline 50X TAE buffer & Tris & $121.14 \mathrm{~g}$ \\
$(500 \mathrm{ml})$ & Acetic acid $(100 \%)$ & $57.1 \mathrm{ml}$ \\
& EDTA $(0.5 \mathrm{M}, \mathrm{pH} 8)$ & $100 \mathrm{ml}$ \\
$\lambda$-DNA marker & $\lambda$-DNA* $(0.3 \mathrm{mg} / \mathrm{ml})$ & $240 \mu \mathrm{l}$ \\
\hline
\end{tabular}




\begin{tabular}{llr}
\hline$(840 \mu \mathrm{l})$ & FD EcoRI $(1 \mathrm{U} / \mu \mathrm{l})^{*}$ & $14 \mu \mathrm{l}$ \\
& FD HindIII $(1 \mathrm{U} / \mu \mathrm{l})^{*}$ & $84 \mu \mathrm{l}$ \\
& $10 X$ FD Buffer Green* & $488 \mu \mathrm{l}$ \\
& $\mathrm{dH}_{2} \mathrm{O}$ & \\
& 2 hours at $37^{\circ} \mathrm{C}$; store at $-20^{\circ} \mathrm{C}$ & $5 \mathrm{ml}$ \\
5X DNA loading dye & Glycerol & $200 \mu \mathrm{l}$ \\
$(10 \mathrm{ml})$ & $50 X$ TAE buffer & $10 \mathrm{mg}$ \\
& Bromophenol blue & $10 \mathrm{mg}$ \\
& Xylene cyanol & $4.5 \mathrm{ml}$ \\
\hline
\end{tabular}

* Thermo Scientific

\section{Digestion and dephosphorylation of DNA}

For the digestion of DNA fragments, Fast Digest (Thermo Scientific) endonucleases and buffers were used. Vectors were first digested for 15 minutes at $37^{\circ} \mathrm{C}$. The samples were cooled on ice while $2.5 \mu \mathrm{l}$ were anlyzed by agarose gel electrophoresis. Then the second enzyme was added to the mixture and the sample was further digested for another 15 minutes at $37^{\circ} \mathrm{C}$. Digested vectors were dephosphorylated by adding 5 units of FastAP Alkaline phosphatase (Thermo Scientific) to the sample and incubating for 5 minutes at $37^{\circ} \mathrm{C}$. PCR products were digested simultaneously with both restriction enzymes for 30 minutes at $37^{\circ} \mathrm{C}$. Fragmets were purified and ligated for subsequent transformation.

\section{Purification of DNA fragments}

The QIAquick ${ }^{\circledR}$ PCR purification kit (QIAGEN, Hilden) was used for purification of linear DNA fragments such as PCR products or digested vectors as described by the manufacturer. The column was incubated in pre-warmed deionized water $\left(70^{\circ} \mathrm{C}\right)$ for 5 minutes at room temperature and DNA was eluted by centrifugation for 1 minute at $14.500 \mathrm{rpm}$.

\section{Ligation of DNA}

DNA fragments were ligated using T4-DNA ligase (Thermo Scientific) in the buffer supplied by the manufacturer. The ligation reaction contained 20 - $200 \mathrm{ng}$ of vector DNA and an excess of the DNA fragment (insert to vector molar ratio of 10:1 to 20:1). After addition of $5 \mathrm{U}$ of T4-DNA ligase 
to a final volume of $20 \mu \mathrm{l}$, the fragments were allowed to ligate for 2 hours at room temperature or overnight at $16^{\circ} \mathrm{C}$. Subsequently the ligated samples were transformed into $E$. coli competent cells.

\section{Analysis of clones by cracking}

Colonies from transformation plates were inoculated in $4 \mathrm{ml} \mathrm{LB}$ medium supplemented with the appropriate antibiotic, and incubated at $37^{\circ} \mathrm{C}$ overnight or until growth was visible. For the analysis, $50 \mu$ of the preculture were harvested for 1 minute at $14.500 \mathrm{rpm}$, and resuspended in resuspension buffer. For the disruption of the cells, $25 \mu \mathrm{l}$ of freshly prepared crack buffer were added and the samples were incubated for 5 minutes at $70^{\circ} \mathrm{C}$. After cooling on ice, $5 \mu \mathrm{l}$ of crack staining were added and the samples were left on ice ofr 10 minutes. Insoluble particles were eliminated by centrifugation at $14.500 \mathrm{rpm}$ for 5 minutes at $4^{\circ} \mathrm{C}$, and the soluble fraction was loaded on an agarose gel for electrophoresis.

Table 8. Cracking buffers

\begin{tabular}{llr}
\hline Resuspension buffer & $\mathrm{Na}_{2}$-EDTA $\cdot 3 \mathrm{H}_{2} \mathrm{O}$ & $37 \mathrm{mg}$ \\
$(10 \mathrm{ml})$ & adjust $p H$ to 8.0 & \\
& $\mathrm{dH}_{2} \mathrm{O}$ & add to $10 \mathrm{ml}$ \\
Crack buffer & $D$-(+)-Sucrose & $200 \mathrm{mg}$ \\
$(1 \mathrm{ml})$ & $\mathrm{SDS}(20 \%)$ & $25 \mu \mathrm{l}$ \\
& $\mathrm{NaOH}(2 \mathrm{M})$ & $100 \mu \mathrm{l}$ \\
& $\mathrm{dH} \mathrm{H}_{2} \mathrm{O}$ & add to $1 \mathrm{ml}$ \\
Crack staining & $\mathrm{KCl}(4 \mathrm{M})$ & $150 \mu \mathrm{l}$ \\
$(200 \mu \mathrm{l})$ & $5 X \mathrm{DNA}$ loading dye & $50 \mu \mathrm{l}$ \\
\hline
\end{tabular}

\section{Long-flanking homology PCR (LFH-PCR)}

The attempt for the introduction of a modified gene in its original locus in B. subtilis was performed with the flanking homology PCR (LFH-PCR) technique (Wach, 1996). For this purpose three fragments were amplified by PCR. A DNA fragment of about $1000 \mathrm{bp}$ with homology to the upstream region of the gene to be modified, a DNA fragment of similar length and region homologous to downtream region of the gene to be modified, and a third fragment to amplify the resistance gene. The usptream and downstream fragments have to harbor a $20 \mathrm{bp}$ flank that anneals with the resistance fragment. These flanks were introduced via oligonucleotide. The 
concentration of the three purified fragments was measure using a NanoDrop ND-1000 Spectrophotometer (PEQLAB)and they were then joined through a PCR reaction described below. B. subtilis was transformed with the LFH-PCR products and clones were examined by PCR to screen for the correctly integrated fragment.

\section{Table 9. LFH-PCR reaction and program}

\begin{tabular}{|c|c|c|c|}
\hline \multicolumn{3}{|c|}{ Compound } & Volume $(\mu \mathrm{l})$ \\
\hline \multicolumn{2}{|c|}{ 5X Phusion HF buffer } & \multicolumn{2}{|c|}{20} \\
\hline \multicolumn{2}{|c|}{ dNTP mix (12.5 mM each) } & \multicolumn{2}{|c|}{4} \\
\hline \multicolumn{2}{|c|}{ upstream fragment (100 ng) } & \multicolumn{2}{|c|}{-} \\
\hline \multicolumn{2}{|c|}{ cassette fragment (150 ng) } & \multicolumn{2}{|c|}{-} \\
\hline \multicolumn{2}{|c|}{ dowstream fragment (100 ng) } & \multicolumn{2}{|c|}{-} \\
\hline \multicolumn{2}{|c|}{ Phusion polymerase } & \multicolumn{2}{|c|}{2} \\
\hline \multicolumn{2}{|l|}{$\mathrm{dH}_{2} \mathrm{O}$} & \multicolumn{2}{|c|}{ to 100} \\
\hline Step & Temperature $\left({ }^{\circ} \mathrm{C}\right)$ & Time & Cycles \\
\hline 1. & 98.5 & $1^{\prime}$ & \\
\hline 2. & 98.5 & $15^{\prime \prime}$ & 10 \\
\hline 3. & 52 & $30 "$ & 10 \\
\hline 4. & 72 & $2^{\prime} 15^{\prime \prime}$ & 10 \\
\hline 5. & 4 & hold & \\
\hline \multicolumn{4}{|c|}{ addition of oligonucleotides $8 \mu \mathrm{l}$ of $5 \mu \mathrm{M}$ stocks } \\
\hline 6. & 98.5 & $15^{\prime \prime}$ & 21 \\
\hline 7. & 52 & $30 "$ & 21 \\
\hline 8. & 72 & $4^{\prime}+5^{\prime \prime} /$ cycle & 21 \\
\hline 9. & 72 & $10^{\prime}$ & \\
\hline 10. & 4 & hold & \\
\hline
\end{tabular}

\section{Sequencing of DNA}

Sequencing of PCR or plasmid samples premixed with the sequencing primer was performed by SeqLab Sequence Laboratories Göttingen GmbH . 


\subsubsection{Preparation and analysis of proteins}

\section{Cell disruption by French press}

The bomb (French Pressure Cell, Thermo Scientific) was pre-cooled on ice for 20 minutes before usage. The cell pellets were resuspended in buffer $W$ (described in Table 17) and applied to the bomb. Before closing the air was squeezed out of the pump. A pressure of 18,000 psi was applied (G. Heinemann press) and the cell extract was recovered slowly and conserved on ice. The samples were disruped 1-3 times depending on the concentration and organism.

\section{Cell disruption by Tissue Lyser}

The cells were disrupted by addition of $0.5 \mathrm{~g}$ of $0.1 \mathrm{~mm}$ diameter glas beads (Roth) to a $2 \mathrm{ml}$ Eppendorf tube. Afterwards, $1 \mathrm{ml}$ of cell culture resuspended in buffer $\mathrm{W}$ was added and the cells were disrupted three times at $30 \mathrm{~s}^{-1}$ for 3 minutes. The samples were placed on ice for cooling after each disruption cycle.

\section{Discontinuous SDS polyacrylamide gel electrophoresis (SDS-PAGE)}

Proteins were analysed by SDS-PAGE following the principle described by Laemmli in 1970. Protein samples were denatured by boiling in SDS loading dye at $95^{\circ} \mathrm{C}$ for 30 minutes. The polyacrylamide concentration of the gels was $12 \%(\mathrm{v} / \mathrm{v})$. Samples were loaded onto the prepared gel and electrophoresis was performed at $120 \mathrm{~V}-200 \mathrm{~V}$ at $4^{\circ} \mathrm{C}$ until the bromophenol blue had reached the lower end of the gel. The self constructed protein marker Page King (Pietack, 2010) or the PageRulerTM Plus Prestained Protein Ladder (ThermoFischer Scientific) were used as size standards. Gels were stained with Coomassie Brilliant Blue G-250, Silver staining of were used for specific protein detection via Western blot.

Table 10. SDS-PAGE materials

\begin{tabular}{llr}
\hline 5X SDS loading dye & Tris (1.5 M; pH 6.8) & $1.33 \mathrm{ml}$ \\
$(10 \mathrm{ml})$ & Glycerol & $5 \mathrm{ml}$ \\
& SDS (20\%) & $2.5 \mathrm{ml}$ \\
& 2-mercaptoethanol & $1.6 \mathrm{ml}$ \\
& Bromophenol blue & $20 \mathrm{mg}$ \\
& Acrylamide:bisacrylamide (37.5:1) (30\%) & $0.83 \mathrm{ml}$ \\
$(5 \mathrm{ml})$ & Tris (1.5 M; pH 6.8) & $0.63 \mathrm{ml}$ \\
\hline
\end{tabular}




\begin{tabular}{llr}
\hline & SDS (20\%) & $25 \mu \mathrm{l}$ \\
& d ${ }_{2} \mathrm{O}$ & $3.46 \mathrm{ml}$ \\
& APS (10\%) & $50 \mu \mathrm{l}$ \\
& TEMED & $5 \mu \mathrm{l}$ \\
12\% Running gel & Acrylamide:bisacrylamide (37.5:1) (30\%) & $2 \mathrm{ml}$ \\
(5 ml) & Tris (1.5 M; pH 8.8) & $1.25 \mathrm{ml}$ \\
& SDS (20\%) & $25 \mu \mathrm{l}$ \\
& dH ${ }_{2} \mathrm{O}$ & $1.67 \mathrm{ml}$ \\
& APS (10\%) & $50 \mu \mathrm{l}$ \\
& TEMED & $2 \mu \mathrm{l}$ \\
10X Running buffer & Glycine & $72 \mathrm{~g}$ \\
(500 ml) & Tris & $30 \mathrm{~g}$ \\
& SDS & $0.5 \mathrm{~g}$ \\
\hline
\end{tabular}

\section{Native-PAGE gels}

Protein samples are kept always on ice and mixed with 5-fold native loading dye. The samples were applied to Native-PAGE gels with or without stacking gel. The separating gels we prepared at $8 \%$. Samples. The electrophoresis was performed overnight at $20 \mathrm{~V}$ at $4^{\circ} \mathrm{C}$. As a marker PageRulerTM Plus Prestained Protein Ladder (ThermoFischer Scientific) was used.

Table 11. Native-PAGE materials

\begin{tabular}{llr}
\hline 5X SDS loading dye & Tris (1.5 M; pH 6.8 or pH 8.8) & $1.33 \mathrm{ml}$ \\
$(10 \mathrm{ml})$ & Glycerol & $5 \mathrm{ml}$ \\
& Bromophenol blue & $20 \mathrm{mg}$ \\
$\mathbf{5 \%}$ Stacking gel & Acrylamide:bisacrylamide (37.5:1) (30\%) & $0.83 \mathrm{ml}$ \\
$(5 \mathrm{ml})$ & Tris (1.5 M; pH 6.8) & $0.63 \mathrm{ml}$ \\
& dH ${ }_{2} \mathrm{O}$ & $3.46 \mathrm{ml}$ \\
& APS (10\%) & $50 \mu \mathrm{l}$ \\
& TEMED & $5 \mathrm{l}$ \\
& Acrylamide:bisacrylamide (37.5:1) (30\%) & $1.33 \mathrm{ml}$
\end{tabular}




\section{Native-PAGE gels for basic proteins}

For the visualization of native basic proteins on a gel was performed as previously described (Niepmann and Zheng, 2006). Briefly, a polyacrylamide gradient gel 6-20\% was prepared from 40\% acrylamide:bisacrylamide 29:1 stock solution. The proteins were incubated for 10 minutes at room temperature with loading dye containing Coomassie Blue $\mathrm{G}$. The gel was run overnight at 15 $\mathrm{V}$, using a histidine $\mathrm{pH} 8.0$ cathode and Tris- $\mathrm{HCl} \mathrm{pH} 8.8$ anode buffer system. The gel was destained and fixated overnight in silver stain destaining solution and developed by silver stain method (see Table 14).

\section{Coomassie staining for polyacrylamide gel}

Protein gels can be stained with Coomassie Brilliant Blue G-250 (Roth) to visualize the proteins. For this, the gels were incubated in staining solution for 30 minutes at room temperature with agitation. To destain the background and make the proteins visible, the gel was incubated in destaining solution until the contrast was sufficient.

Table 12. Solutions for Coomassie gel staining

\begin{tabular}{llr}
\hline Staining solution & Coomassie Brilliant Blue G-250 & $2.5 \mathrm{~g}$ \\
(1 I) & Acetic acid & $100 \mathrm{ml}$ \\
& Methanol & $500 \mathrm{ml}$ \\
& $\mathrm{dH}_{2} \mathrm{O}$ & add to $1 \mathrm{I}$ \\
Destaining solution & Ethanol & $200 \mathrm{ml}$ \\
$(1 \mathrm{l})$ & Acetic acid & $50 \mathrm{ml}$ \\
& $\mathrm{dH}_{2} \mathrm{O}$ & add to $1 \mathrm{I}$ \\
\hline
\end{tabular}




\section{Western blot}

After polyacrylamide gel electrophoresis the proteins were immobilized in a PVDF membrane (Biorad) that had previously been activated in methanol. The proteins from the gel were transferred to the membrane in a semidry blotting apparatus for 2 hours with a current of $80 \mathrm{~mA}$ per gel. The membrane was blocked for 30 minutes in blocking solution and incubated overnight with the primary antibodies in TBS-T at $4^{\circ} \mathrm{C}: 1: 1000$ anti-FLAG or anti-Strep (PromoKine) and 1:30,000 anti-GapA (Meinken et al., 2003). The membranes were washed three times for $15 \mathrm{~min}$ with TBS-T. The secondary antibody (Anti-Rabbit IgG (Promega), 1:100,000 in TBS-T) was added for 1 hour and then the membrane was washed again three times for 20 min with TBS-T. Before the addition of the CDP-Star reagent (Roche) for development of the membrane, it was incubated for 5 minutes in buffer III. The CDP-Star was then added in buffer III (5 $\mu \mathrm{l} / 500 \mu \mathrm{l})$.

Table 13. Buffers for Western blot

\begin{tabular}{|c|c|c|}
\hline 10X TG buffer & Tris & $30.3 \mathrm{~g}$ \\
\hline \multirow[t]{2}{*}{ (1 I) } & Glycine & $144.1 \mathrm{~g}$ \\
\hline & $\mathrm{dH}_{2} \mathrm{O}$ & add to $1 \mathrm{I}$ \\
\hline 1X Transfer buffer & 10X TG buffer & $100 \mathrm{ml}$ \\
\hline \multirow[t]{2}{*}{ (1 L) } & Methanol & $200 \mathrm{ml}$ \\
\hline & $\mathrm{dH}_{2} \mathrm{O}$ & add to $1 \mathrm{I}$ \\
\hline $10 \times$ TBS & Tris & $60.57 \mathrm{~g}$ \\
\hline \multirow[t]{3}{*}{ (1 l) } & $\mathrm{NaCl}$ & $87.6 \mathrm{~g}$ \\
\hline & adjust $p H$ to 7.5 & \\
\hline & $\mathrm{dH}_{2} \mathrm{O}$ & add to $1 \mathrm{I}$ \\
\hline $1 \times$ TBS-T & $10 \times \mathrm{TBS}$ & $100 \mathrm{ml}$ \\
\hline \multirow[t]{2}{*}{ (1 l) } & Tween-20 & $500 \mu \mathrm{l}$ \\
\hline & $\mathrm{dH}_{2} \mathrm{O}$ & add to $1 \mathrm{I}$ \\
\hline Blocking solution & TBS-T & $50 \mathrm{ml}$ \\
\hline$(20 \mathrm{ml})$ & Skimmed milk powder & $2.5 \mathrm{~g}$ \\
\hline Buffer III & Tris & $12.11 \mathrm{~g}$ \\
\hline \multirow[t]{3}{*}{ (1 l) } & $\mathrm{NaCl}$ & $5.84 \mathrm{~g}$ \\
\hline & adjust $\mathrm{pH}$ to 9.5 & \\
\hline & $\mathrm{dH}_{2} \mathrm{O}$ & add to $1 \mathrm{I}$ \\
\hline
\end{tabular}




\section{Silver stain for polyacrylamide gel}

The proteins separated by SDS-PAGE can be visualized by the method of the Silver stain. It is more sensitive than other staining methods like Coomassie when detecting low amounts of proteins (up to $1 \mathrm{ng}$ (Weiss et al., 2009)). The staining proceeds in several steps were the gel is incubated in different solutions, all described below.

Table 14. Silver stain protocol

\begin{tabular}{|c|c|c|}
\hline Fixing solution 1 & Methanol (100\%) & $25 \mathrm{ml}$ \\
\hline \multirow[t]{3}{*}{$(100 \mathrm{ml})$} & Acetic acid (100\%) & $6 \mathrm{ml}$ \\
\hline & Formaldehyde (37\%) & $50 \mu \mathrm{l}$ \\
\hline & $\mathrm{ddH}_{2} \mathrm{O}$ & add to $50 \mathrm{ml}$ \\
\hline $\mathrm{Na}_{2} \mathrm{~S}_{2} \mathrm{O}_{3}$ solution 2 & $\mathrm{Na}_{2} \mathrm{~S}_{2} \mathrm{O}_{3} \cdot 5 \mathrm{H}_{2} \mathrm{O}$ & $10 \mathrm{mg}$ \\
\hline$(100 \mathrm{ml})$ & $\mathrm{dd} \mathrm{H}_{2} \mathrm{O}$ & add to $50 \mathrm{ml}$ \\
\hline Impregnating solution 3 & $\mathrm{AgNO}_{3}$ & $0.1 \mathrm{~g}$ \\
\hline \multirow[t]{2}{*}{ (100 ml) } & Formaldehyde (37\%) & $18.5 \mu \mathrm{l}$ \\
\hline & $\mathrm{ddH}_{2} \mathrm{O}$ & add to $50 \mathrm{ml}$ \\
\hline Developing solution 4 & $\mathrm{Na}_{2} \mathrm{CO}_{3}$ & $3 \mathrm{~g}$ \\
\hline \multirow[t]{3}{*}{$(100 \mathrm{ml})$} & $\mathrm{Na}_{2} \mathrm{~S}_{2} \mathrm{O}_{3}$ solution 2 & $1 \mathrm{ml}$ \\
\hline & Formaldehyde (37\%) & $25 \mu \mathrm{l}$ \\
\hline & $\mathrm{ddH}_{2} \mathrm{O}$ & add to $50 \mathrm{ml}$ \\
\hline STOP solution 5 & $\mathrm{Na}_{2}$-EDTA & $0.93 \mathrm{~g}$ \\
\hline$(100 \mathrm{ml})$ & $\mathrm{dd} \mathrm{H}_{2} \mathrm{O}$ & add to $50 \mathrm{ml}$ \\
\hline Step & Reagent & Duration \\
\hline Fixing & Fixing solution 1 & $1-24 \mathrm{~h}$ \\
\hline Washing & EtOH 50\% & $3 \times 20^{\prime}$ \\
\hline Reduction & $\mathrm{Na}_{2} \mathrm{~S}_{2} \mathrm{O}_{3}$ solution 2 & $1^{\prime} 30^{\prime \prime}$ \\
\hline Washing & $\mathrm{dH}_{2} \mathrm{O}$ & $3 \times 20^{\prime \prime}$ \\
\hline Staining & Impregnating solution 3 & $15^{\prime}-25^{\prime}$ \\
\hline Washing & $\mathrm{dH}_{2} \mathrm{O}$ & $2 \times 20^{\prime \prime}$ \\
\hline Development & Developing solution 4 & until stained \\
\hline Washing & $\mathrm{dH}_{2} \mathrm{O}$ & $2 \times 20^{\prime \prime}$ \\
\hline
\end{tabular}




\section{Overexpression of proteins in E. coli}

The 1 liter LB cultures of the desired strains were inoculated from overnight cultures and incubated at $37^{\circ} \mathrm{C}$. When the cultures had reached $\operatorname{adn} \mathrm{OD}_{600}$ of 0.5 , the expression of heterologous proteins was induced by addition of isopropyl- $\beta$-D-thio-galactopyranoside (IPTG) to a final concentration of $1 \mathrm{mM}$ (PEQLAB). The cultures were incubated for three hours at $37^{\circ} \mathrm{C}$ and harvested before storing the pellets at $-20^{\circ} \mathrm{C}$.

\section{Purification of $\mathrm{His}_{6}$-tagged proteins}

For protein purification, the frozen pellets were resuspended in cold cell disruption buffer, and the cells were disrupted by 3 passages through the French pressure cell (Thermo Scientific) at 18,000 psi. Cell debris and other insoluble material was removed by ultracentrifugation for 1 hour at $35,000 \mathrm{rpm}$ at $4^{\circ} \mathrm{C}$ in a Sorvall WX Ultra Series Centrifuge (Thermo Scientific). For purification of recombinant $\mathrm{His}_{6}$-tagged proteins the supernatant fraction was loaded onto a bed of $500 \mu \mathrm{l}$ of $\mathrm{Ni}^{2+}$-NTA resin (IBA) in a Poly-Prep Chromatography Column (Biorad) that had been preequilibrated in disruption buffer. After applying the cell extract, the column was washed 5 times with $5 \mathrm{ml}$ of disruption buffer containing $10 \mathrm{~mm}$ imidazole. The elution was performed in steps of $5 \mathrm{ml}$, with increasing concentrations of imidazole (30 mM, $50 \mathrm{~mm}, 75 \mathrm{~mm}$ and $100 \mathrm{~mm}$ ). The relevant fractions were combined and concentrated by centrifugation through Vivaspin turbo 15 (Sartorius) for 15 minutes at $4.000 \times \mathrm{xg}$ and $8^{\circ} \mathrm{C}$ in Heraeus Megafuge 16R (Thermo Scientific). Protein concentration was determined following the Bradford assay as described further in this section. The pooled fraction was further purified and analysed via Size-exclusion chromatography (SEC).

Table 15. Disruption buffer

\begin{tabular}{llr}
\hline 10X HEPES buffer & HEPES & $119.15 \mathrm{~g}$ \\
& $\mathrm{NaCl}$ & $116.8 \mathrm{~g}$ \\
& adjust $\mathrm{pH}$ to 7.5 & \\
& $\mathrm{dH} \mathrm{H}_{2} \mathrm{O}$ & add to $1 \mathrm{~L}$ \\
& add imidazole to different concentrations
\end{tabular}




\section{Size exclusion chromatography}

The experiments were performed at room temperature in a HiLoad 16/600 Superdex $200 \mathrm{pg}$ using an ÄKTAprime plus (GE Healthcare Life Sciences). Purified protein was applied to the column equilibrated with $20 \mathrm{~mm}$ Tris- $\mathrm{HCl}, 50 \mathrm{mM} \mathrm{NaCl}, \mathrm{pH} 8.0$ buffer. The program was set to $1 \mathrm{ml} / \mathrm{min}$ and several elution fractions were recovered, where protein concentration was measued by a spectrophotometer coupled to the column. A calibration run was performed with molecular weight standards and related to their elution volumes for both column sizes. The elution volume presents a linear relationship to the $\log _{10}(\mathrm{Mw})$.

Table 16. Standard curve for HiLoad 16/600 Superdex 200 pg

\begin{tabular}{ccc}
\hline Mw (KDa) & $\log M w$ & Retention volume (ml) \\
\hline 670 & 2.83 & 50.45 \\
158 & 2.20 & 64.92 \\
44 & 1.64 & 81.19 \\
17 & 1.23 & 93.02 \\
1.35 & 0.13 & 111.92 \\
\hline
\end{tabular}

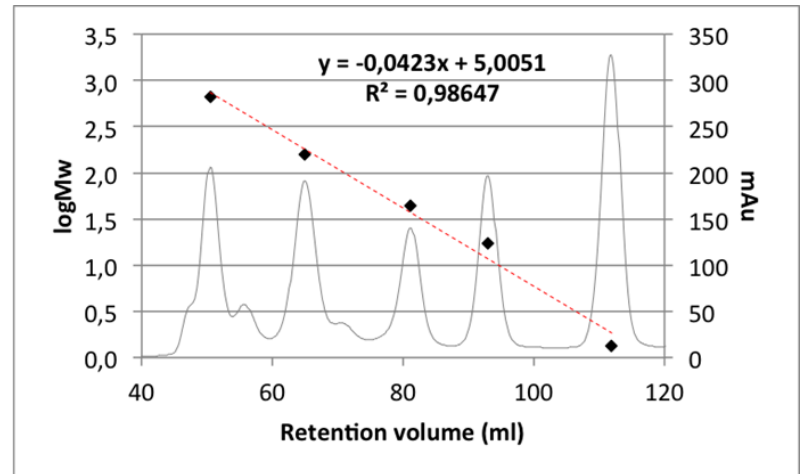

Figure 8. Standard curve in a HiLoad 16/600 Superdex 200 pg chromatography column. Proteins of different sizes were injected into the size-exclusion chromatography column. The grey line, corresponding to the secondary vertical axis, represents the spectrum of elution. The logarithm of the molecular weight of each protein was plotted against its retention volume. The standard curve was then used to interpolate molecular weight from experimental retention times.

\section{SPINE (Śtrep-protein interaction experiment)}

The SPINE experiment was performed as described (Herzberg et al., 2007). Briefly, the cultures of the relevant strains of $B$. subtilis were grown to the desired $\mathrm{OD}_{600}$. For the experiments that required crosslinking, half of the cultures were incubated for 20 minutes with $0.6 \%$ formaldehyde (FA) solution. The prepared cultures were harvested by centrifugation at 5,000 rpm in a Sorvall RC 
$6+$ Centrifuge (Thermo Scientific). The pellets were washed in buffer $W$ and disrupted by 3 passages through the French pressure cell. The cells debris was eliminated by ultracentrifugation at 35,000 for 30 minutes and $4^{\circ} \mathrm{C}$. The crude cell extracts were applied to a Poly-Prep Chromatography column (Biorad) that contained $50 \%$ Streptactin Sepharose (IBA) preequilibrated in buffer $W$. The matrix specifically binds the Streo sequence of eight amino acids (WSHPQFEK). The amount of resin was $500 \mu \mathrm{l} / 250 \mathrm{ml}$ of culture. After the proteins were allowed to bind the resin, it was washed 5 times with $5 \mathrm{ml}$ of buffer $\mathrm{W}$. The elution was performed with one bed volume of buffer $\mathrm{E}$, which contains D-desthiobiotin (IBA). The fractions were analysed via SDS-PAGE, Native-PAGE and Western blot.

Table 17. Buffers for Strep-protein purification

\begin{tabular}{llr}
\hline Buffer W & Tris & $12.11 \mathrm{~g}$ \\
$(1 \mathrm{l})$ & $\mathrm{NaCl}$ & $8.76 \mathrm{~g}$ \\
& adjust $p H$ to 7.5 & \\
& $\mathrm{dH}_{2} \mathrm{O}$ & add to $1 \mathrm{~L}$ \\
& Buffer W & $250 \mathrm{ml}$ \\
Buffer E & D-desthiobiotin & $134 \mathrm{mg}$ \\
\hline
\end{tabular}

\section{Calculation of protein amounts by the Bradford method}

To measure the concentration of protein in solution we made use of the principle for proteindye binding described by Bradford in 1976. For this we prepared a one-fold solution of the Bradford reagent by diluting the 5 fold Roti-Quant (Roth) with distilled water.

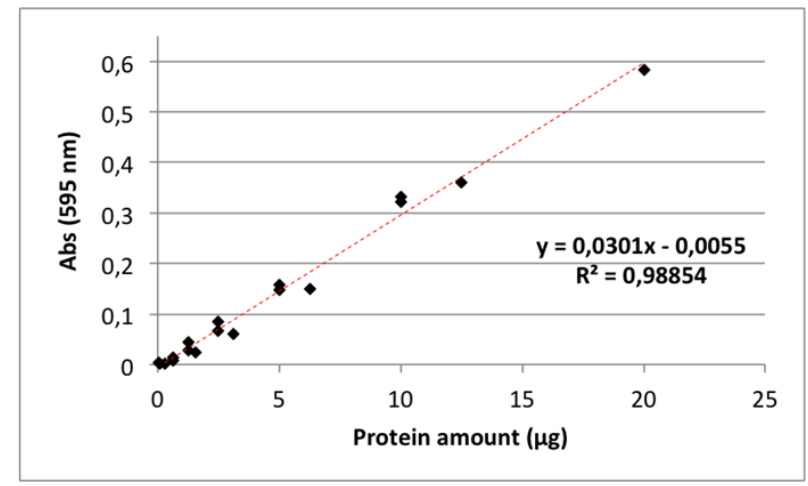

Figure 9. Standard curve for Bradford protein amount calculation. Different concentrations of BSA diluted in water were measured using the Bradford reagent. The protein amount in micrograms was plotted against the absorbance obtained at $595 \mathrm{~nm}$. The measurements were adjusted to a linear function whose slope was used to interpolate amount of protein from the absorbance measured. 
The protein samples were mixed with the Bradford reagent to a total volume of $1 \mathrm{ml}$ and the absorbance was measured in an Ultrospec 2100 Pro spectrophotometer (Amersham Biosciences) at a wavelength of $595 \mathrm{~nm}$. A blank sample was prepared by mixing the buffer with the Bradford reagent in the same proportion as the protein samples. The protein amount per sample was interpolated from the standard curve depicted in Figure 9 that was prepared using bovine serum albumin (BSA) protein (AppliChem).

\section{PNPase in vitro degradation assay}

The purified protein PNPase from B. subtilis was used for analysis of its in vitro activity similar to previously described (Nurmohamed et al., 2011). For this, the protein (250 nM) was mixed with 40 $\mathrm{mM}$ inorganic phosphate $(\mathrm{Pi})$ a divalent cation $\left(\mathrm{MgCl}_{2}\right.$ or $\left.\mathrm{MnCl}_{2}\right)$ and a short fragment of poly $(\mathrm{A})$ RNA of 15 bases (15-mer RNA) (50 $\mu \mathrm{M})$ (Sigma Aldrich).

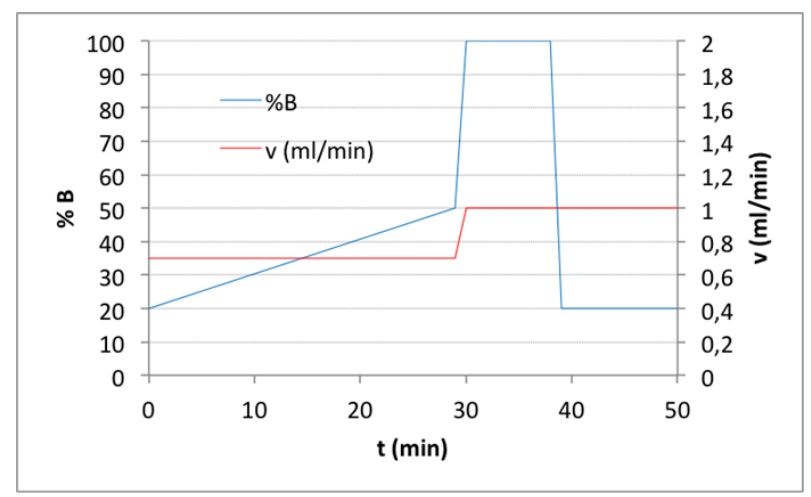

Figure 10. Elution program ion-exchange HPLC. Percentage of buffer $\mathrm{B}(20 \mathrm{mM}$ Tris- $\mathrm{HCl}, 1 \mathrm{M} \mathrm{NaCl}, \mathrm{pH} 8.0)$ is represented by a blue line and corresponds to the primary vertical axis. The red line represents the flow though the HPLC system and corresponds to the seconday vertical axis.

The reaction was performed in $5 \mu$ of final volume witin a buffer solution of $20 \mathrm{~mm}$ Tris- $\mathrm{HCl}$, $\mathrm{pH} 8.0$ and incubated at $25^{\circ} \mathrm{C}$ for a determined amount of time. Purified PfkA, enolase, Mg-citrate as well as c-di-AMP and c-di-GMP (Biolog) were added to the reactions to assay possible effects on the reaction. The reaction was stopped and analysed via ion-exchange HPLC through a BioLC DNA Pac PA200 4x250 mm Analytical column and 4x50 mm Guard (Dionex) associated with a JASCO chromatography system. The reaction samples ware monitored through a spectrophotometer that was coupled to the column $(260 \mathrm{~nm})$. The spectra were analysed by Borwin 1.50 software (Jasco). The equipment for ion-exchange HPLC that I had access to was in the Institute for Organic and Biomolecular Chemistry, in the group of Prof. Dr. Ulf Diederichsen, with the technical support of Mr. Daniel. The buffer system used for the HPLC was 20 mM Tris- 
$\mathrm{HCl}, \mathrm{pH} 8.0$ (A) and $20 \mathrm{~mm}$ Tris- $\mathrm{HCl}, 1 \mathrm{M} \mathrm{NaCl}, \mathrm{pH} 8.0$ (B). The program used for the HPLC is depicted in Figure 10.

\subsubsection{Light and fluorescence microscopy}

For the microscopic analysis the samples of $B$. subtilis were grown in $L B$ medium at $37^{\circ} \mathrm{C}$ or $28^{\circ} \mathrm{C}$ to the desired $\mathrm{DO}_{600}$. A total of $0.3 \mu \mathrm{l}$ were placed on a slide covered with a thin layer of $1 \%$ agarose dissolved in water. When the sample had dried a coverslip was placed over the sample. The pictures were taken using the Axiolmager M2 equipped with a digital camera AxioCam MRm and the AxioVision Rel 4.8 software for image uptake (Zeiss). The objectives used ECPlanNEOFLUAR 100X/1.3 (Zeiss). For the fluorescence images the applied filtersets used were 49 G365, FT395, BP445/50 (Zeiss) for DAPI detection, the Filterset 38 BP470/40, FT495, BP525/50 (Zeiss) for GFP detection and the Filterset 43 BP545/25, FT570, BP605/70 (Zeiss) for Nile Red detection. The Axioskop 40 (Zeiss) was equipped with an AxioCam MRm and the objectives Plan Neofluar 100x/1.30 and Plan Neofluar 40x/0.75 (Zeiss). The filterset used for visualization of GFP was Filterset 2 (AHF Analysentechnik). For DAPI and Nile Red, the filtersets described above were used. For uptake of images the AxioVision Rel. 4.7 (Zeiss) was used. The software Image J 1.49p (National Institutes of Health, USA) was used for processing of the images. The cells were incubated for 5 minutes at $37^{\circ} \mathrm{C}$ and $200 \mathrm{rpm}$ with the Nile Red (Sigma-Aldrich) or DAPI (Applichem) dyes at a final concentration of $1 \mu \mathrm{l} / \mathrm{ml}$ to visualize the cell membrane or the genetic material, respectively. To perform the experiments where the transcription was interrupted, the cells were incubated for 10 minutes at $37^{\circ} \mathrm{C}$ and $200 \mathrm{rpm}$ with rifampicin (dissolved in methanol; Sigma) at a final concentration of $200 \mathrm{mg} / \mathrm{ml}$. As a negative control the same amount of methanol was added to the cells in the same conditions. To induce the expression of GFP protein fusion whose expression was under control of a xylose-inducible promoter, $0.1 \%$ of xylose was added to the cell cultures. The exposure times were $1 \mathrm{~s}$ for GFP (except for Eno-GFP, $500 \mathrm{~ms}$ ), $500 \mathrm{~ms}$ for Nile Red and 100 md for DAPI. (Adapted from Cascante-Estepa et al., 2016). 


\section{Results}

\subsection{Localization of components of the RNA-degrading complex of $B$. subtilis}

This chapter is extracted from the previously published material in Cascante-Estepa N., Gunka K. and Stülke J. (2016) Localization of components of the RNA-degrading machine in Bacillus subtilis. Front. Microbiol. 7:1492.

For years it has been known that, not only in eukaryotes but also in bacteria, compartmentalization and subcellular organization are essential for the normal functioning of a cell (Shapiro and Losick, 2000; Lewis et al., 2000; Errington, 2003). The possibility of fusing fluorescent proteins to visualize the in vivo localization of proteins has greatly improved our understanding of the cell dynamics in the past years. Indeed, the researchers that discovered and described the green fluorescent protein (GFP) were awarded in 2008 the Nobel Prize in Chemistry (Chalfie et al., 1994). However, the ability of the green fluorescent protein (GFP) to dimerize can cause artifacts in the localization of the fusion protein within the cells, which can be avoided by the use of monomeric fluorescent proteins (Miyawaki, 2011; Margolin, 2012). Moreover, the addition of a tag to a protein could affect its functionality and localization in vivo, by avoiding interactions, conformational changes or proper folding (Gunka et al., 2013). Furthermore, the overexpression of labeled proteins may result in aggregation and mis-localization (Miyawaki, 2011; Margolin, 2012). For these reasons, to study the localization of the proteins implicated in RNA degradation in B. subtilis, we used a monomeric GFP variant (Oliva et al., 2010) and integrated the constructs into the original loci of the chromosome, ensuring that the labeled proteins are expressed from their native promoters. Additionally, we verified that these fusion proteins had retained their native activity in vivo.

Several ribonucleases, RNA helicases and glycolytic enzymes were proposed to form an RNAdegrading complex in B. subtilis (see 1.5). However, the subcellular localization of some of these proteins has not yet been determined in vivo by fluorescence labeling

\subsubsection{Functionality of the proteins fused to GFP in vivo}

To confirm that the fusion proteins had retained their original activity, we compared the strains harboring said fusions to the wild type and to their respective deletion mutants. We considered that, if the fusion to GFP rendered the proteins inactive, the strains would show a phenotype similar to the corresponding deletion mutants. 
The deletion of the pnpA gene encoding polynucleotide phosphorylase causes the cells to grow in long cell chains and results in cold sensitivity (Wang and Bechhofer, 1996). The B. subtilis GP1698 strain, which harbors the PNPase-GFP fusion, was able to grow with a normal cell length (Figure 11A). RNase J1, encoded by the $r n j A$ gene, has been regarded as essential until recently. Even though the construction of a deletion mutant is possible, this strain shows severely affected cell morphology, with cells growing in curly long chains (Figaro et al., 2013). Our strain GP1722 expresses the RNase J1-GFP fusion and showed normal cell morphology and not a filamentous and curly-cell phenotype (Figure 11B).

Although RNase J2, the paralogue of RNase J1, can be deleted without any visible phenotype, it has been proven to interact in vitro with RNase J1 with a 1:1 stoichiometry (Mathy et al., 2010). Moreover, we have observed a strong interaction of both proteins by in vivo co-purification (Figure 12). As we cannot assay the functionality of RNase J2, we would assume that a similar localization of RNases J1 and J2 indicates that the GFP tag did not affect J2 activity and localization (see Figure 16).

A

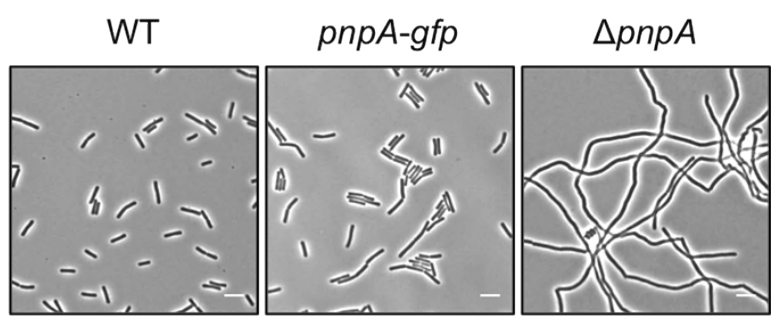

B

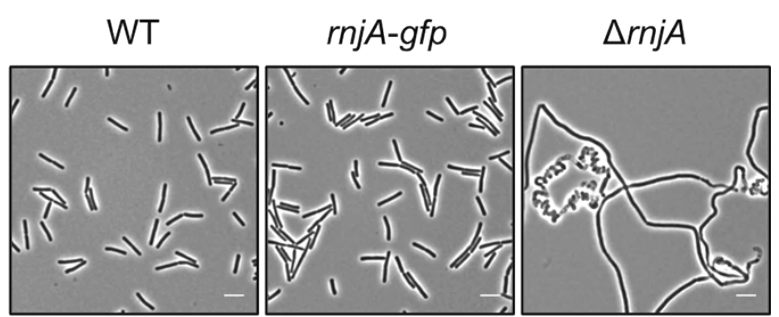

Figure 11. The strains that contain the GFP fusions to PNPase and RNase J1 have a wild type phenotype under the microscope. Light microscopy of strains (A) 168 (WT), GP1698 (pnpA-gfp), and GP1748 ( GP1722 (rnjA-gfp), and GP2502 ( $\Delta r n j A)$. The strains were grown in LB medium at $37^{\circ} \mathrm{C}$ to stationary phase. Both strains harboring the GFP fusions form short cells comparable to the wild type strain and are not elongated as their respective deletion mutants. Scale bar, $5 \mu \mathrm{m}$. WT, wild type.

RNase $\mathrm{Y}$ is encoded by rny, the first gene of the bi-cistronic rny-ymdB operon (Diethmaier et al., 2011). To avoid interference with the expression of the phosphodiesterase YmdB, we constructed a strain expressing the RNase Y-GFP fusion under the control of a xylose-inducible promoter. As membrane localization of RNase $Y$ has been demonstrated in several independent 
studies (Hunt et al., 2006; Lehnik-Habrink et al., 2011a; Bürmann et al., 2012), no further functional analyses were performed.

A

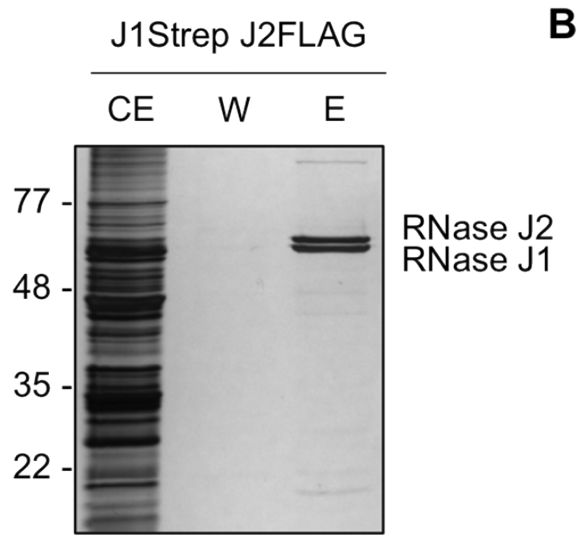

B



Figure 12. RNase J1 and J2 interact in vivo forming a complex. Cells from strain GP1048 ( $r n j A-S t r e p ~ r n j B-3 x F L A G)$ were cultured in $\mathrm{LB}$ medium at $37^{\circ} \mathrm{C}$ to an $\mathrm{OD}_{600}$ of 1 . The cells were then disrupted and RNase J1-Strep was purified by StrepTactin column as described above. (A) The fractions were analyzed by denaturing PAGE and visualized by silver staining. The faint eluted bands at the top and the bottom of the gel correspond to PycA and AccB, respectively, the two biotin-containing proteins of $B$. subtilis (Meyer et al., 2011). (B) The identity of RNase J2 was proven by Western blot analysis. CE, cell extract; $W$, wash fraction; $E$, elution fraction.

The cshA deletion mutant, however, grows poorly at temperatures lower than $28^{\circ} \mathrm{C}$ (LehnikHabrink et al., 2013) but the strain GP1721, which harbours the CshA-GFP fusion, was able to grow at $28^{\circ} \mathrm{C}$ like the wild type (Figure $13 \mathrm{~A}$ ). The glycolytic enzymes enolase and phosphofructokinase (PfkA) were for years thought to be essential for the growth of $B$. subtilis (see 1.5.2). This essentiality, however, has been recently re-analyzed (Muñoz-Márquez and Ponce-Rivas, 2010; Commichau et al., 2013). There, enolase was shown to be essential for the growth of $B$. subtilis in LB medium, while the $p f k A$ gene, albeit not essential, was proven to be required for normal growth on minimal medium with glucose as carbon source. For strain GP1720 expressing the phosphofructokinase fused to GFP, we observed growth on minimal medium with glucose as the carbon source, indicating activity of the fusion protein (Figure 13B). The strain encoding the fusion of enolase to GFP (GP1700) was viable and grew as the wild type strain, indicating functionality of enolase when fused to GFP (Figure 13C). 
A

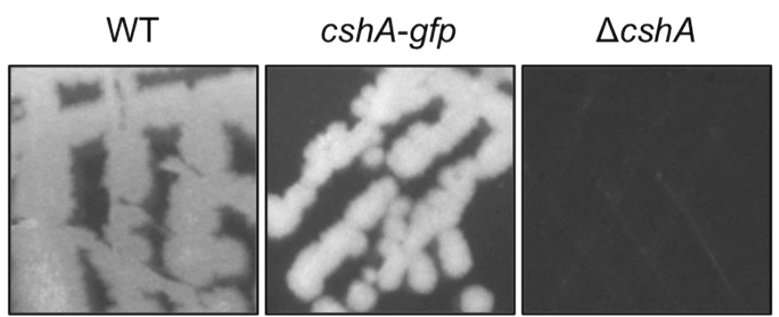

B

WT

pfkA-gfp

$\triangle p f k A$
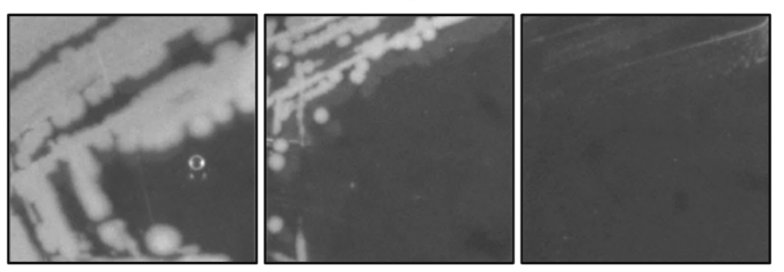

C

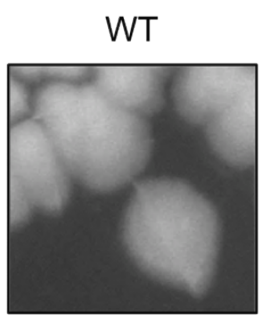

eno-gfp

$\Delta e n o$
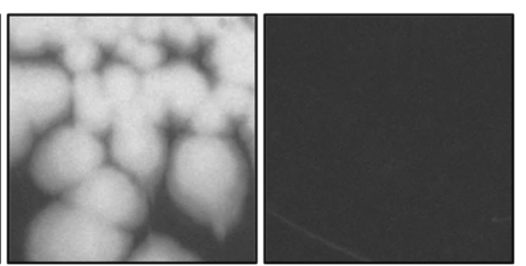

Figure 13. The strains harbouring GFP fusions to CshA, PfkA and enolase show no growth defect. (A) Strains 168 (WT), GP1721 (cshA-gfp), and GP1035 ( $\triangle \operatorname{csh} A)$ were streaked on LB agar and incubated at $28^{\circ} \mathrm{C}$ overnight. The strain harboring the $\operatorname{csh} A$-gfp fusion in the genome is able to grow under these conditions while the deletion mutant has a growth defect. (B) Strains 168 (WT), GP1720 (pfkA-gfp), and GP1747 ( $\triangle p f k A)$ were streaked on CE minimal medium plates with $0.5 \%$ glucose and incubated for 48 hours at $37^{\circ} \mathrm{C}$. The strain with the $p f k A-g f p$ fusion is able to grow under these conditions, in contrast to the deletion mutant. (C) Strains 168 (WT), GP1700 (eno-gfp), and GP594 ( $\Delta$ eno) were streaked on LB plates and incubated at $37^{\circ} \mathrm{C}$ overnight. The strain harboring the eno-gfp fusion can grow under these conditions, while the deletion mutant is unable to grow. WT, wild type.

\subsubsection{Localization of the proteins fused to GFP within the B. subtilis cell}

RNase $Y$ has been proposed to provide the scaffold for RNA-degrading enzymes in B. subtilis, while anchoring this putative complex to the cell membrane. In fact, several studies have reported membrane localization of this protein (Hunt et al., 2006; Zweers et al., 2009; LehnikHabrink et al., 2011a; Bürmann et al., 2012; Strahl et al., 2014). The fluorescence microscopy on the strain GP1684, which expresses the RNase Y-GFP fusion protein, shows that the localization of the enzyme perfectly co-localized with the membrane (Figure 14). Interestingly, we observed a higher intensity of RNase $Y$ localization at the division septa. We investigated afterwards the localization of the exoribonucleases PNPase, RNase J1 and RNase J2. For PNPase, we observed that it was localized with a uniform distribution throughout the cell cytoplasm (Figure 15A). The GFP fusions of the RNases J1 and J2 were found to localize in the cytoplasm with a lower 
concentration of fluorescence at central region of the cell, that was identified by DAPI stain as the location for the nucleoid (Figure 16).
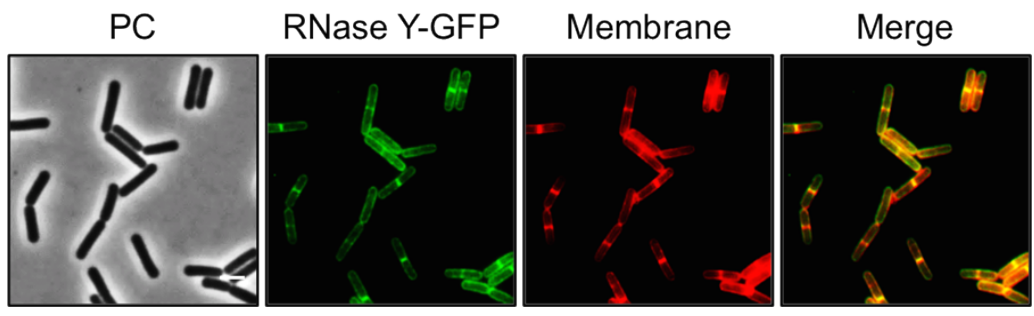

Figure 14. RNase Y localizes to the cell membrane. Fluorescence microscopy of the strain GP1684 (Pxyl-rny-gfp) grown in LB medium at $28^{\circ} \mathrm{C}$ to stationary phase. The expression of the fusion protein was induced by addition of $0.1 \%$ xylose to the culture medium. The membrane was stained with Nile Red. RNase Y-GFP co-localizes with the Nile Red staining, confirming the membrane localization of the protein. Scale bar, $2 \mu \mathrm{m}$. PC, phase contrast.

In order to confirm the exclusion of RNases $\mathrm{J} 1$ and $\mathrm{J} 2$ from the nucleoid region, we treated cultures expressing the fusion proteins with rifampicin to stop transcription. The stop in transcription results in relaxation of the nucleoid and, as a result, it delocalizes from the central region of the cell and spreads to the whole cytoplasm (Hunt et al., 2006). This effect is accompanied by a complete delocalization of RNases $\mathrm{J} 1$ and $\mathrm{J} 2$, which now are evenly distributed throughout the cytoplasm (Figure 17). Similar localization and delocalization pattern upon rifampicin treatment have been shown previously for ribosomes in B. subtilis (Mascarenhas et al., 2001).

A

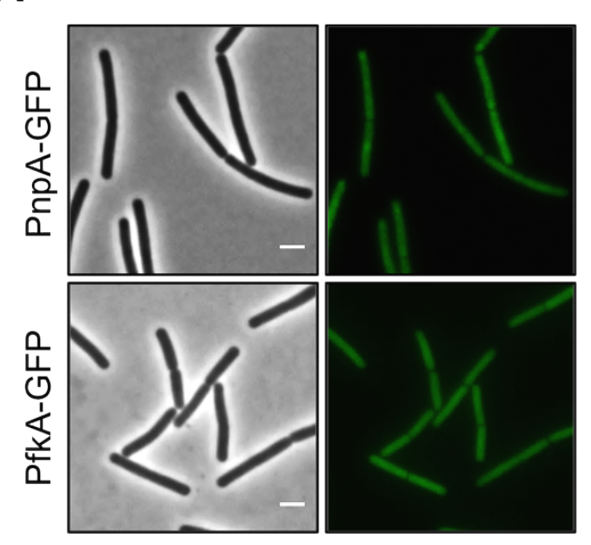

B

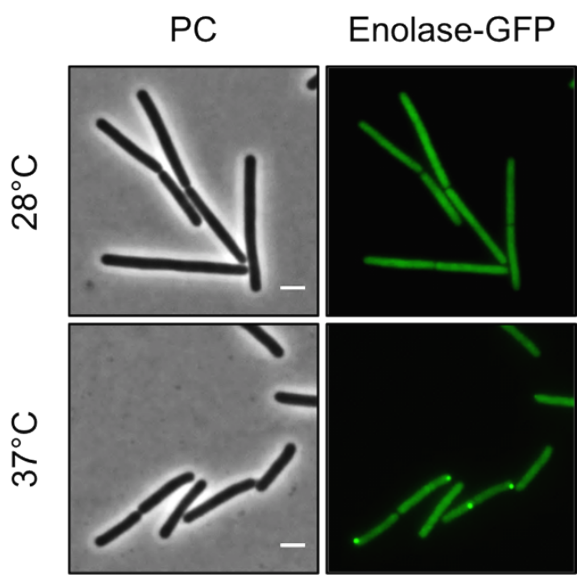

Figure 15. The enzymes PNPase, PfkA, and enolase show a cytosolic localization. Fluorescence microscopy of strains harboring GFP fusions. (A) The strains GP1698 (pnpA-gfp) and GP1720 (pfkA-gfp) were grown in LB medium at $28^{\circ} \mathrm{C}$ to mid-exponential phase. The fusion proteins are homogenously distributed within the cytoplasm. (B) Strain GP1700 (eno-gfp) was grown to mid-exponential phase in LB medium at $28^{\circ} \mathrm{C}$ or $37^{\circ} \mathrm{C}$. The protein appears widespread in the cytoplasm at both temperatures but at $37^{\circ} \mathrm{C}$ some cells show bright spots localized at the poles. Scale bar, $2 \mu \mathrm{m}$. PC, phase contrast. 
We were able to confirm the localization of the CshA around the nucleoid (Figure 16) and its delocalization upon rifampicin-inhibited transcription (not shown). Taken together, these observations suggest that both RNase $\mathrm{J} 1$ and $\mathrm{J} 2$ are localized to those areas in the cytoplasm where the RNA target molecules are present. Interestingly, very similar results have been obtained for the localization of the DEAD box helicase CshA (Hunger et al., 2006).

For the glycolytic enzymes enolase and phosphofructokinase, we detected an even distribution in the cytoplasm (Figure 15). Interestingly, enolase formed bright spots at the polar regions of some cells at $37^{\circ} \mathrm{C}$ but not at $28^{\circ} \mathrm{C}$.

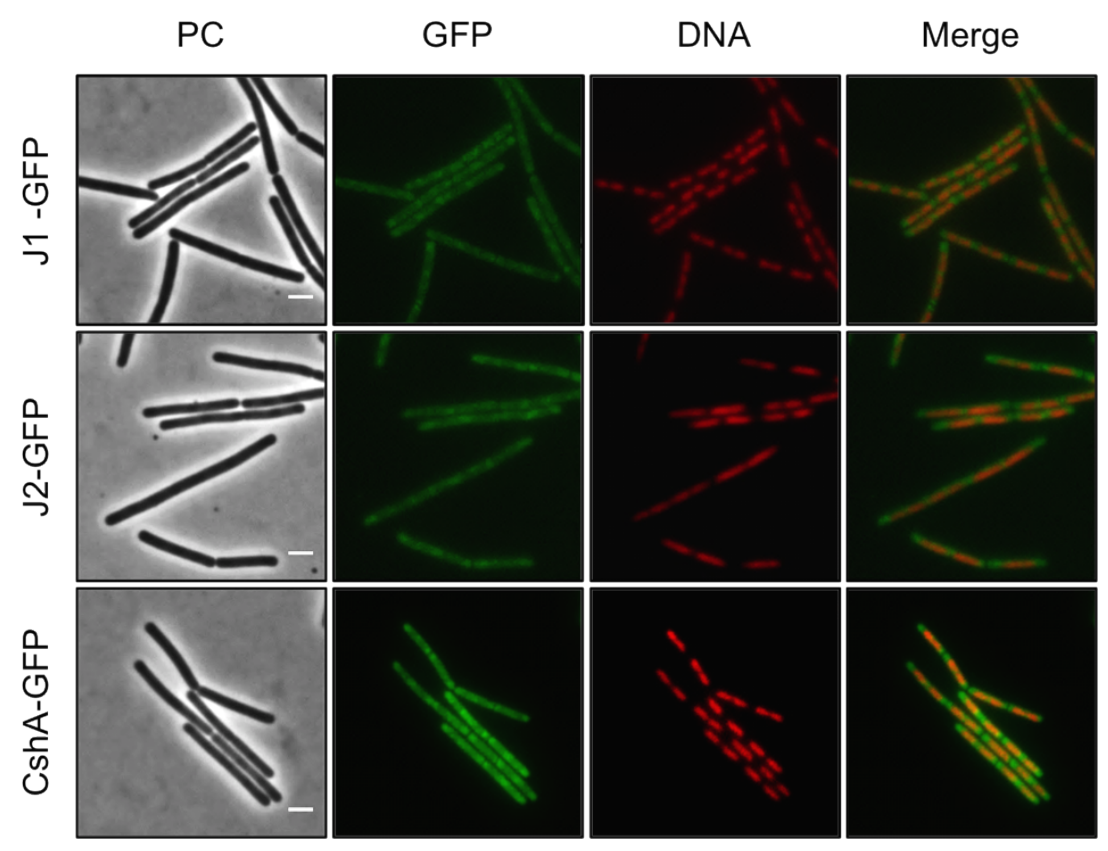

Figure 16. The RNases J1 and J2, as well as the RNA helicase CshA are localized to the cytosol, surrounding the nucleoid. Fluorescence microscopy of strains GP1722 (rnjA-gfp), GP1699 (rnjB-gfp), and GP1721 (cshA-gfp). The cells were grown in LB medium at $28^{\circ} \mathrm{C}$ to mid-exponential phase. The nucleoid was stained by DAPI as described above in the materials and methods section. The proteins are distributed in the cytoplasm concentrating at the poles. The concentration of the proteins is lower at the centre of each cell, where the nucleoid is positioned, as can be observed by DAPI stain. Scale bar, $2 \mu \mathrm{m}$. PC, phase contrast. 
A
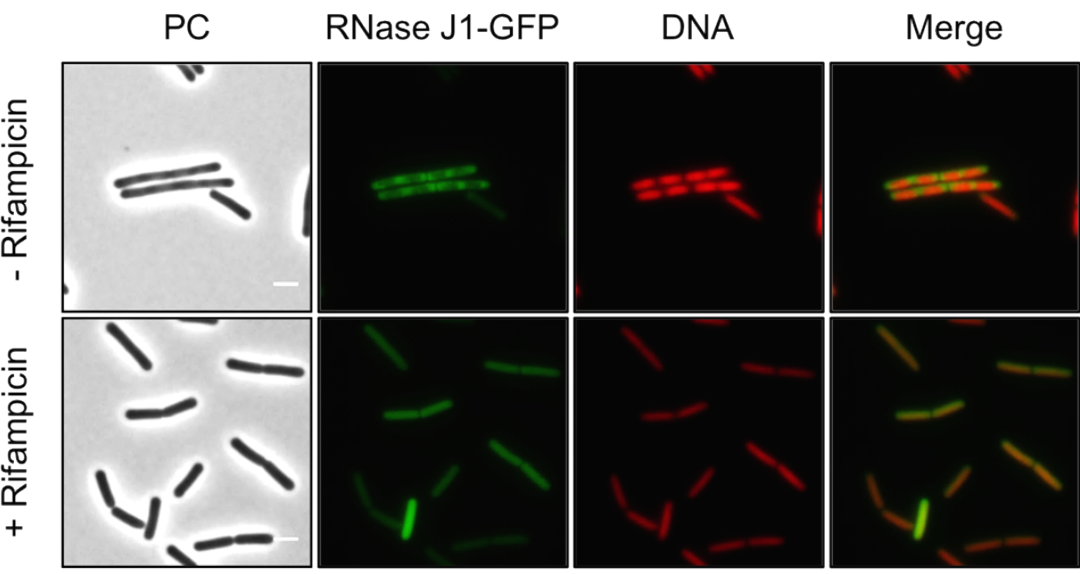

B

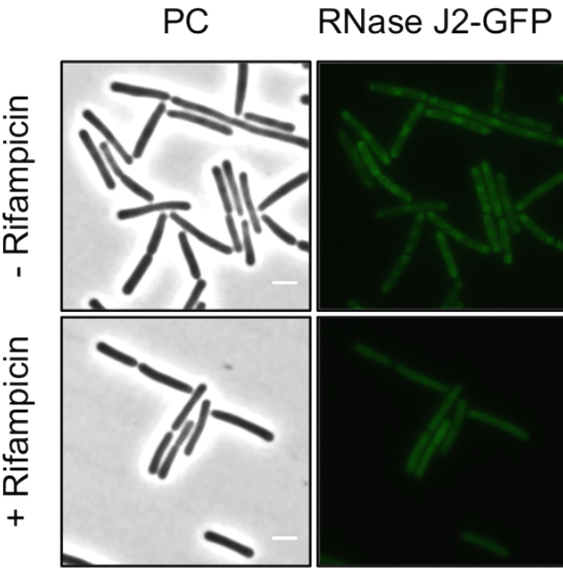

DNA

Merge
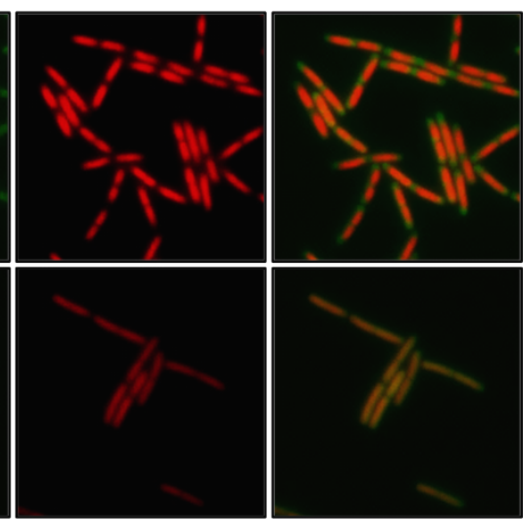

Figure 17. RNase J1 as well as its paralogue RNase J2 delocalize upon treatment with rifampicin. Fluorescence microscopy of strains (A) GP1694 (Pxyl-rnjA-gfp) and (B) GP1695 (Pxyl-rnjB-gfp). Bacteria were grown in LB medium at $37^{\circ} \mathrm{C}$ to mid-exponential phase, when rifampicin or methanol was added to the cultures as described above. The expression of RNase J1-GFP and RNase J2-GFP was induced by addition of $0.1 \%$ xylose to the culture medium. The nucleoid was stained by DAPI as described in the Material and methods section. The sub-polar localization of both RNases $\mathrm{J} 1$ and $\mathrm{J} 2$ is lost as the RNA synthesis is inhibited and the proteins appear evenly distributed in the cytoplasm. Upon addition of rifampicin the nucleoid, stained by DAPI, spreads occupying the majority of the cell volume. Scale bar, $2 \mu \mathrm{m}$. PC, phase contrast.

\subsubsection{Conclusions}

We have performed a detailed analysis of the localization of the proteins involved in RNA degradation in B. subtilis. However, our results are in contradiction with the existence of an RNA degradosome in this bacterium: while RNase $\mathrm{Y}$ is located at the cytoplasmic membrane, the exoribonucleases RNase J1 and J2 as well as the RNA helicase CshA are localized in the peripheral regions of the cell, i. e., the region where the bulk of the RNA is localized. Moreover, the polynucleotide phosphorylase and the glycolytic enzymes are found homogeneously distributed in the cytoplasm. 


\subsection{In vivo interaction of the paralogous RNases J1 and J2}

RNase J1 and RNase $\mathrm{J} 2$ have been shown to form a complex in vivo, that also modifies the individual specificities of the enzymes (Mathy et al., 2010). However, there is still controversy regarding the oligomeric state of the proteins in vivo. It is known by structural and functional analysis that the C-terminal domain of RNase J1 (see Figure 6) is necessary for its dimerization and for its activity in vitro. However, the relevance of the C-terminal domain for the in vivo interaction and activity of RNase $\mathrm{J} 1$ and $\mathrm{J} 2$ of $B$. subtilis is not known.

\subsection{1. $\mathrm{RNases} \mathrm{J} 1$ and $\mathrm{J} 2$ interact in vivo through the $\mathrm{C}$-terminal domain}

To analyze the relevance of the C-terminal domain in the interaction of the paralogous RNases $\mathrm{J} 1$ and $\mathrm{J} 2$, several strains were constructed in which the proteins were fused to a tag that made them possible to be identified. The constructs were then integrated in the chromosome, so that the fusion proteins could be expressed from their native promoters. The addition of a tag was necessary to be able to purify the proteins through an affinity column. Furthermore, the tags serve the second purpose of identification, since the proteins have very similar molecular weights (see Table 18). Thus, the strains GP1048 (rnjA-Strep rnjB-3xFLAG), GP1731 (rnjB-Strep rnjA3xFLAG) were used. Furthermore, two strains were created in which the C-terminal domain of RNase J2 (amino acids 450-555) was truncated (see Figure 6), assuming that the structures of RNase $\mathrm{J} 1$ and $\mathrm{J} 2$ are superimposable (sequences share $49 \%$ identity and $70 \%$ similarity). These strains were GP1740 (rnjA-Strep rnjBACter-3xFLAG) and GP1741 (rnjBACter-Strep rnjA-3xFLAG). To perform the experiment, the strains were grown in LB medium and the cultures were harvested. The pellets were resuspended in buffer and the cells were broken open by French press, and Strep-tagged proteins were purified as decribed above.

Table 18. Molecular weight of proteins calculated by ExPASy from their amino acid sequence.

\begin{tabular}{c|ccc} 
& WT & Strep & $3 x$ FLAG \\
\hline RNase J1 & 61.52 & 63.43 & 65.10 \\
RNase J2 & 61.17 & 63.09 & 64.76 \\
RNase J2 $\Delta$ Cter & 49.09 & 51.00 & 52.67
\end{tabular}

To analyse the interaction partners of the bait proteins we performed SDS-PAGE. Furthermore, the proteins could be identified by Western blot. Same concentration of each cell extract has been loaded in the gel, to confirm the expression of all the tagged proteins (Figure 18B and C). Interestingly, the expression of the truncated RNase $\mathrm{J} 2$ seems to be higher than that of the full 
protein (Figure 18B lanes 5 and 7, and 17C lanes 1 and 3). This could indicate a destabilizing effect of the C-terminal domain, or a regulatory mechanism involving this part of the gene. The amounts of RNase J1 seem to also be slightly increased in presence of the truncated RNase J2 (Figure 18B lanes 1 and 3).

A

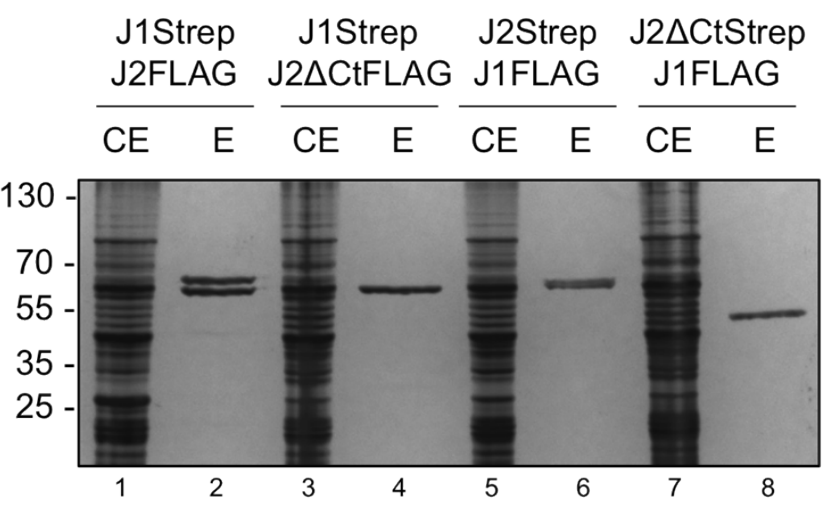

B

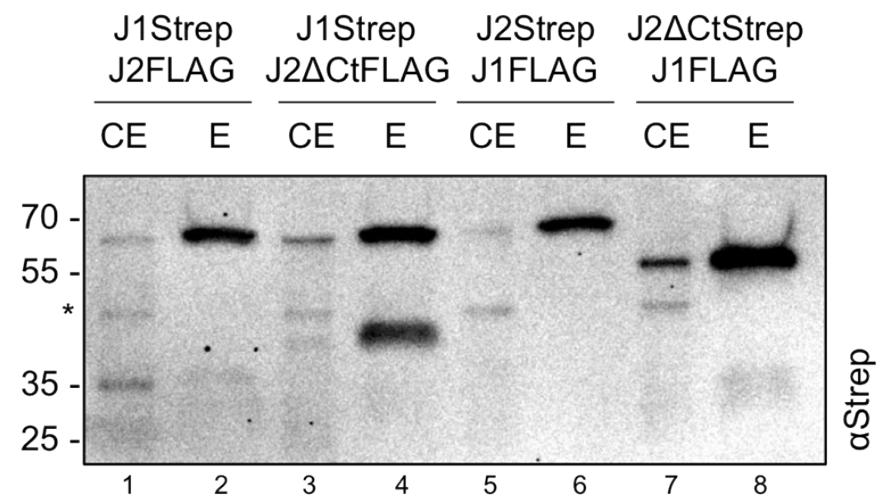

C



Figure 18. RNase J1 and J2 interact thorugh the C-terminal domain of RNase J2 in vivo. Cells from strains GP1048 (rnjA-Strep rnjB-3xFLAG), GP1731 (rnjB-Strep rnjA-3xFLAG), GP1740 (rnjA-Strep rnjBACter-3xFLAG) and GP1741 ( $r n j B \triangle C$ Cter-Strep $r n j A-3 \times F L A G$ ) were cultured in $L B$ at $37^{\circ} \mathrm{C}$ to an $\mathrm{OD}_{600}$ of 1 . The cells were disrupted and proteins were purified though a StrepTactin chromatography column as described above. The fractions were analyzed by denaturing PAGE and visualized by silver staining (A), and Western blot with antibodies anti-Strep (B), and anti-Flag (C). CE, cell extract; Ct, C-terminal domain; E, elution fraction; *, unspecific bands. 
It was previously shown that a deletion of RNase J2 increases the expression of RNase J1 1.4fold (Jamalli et al., 2014). This could indicate that the truncated version of RNase J2 is not active. Furthermore, we can observe that RNase J2 co-purifies with RNase J1 and vice versa (Figure 18 lanes 2 and 6). We can also confirm that the C-terminal domain is necessary for the interaction between RNase J1 and J2, since the truncated RNase J2 cannot interact with the full-length RNase J1 (Figure 18 lanes 4 and 8). It is interesting to note that, in the presence of truncated RNase J2, there seems to be an accumulation of a smaller fragment of RNase J1 (Figure 18B lane 4). We can speculate that RNase $\mathrm{J} 1$ is less stable in the absence of interaction with RNase J2. Furthermore, we observe degradation products of RNase J2 (Figure 18C lane 2). These shorter protein fragments are not present when RNase J2 is Strep-tagged (Figure 18B lane 6), so we can hypothesize that the addition of the 3xFlag tag destabilizes the protein, making it more sensitive to degradation. Interestingly, the calculated isoelectric point ( $\mathrm{pl}$ ) of RNase J2 is very basic (pl calculated by ExPASy from the primary structure, 8.47). However, the calculated pl decreases drastically upon addition of the 3xFLAG tag to 6.43 (see Table 19).

Table 19. Isoelectric point calculated by ExPASy from the amino acid sequence.

\begin{tabular}{c|ccc} 
& WT & Strep & $3 x$ FLAG \\
\hline RNase J1 & 5.93 & 5.97 & 5.57 \\
RNase J2 & 8.47 & 8.41 & 6.43 \\
RNase J2 $\Delta$ Cter & 7.74 & 7.71 & 6.14
\end{tabular}

\subsubsection{Oligomerization of the RNases $\mathrm{J} 1$ and $\mathrm{J} 2$ in vivo}

As has been described before (see 1.5.5), RNases J1 and J2 interact in vivo and in vitro, and can form dimers and heterodimers. However, it is not known how these complexes exist in vivo naturally, and how the disruption of the interaction affects the complex formation. The native state of the complex in the cell was studied following the same procedure as described above (see 3.2.1), although disrupted by tissue lyser. The elution fractions were, however, loaded on a native-PAGE gel and the proteins were identified by Western blot. In Figure 19 we can observe that RNase $\mathrm{J} 1 / \mathrm{J} 2$ exists as a dimer or tetramer, and both oligomers are present in similar amounts (lanes 1 and 3). It was shown that when its C-terminal domain is truncated, RNase J2 can no longer interact with its paralogue RNase J1 (Figure 18 lanes 4 and 8). Nonetheless, this does not impede the formation of homodimers and homotetramers by RNase J1 (Figure 19 lane 2). However, the truncated RNase $\mathrm{J} 2$ cannot self-interact, as it is demonstrated by the absence of oligomers (Figure 19A lane 4). 
It is still unknown, however, if full-length RNase J2 was able to self-interact in the absence of RNase J1. Furthermore, it had not been assessed whether RNase J1 could also oligomerize when RNase J2 is completely deleted. Several strains were created in order to investigate these interactions further, combining Strep-tag fusion proteins and protein deletions. The strain GP1034 (rnjA-Strep) was transformed with genomic DNA from the srains GP1291 ( $\Delta r n j B)$ and GP1732 (rnjBACter), to generate the strains GP1723 (rnjA-Strep $\Delta r n j B)$ and GP1736 (rnjA-Strep rnjBACter), respectively. Furthermore, the strain GP2318 (rnjBStrep $\Delta$ rnjA) was created by transforming chromosomal DNA from the GP2502 strain ( $\Delta r n j A)$ into GP1687 (rnjB-Strep). The strain GP1737 harbors the fusion of a Strep-tag to the truncated RNase J2 protein.

A

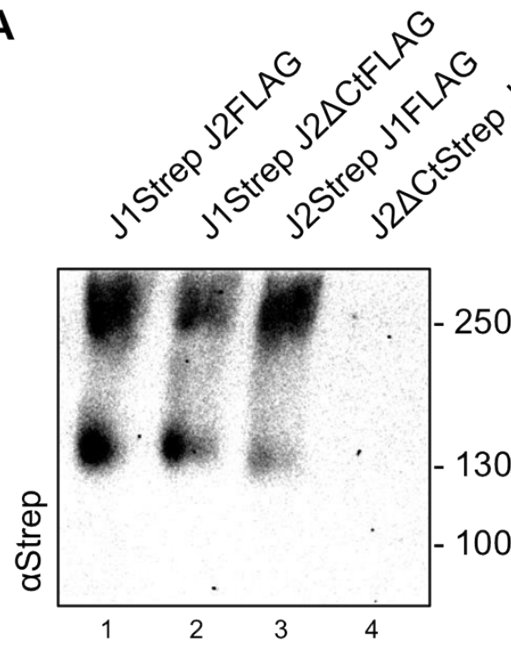

B

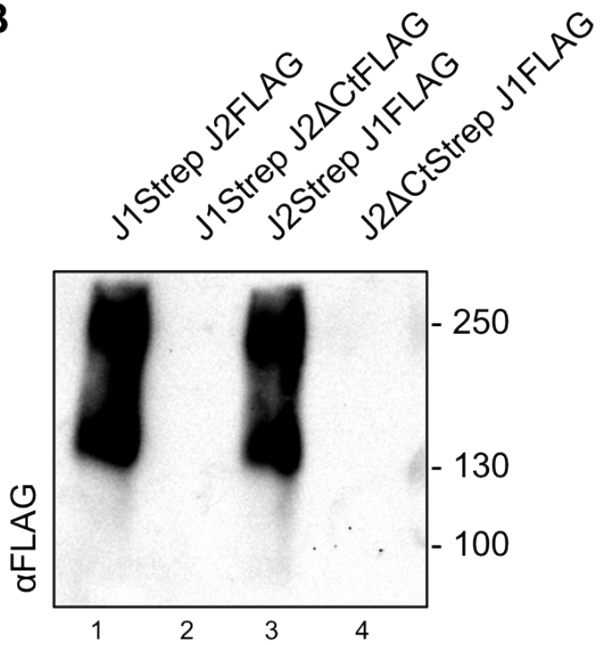

Figure 19. RNase J1 and J2 oligomerize as dimer and tetramer in vivo. RNase J1 can also form dimers and tetramers itself. Cells from strains GP1048 (rnjA-Strep rnjB-3xFLAG), GP1731 (rnjB-Strep rnjA-3xFLAG), GP1740 (rnjAStrep rnjBACter-3xFLAG) and GP1741 ( $r n j B \Delta C$ Cter-Strep rnjA-3xFLAG) were cultured in LB at $37^{\circ} \mathrm{C}$ to an $\mathrm{OD}_{600}$ of 1 . The cells were disrupted by tissue lyser and proteins were purified though a StrepTactin chromatography column as described. The fractions were analyzed by native PAGE and visualized by Western blot with antibodies anti-Strep (A) and anti-FLAG (B). Ct, C-terminal domain.

The cells were grown in $L B$ at $37^{\circ} \mathrm{C}$ and disrupted by French press as described. After purification through a Streptactin column, the elution fractions were analysed in a native-PAGE and Western blot, as for Figure 19A. However, the oligomerization of the proteins could not be detected, since the native-PAGE protocol used does not allow the migration of basic proteins. The homodimeric and homotrimeric forms of RNase $\mathrm{J} 1$ could be detected (not shown), but no oligomer involving RNase $\mathrm{J} 2$ was seen. The proteins RNase J1 and RNase J2 have very different calculated isoelectric points (pl) (see Table 19). For this reason, the elution fractions were analysed on a native-PAGE for basic proteins, where they are artificially charged by the dye Coomassie Brilliant Blue G, allowing the basic proteins to migrate towards the anode. The cell extracts were incubated for one hour with DNase I and RNase A, previous to centrifugation, and 
subsequently applied to a Streptactin chromatography column. The elution fractions were loaded onto a gel, and the proteins could properly migrate and separate (Figure 20).
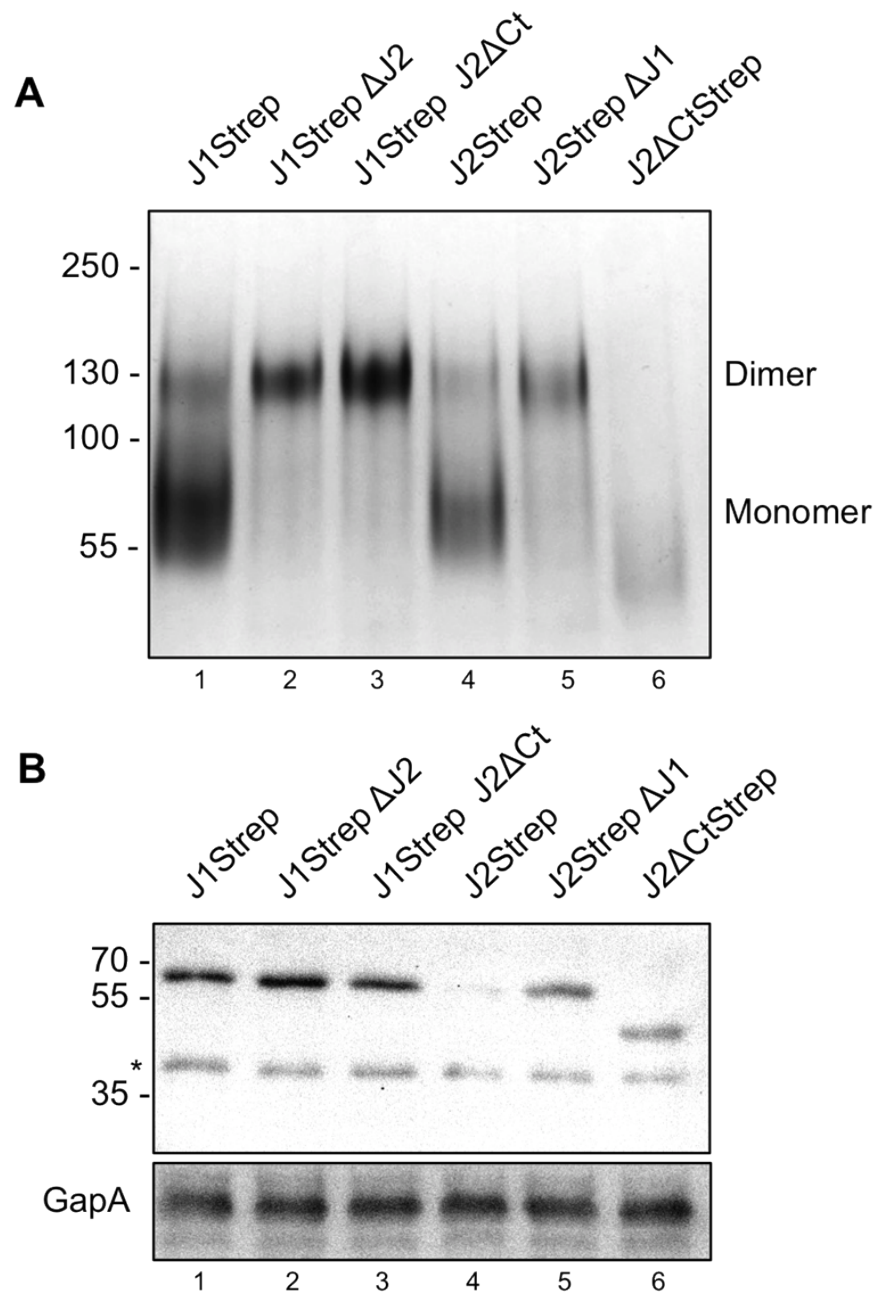

Figure 20. RNase $\mathbf{J 1}$ and $\mathbf{J 2}$ interact in vivo forming hetero- and homodimers. Cells from strains GP1034 (rnjA-

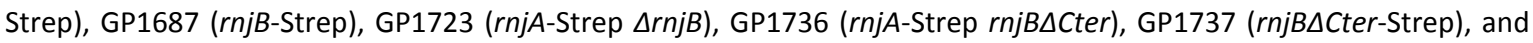
GP2318 (rnjBStrep $\triangle r n j A$ ) were cultured in $\mathrm{LB}$ at $37^{\circ} \mathrm{C}$ to an $\mathrm{OD}_{600}$ of 1 . The cells were disrupted by French press and the cell extract was incubated for 1 hour on ice with $6.75 \mu \mathrm{g} / \mathrm{ml} \mathrm{RNase} A$ and $5 \mu \mathrm{g} / \mathrm{ml}$ DNase I. (A) Proteins were purified though a StrepTactin chromatography column as described above. The fractions were analyzed by Native PAGE for basic proteins and visualized by silver staining. (B) A total of $15 \mu \mathrm{g}$ of protein from the cell extracts were loaded on a denaturing PAGE and analyzed by Western blot with anti-Strep antibody. Antibody anti-GapA was used as a loading control. CE, cell extract; Ct, C-terminal domain; E, elution fraction; ${ }^{*}$, unspecific band.

In the absence of RNase $\mathrm{J} 2$ or in the presence of the truncated RNase J2 protein, RNase J1 is able to homodimerize (Figure 20A lanes 2 and 3). Interestingly, the dimer of RNase J1 and J2 was also present. However, a greater amount of monomer is visible (Figure 20A lane 1). This contradicts what was seen before (Figure 19 lanes 1 and 3). This effect is also visible when the pull-down is performed with RNase $\mathrm{J} 2$ as bait (Figure 20A lane 4). However, RNase J2, in the absence of RNase $\mathbf{J} 1$, is able to self-interact and form dimers (Figure 20A lane 5). The truncated 
RNase J2 protein, as was shown before (Figure 19B lane 4), is not able to oligomerize. Interestingly, the presence of tetramers could not be observed. In this experiment, compared to the one described above (see 3.2.2), the cell extracts were incubated with RNase A and DNase I. It is tempting to speculate that the tetramers are formed when the proteins can bind to RNA. Furthermore, the addition of Coomassie Brilliant Blue $\mathrm{G}$ could have, indeed, affected the native oligomerization state. Moreover, the presence of monomers in the strains where RNase J1 and J2 can interact in a native state, but not when only one of the proteins is present, raises many questions.

Furthermore, the cell extracts were also analyzed by SDS-PAGE and Western blot. A total of 15 $\mu \mathrm{g}$ of protein were loaded in each lane. An antibody raised against GapA was used as a loading control. Interestingly, we observe again an increase in the protein amounts of RNase J2, when the C-terminal part is truncated (Figure 20B lanes 4 and 6). Moreover, the deletion of RNase J1 seems to affect the levels of RNase J2 in the same manner. However, silver stain analysis of the elution fractions after SDS-PAGE showed that several proteins that bind non-specifically to the column were also highly increased in this strain (not shown). This could be a consequence of the global effect of the deletion of RNase J1 on the mRNA levels (see 1.5.5). The increase in the levels of RNase J1 in the absence of RNase J2 is also visible (Figure 20 lanes 1 and 2); in the presence of the truncated RNase $\mathrm{J} 2$, however, it is not possible to appreciate.

\subsubsection{Localization of the RNases $\mathrm{J} 1$ and $\mathrm{J} 2$ in different deletion mutants}

To further investigate the behaviour of the RNases J1 and J2 in vivo in the absence or presence of the paralogues, fluorescence microscopy was performed, as described in materials and methods. Furthermore, the effect of the deletion or truncation of RNase J2 on the cell morphology was studied. The deletion of the rnjA gene, coding for RNase J1, shows very strong morphological defects, such as elongated and curly cells. The deletion of RNase J2, however, does not produce such a strong phenotype. Indeed, the majority of the cells within the population show a wild type phenotype. Some elongated cells are present, although they do not present the bulges and curls that exist in the deletion of rnjA. Furthermore, the elongated cells are not as long as those of the RNase J1 mutant (Figure 21). The same observations are true for the truncation of RNase J2. These results show that, although the deletion of RNase J2 causes a milder phenotype than that of RNase $\mathrm{J} 1$, the protein could also be involved in the processing of certain transcripts necessary for proper cell division. Furthermore, the truncation of the RNase J2 produces a same effect, raising the question of whether the activity of RNase $\mathrm{J} 2$ or its oligomerization is necessary for a normal phenotype. 
To address the question of the localization of these paralogous RNases several strains were constructed. RNase J1 was fused to GFP and combined with the deletion and truncation of RNase J2 (strains GP1722 (rnjA-gfp), GP1734 (rnjA-gfp rnjBACter), and GP2317 (rnjA-gfp $\Delta r n j B)$ ). Furthermore, RNase $\mathrm{J} 2$ was fused to GFP in the presence and absence of RNase J1, generating strains GP1749 (rnjB-gfp), and GP1750 (rnjB-gfp $\Delta r n j A)$, respectively. To answer the question of whether the truncation of RNase J2 altered its normal localization, the truncated protein was fused to GFP in the strain GP1733 (rnjBDCter-gfp). All the GFP fusions were expressed from the native locus of the proteins, and a second copy of the tagged protein was not present. As was shown before, RNase J1 and J2 localize to the cytoplasm of the cell, surrounding the nucleoid (Figure $22 \mathrm{~A}$ and $\mathrm{B}$ ). As its is shown, the absence of RNase $\mathrm{J} 2$ or the truncation of its C-terminal domain does not seem to affect the localization of RNase J1 (Figure 22A). However, the morphology of the cell is affected, presenting elongated and thickened cells that even present bulges. This is interesting, since it only happens in when the fusion of RNase J1 to GFP is combined with either the deletion or truncation of RNase $\mathrm{J} 2$.

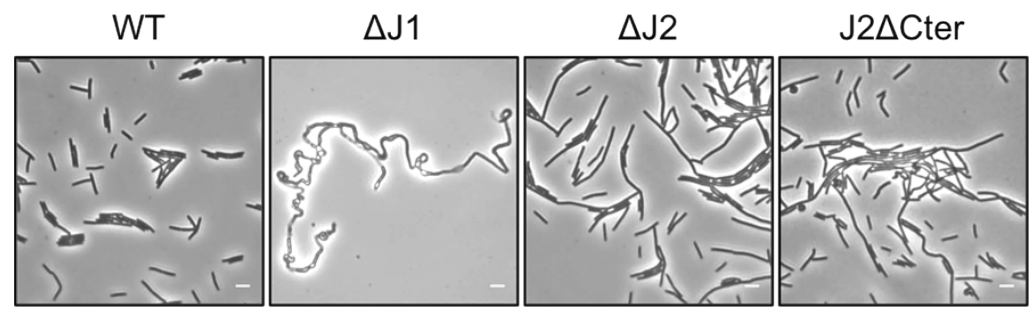

Figure 21. The deletion strain of RNase J1 shows a filamentous and curly phenotype. The deletion of RNase J2 or truncation of the C-terminal domain causes some cells to be elongated. Phase contrast images of strains 168 (WT),

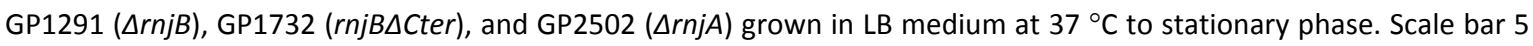
$\mu \mathrm{m}$.

The impact of the deletion of $r n j A$ on the localization of RNase J2 is, however, very strong. In the absence of RNase J1, RNase J2 localizes in defined spots, which are even visible in the light microscopy image (Figure 22B). This localization suggests that the protein is aggregating. However, it has been proven that RNase J2 does not aggregate but oligomerizes in the absence of RNase J1 (Figure 20A). Furthermore, the curly and elongated phenotype is more severe than that of the deletion of RNase J1 (Figure 21). Moreover, the truncated version of RNase J2 can be found evenly disperse in the cytoplasm, confirming that it cannot interact with RNase J1. 
A

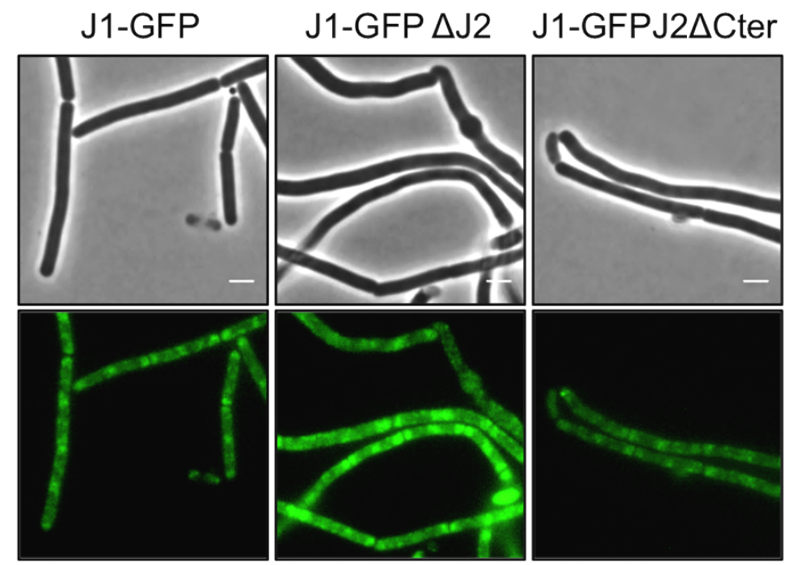

B

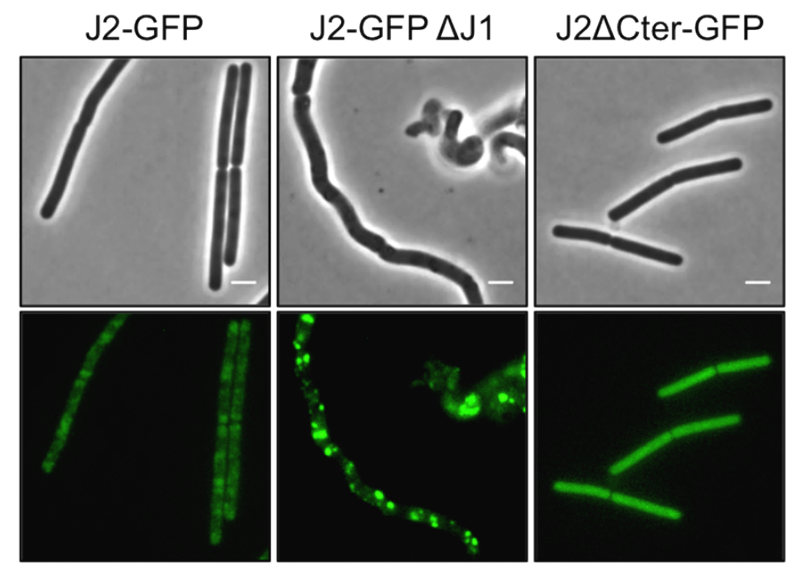

Figure 22. RNase J1 maintains its localization when RNase J2 does not interact with it. RNase J2 can no longer interact with RNA when RNase J1 is not present. Phase contrast and fluorescent microscopy of strains (A) GP1722 (rnjA-gfp), GP1734 (rnjA-gfp rnjBACter), and GP2317 (rnjA-gfp $\Delta r n j B)$ and (B) GP1733 (rnjBACter-gfp), GP1749 (rnjB-gfp), and GP1750 (rnjB-gfp $\Delta r n j A)$ grown in LB medium at $37{ }^{\circ} \mathrm{C}$ to mid-logarithmic phase.

\subsubsection{Conclusions}

RNases J1 and J2 can interact in vivo through their C-terminal domains. Furthermore, they oligomerize, forming dimers and tetramers in similar amounts. RNase J1 and J2 are both, however, able to interact amongst each other. Furthermore, the deletion of the RNase J1 affects the localization of RNase $\mathrm{J} 2$ in the cell, while RNase J1 remains localized as wild type in the absence of RNase J2. Although the absence of RNase J2 does not cause a very strogn phenotype alone, the additional fusion of RNase J1 to GFP increases the length and thickness of the cells. The truncation of the C-terminal domain of RNase $\mathrm{J} 2$ hinders its interaction with RNase $\mathrm{J} 1$ and with itself, as well as its localization in the cell. 


\subsection{In vitro activity of the enzyme PNPase of Bacillus subtilis}

Several regulatory mechanisms have been described for PNPase of different organisms, however, not much is known about the regulation of the $B$. subtilis PNPase. PNPase has been related to carbon metabolism, since it is part of a putative complex with the glycolytic enzymes enolase and PfkA and several other RNA-related proteins (see 1.5). Thus, the enzymes enolase and PfkA have been purified to assay their effect on the in vitro degradation activity of PNPase. Furthermore, several metabolites affect the acitivity of PNPase, although it is not known whether they have any effect on the activity of PNPase. The affect of c-di-AMP, c-di-GMP and citrate was assayed. Furthermore, the crystal structure of PNPase from B. subtilis was obtained in collaboration with Johannes Arens, Achim Dickmanns and Piotr Neumann (Prof. Dr. Ficner, Dept. Molecular and Structural Biology, Göttingen Universität).

\subsubsection{Crystal structure of PNPase from B. subtilis}

The PNPases of several organisms have been crystallized (Symmons et al., 2000; Shi et al., 2008; Nurmohamed et al., 2009; Hardwick et al., 2012), however, the structure of the PNPase from $B$. subtilis was not available. During my Master's thesis I was able to purify the enzyme (Cascante-Estepa, 2014). Subsequently, the enzyme was crystallized and th ediffraction pattern could be used to obtain the crystal structure at a resolution of $2.3 \AA$, in the Department of Molecular Structural Biology (Arens, 2015).

The PNPase of $B$. subtilis possesses a domain organization similar to other PNPases. It is composed of five domains: two PH domains, of which only the second is active, a poorly-conseved helical domain, and two RNA-binding domains, KH and S1 (Figure 23).

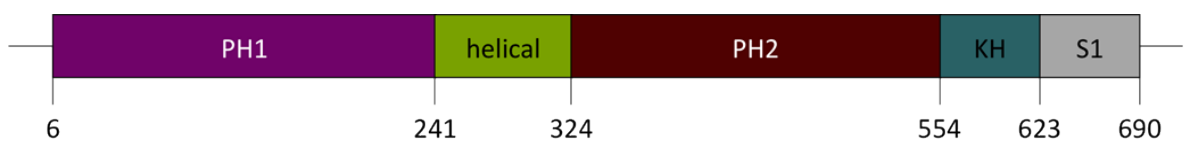

Figure 23. Domain organization of the enzyme PNPase of Bacillus subtilis. The enzyme possesses five defined domains. PH2 contains the active site, while PH1 has lost the enzymatic activity. $\mathrm{KH}$ and $\mathrm{S} 1$ domains are the RNAbinding domains. (Symmons et al., 2000; Jarrige et al., 2002; Stickney et al., 2005; Briani et al., 2007; Shi et al., 2008).

PNPase is a trimer that oligomerizes as a ring-like structure, with a central channel that serves as the entrance for the RNA. Although the crystal structure of PNPase with an RNA molecule could not be obtained, the base stacking of the amino acid phenylalanine 77 with an RNA base in the center of the channel could be seen (Figure 24A). The PH domains form the ring in the structure, while the helical domain and the $\mathrm{KH}$ and S1 domains are localized outwards from the central 
channel. The $\mathrm{KH}$ and S1 domains seem to be very flexible (Figure 24B). Only one of the PH domains is, however, active. The enzyme possesses one active site at the $\mathrm{PH} 2$ domain, which could be identified by the presence of an ADP molecule (Figure 24C). The color code of the structure corresponds to that of the domains in Figure 23.
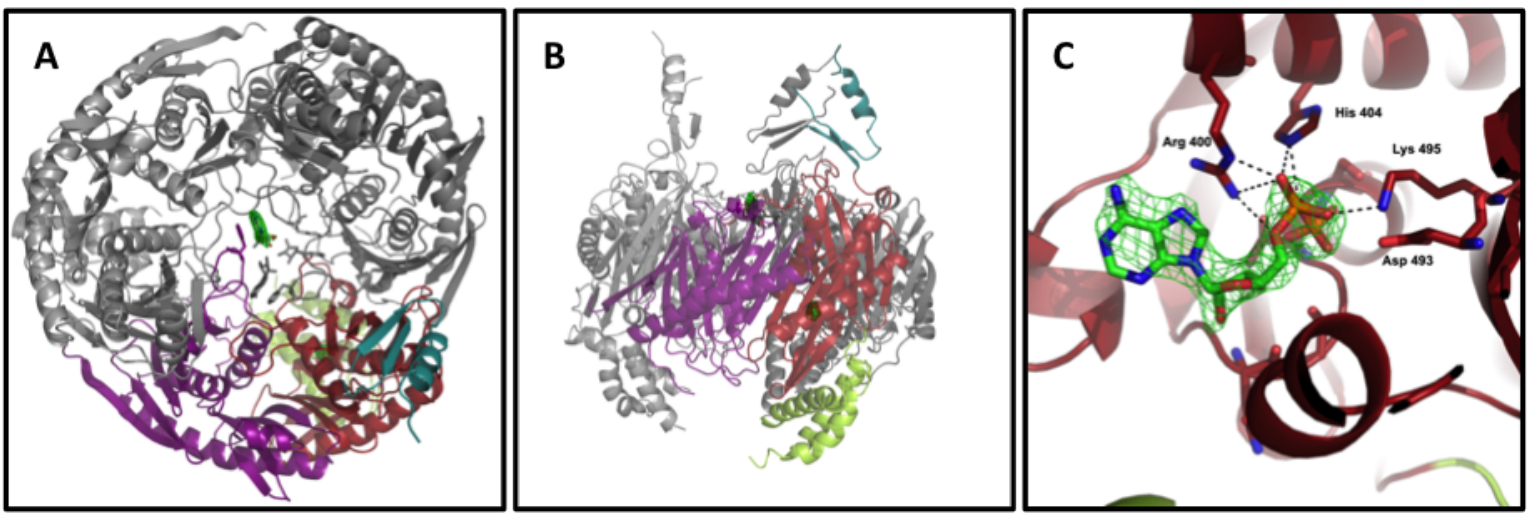

Figure 24. Crystal structure of PNPase interacting with and RNA base, inorganic phosphate and ADP (2.3 Å). Johannes Arens, Achim Dickmanns, and Piotr Neumann crystallized and modelled the enzyme. The obtained crystal structure of $\mathrm{His}_{6}$-PNPase has a resolution of $2.3 \AA$. The enzyme oligomerizes as a trimer with a ring-like structure. The central channel is the entry site for RNA, where it gains access to the active site. In the first image we can see a base of an RNA molecule base stacking with Phe77 of PNPase. The enzyme possesses one active site per monomer situated at the $\mathrm{PH} 2$ domain. In the second image we can see the active site identified by the presence of a $\mathrm{Pi}$ in the crystal structure. In the third image we can observe the interactions of adenosine diphosphate (ADP) with the amino acids of the active site. (Arens, 2015)

\subsubsection{Purification of PNPase, enolase and PfkA}

For the purification the enzymes PfkA, enolase, and PNPase the plasmids pGP393, pGP563, and pGP838 were used, respectively. The proteins are fused to an N-terminal His 6 -tag. Briefly, the plasmids were transformed into a producer strain of $E$. coli and the expression of the proteins was induced in LB medium at $37^{\circ} \mathrm{C}$ by addition of IPTG. Upon disruption of the cells, the tagged proteins were purified through a $\mathrm{Ni}^{2+}-\mathrm{NTA}$ sepharose column, and eluted by increasing amounts of imidazole as described (see Table 15). After analysis of the fractions by SDS-PAGE, the relevant fractions were pooled and applied to a size-exclusion chromatography (SEC). The fractions containing the protein were concentrated and stored in aliquots at $-80^{\circ} \mathrm{C}$.

The purification of PNPase had been previously performed (Cascante-Estepa, 2014) and the concentration of imidazole was known, so the protein was eluted from the column by directly applying buffer with $100 \mathrm{mM}$ imidazole (Figure 25A). The elution fractions were very clean and were analyzed by SEC. This revealed a bigger peak with elution time 60.29 minutes, which corresponds to a molecular weight of $284.99 \mathrm{KDa}$. The molecular weight of a monomer of $\mathrm{His}_{6}{ }^{-}$ PNPase is $78.86 \mathrm{KDa}$; consequently, the peak would correspond to $2.6 \approx 3$ monomers. As 
expected, PNPase is a trimer in solution. The presence of the protein in the peak at 60.29 was confirmed by analyzing the fractions 14,15 , and 16 by SDS-PAGE (Figure 25A). Subsequently, the protein was concentrated to $1.63 \mathrm{mg} / \mathrm{ml}$ or $20.66 \mu \mathrm{M}$.
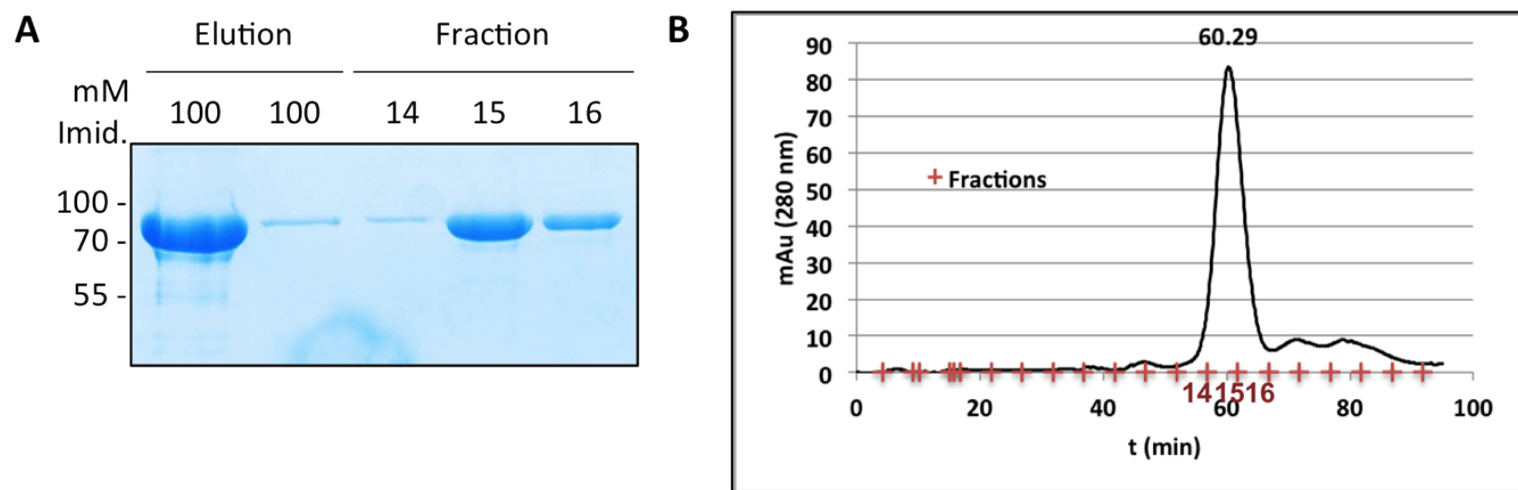

Figure 25. Purification of His $_{6}$-PNPase from DH5 $\alpha:$ :pGP838 and size-exclusion chromatography. Expression of Histagged PNPase was induced by addition of $1 \mathrm{mM}$ IPTG to a culture of E. coli harbouring the pGP838 plasmid. (A) The cells were disrupted and purification was performed as described above. (B) Relevant elution fractions were pooled and applied to a size-exclusion chromatography column as described in Materials and methods. The fractions were analysed by SDS-PAGE and Coomassie staining and the ones containing enzyme were concentrated and preserved in aliquots at $80^{\circ} \mathrm{C}$. Imid., imidazole.

For the purification of $\mathrm{His}_{6}$-enolase several elution steps were performed with increasing amounts of imidazole. Although the wash fractions were already very clean, many additional bands were eluted with $30 \mathrm{~mm}$ imidazole (Figure 26A). Consequently, only the other three fractions were pooled and analyzed by SEC. This showed three major peaks with elution times of $35.60,44.67$, and 58.13 minutes (Figure 26B). Fractions $8,10,12$, and 13, corresponding to the peaks, were analyzed by SDS-PAGE (Figure 26C). Fractions 8 and 12 contained no protein. The fractions 12 and 13 corresponded to the peak with 58.13 minutes elution time, which corresponds to a size of $351.72 \mathrm{KDa}$. The molecular weight of a monomer of $\mathrm{His}_{6}$-eno is 47.98 $\mathrm{KDa}$; consequently, the peak would correspond to $7.33 \approx 7$ monomers. However, the crystal structure of enolase revealed that the protein oligomerized as an octamer (Newman et al., 2012). Nonetheless, the size-exclusion chromatography only offers an approximate size, which is more accurate for globular proteins. For this reason, it can be assumed that 7.33 corresponds to an octamer. Subsequently, the protein was concentrated to $0.23 \mathrm{mg} / \mathrm{ml}$ or $4.79 \mu \mathrm{M}$.

For the purification of $\mathrm{His}_{6}$-PfkA several elution steps were performed with increasing amounts of imidazole. An intermediate washing step with $2.5 \mathrm{M} \mathrm{NaCl}$ had been performed. The elution fractions (Figure 27A) were pooled and analyzed by SEC. This showed two peaks with elution times 44.30 , and 71.77 minutes (Figure 27B). Fractions 10, 15, and 16 corresponding to the peaks were analyzed by SDS-PAGE (Figure 27C). Fractions 10 contained little amounts of protein, while 
fractions 15 and 16, corresponding to the peak with 71.77 minutes elution time, contained the majority of the protein.

A

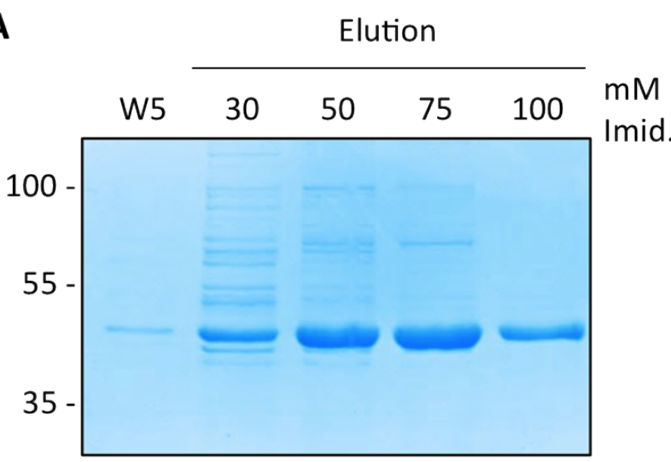

C

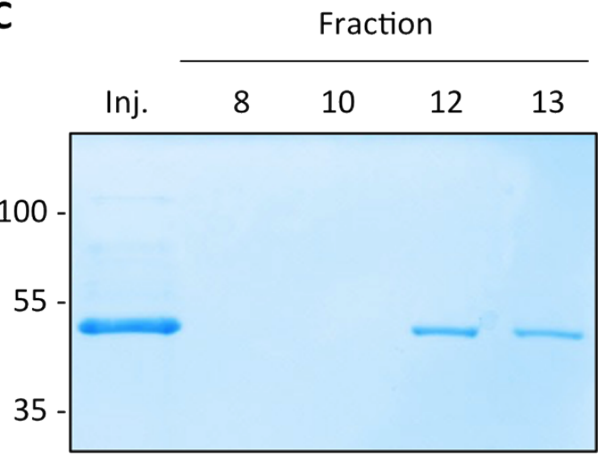

B

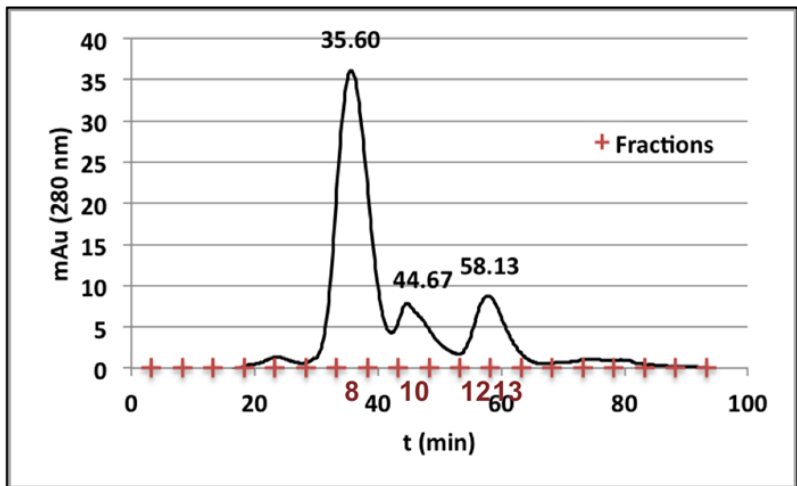

Figure 26. Purification of $\mathrm{His}_{6}$-enolase from DH5 $\alpha$ ::pGP563 and size-exclusion chromatography. Expression of Histagged enolase was induced by addition of $1 \mathrm{mM}$ IPTG to a culture of $E$. coli harbouring the pGP563 plasmid. (A) The cells were disrupted and purification was performed as described above, and the fractions were analysed by SDS-PAGE and Coomassie staining. (B) Relevant elution fractions were pooled and applied to a size-exclusion chromatography column as described in Materials and methods. (C) The fractions were analysed by SDS-PAGE and Coomassie staining and the ones containing enzyme were concentrated and preserved in aliquots at $-80^{\circ} \mathrm{C}$. Inj., injection; Imid., imidazole; W5, wash 5.

The molecular weight of a monomer of $\mathrm{His}_{6}-\mathrm{PfkA}$ is $35.65 \mathrm{KDa}$; consequently, the peak would correspond to $2.6 \approx 3$ monomers. However, the crystal structure of PfkA revealed that the protein oligomerized as a tetramer (Newman et al., 2012). As was mentioned for the purification of enolase, the size-exclusion chromatography only offers an approximate size, which is more accurate for globular proteins. Nonetheless, it could be that the washing with high salt affected the oligomerization. However, this more likely would result in aggregation or complete disruption of the oligomer. The small peak at 45.30 elution time could be aggregated protein, but was still the smaller peak. The protein from fractions 15 and 16 was then concentrated to $0.75 \mathrm{mg} / \mathrm{ml}$ or $21.04 \mu \mathrm{M}$. 
A

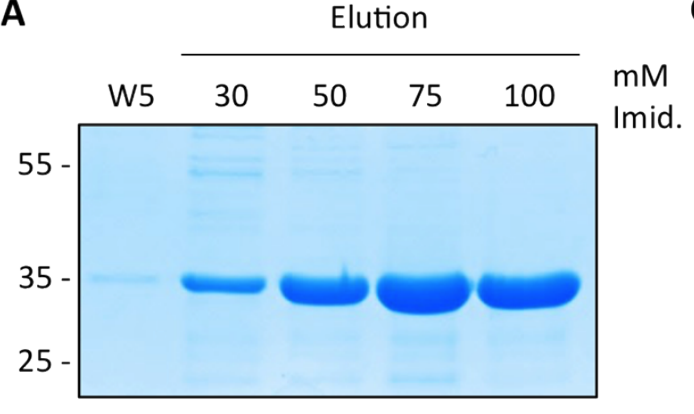

C

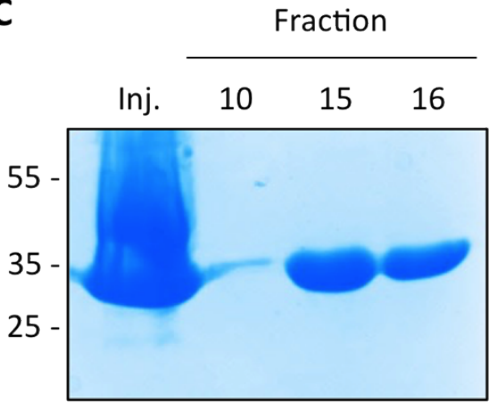

B

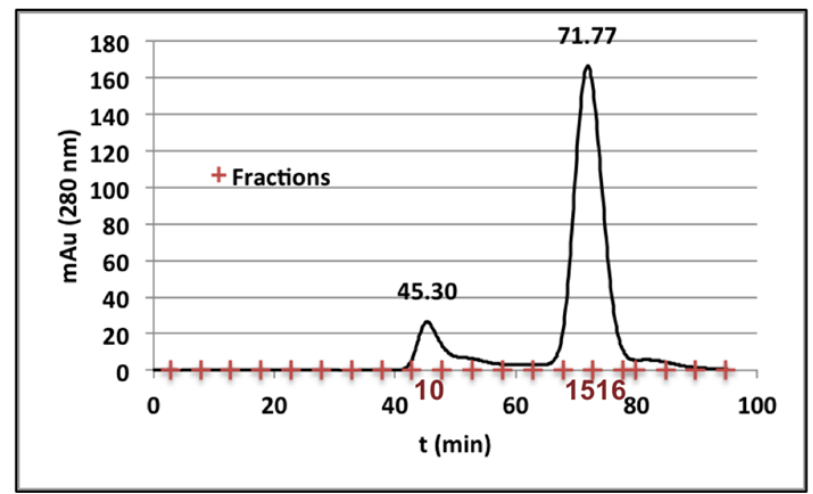

Figure 27. Purification of $\mathrm{His}_{6}$-PfkA from DH5 $\alpha$ ::pGP393 and size-exclusion chromatography. Expression of Histagged PfkA was induced by addition of $1 \mathrm{mM} \mathrm{IPTG}$ to a culture of $E$. coli harbouring the pGP393 plasmid. (A) The cells were disrupted and purification was performed as described above, and the fractions were analysed by SDS-PAGE and Coomassie staining. (B) Relevant elution fractions were pooled and applied to a size-exclusion chromatography column as described in Materials and methods. (C) The fractions were analysed by SDS-PAGE and Coomassie staining and the ones containing enzyme were concentrated and preserved in aliquots at $-80^{\circ} \mathrm{C}$. Inj., injection; Imid., imidazole; W5, wash 5.

\subsubsection{Degradation activity of PNPase in vitro}

The purified PNPase was used to assay its activity in vitro. However, the conditions could only be improved in this time for the degradation activity. Nonetheless, degradation activity by the purified enzyme in vitro was also observed (not shown). To study the degradation of PNPase, the conditions were improved by following the already published assay for in vitro activity of PNPase from E. coli (Nurmohamed et al., 2011). Briefly, a reaction mix was prepared that contained 15 mer poly(A) RNA, inorganic phosphate, Tris- $\mathrm{HCl} \mathrm{pH} 8.0$ buffer, $\mathrm{MgCl}_{2}$, and $250 \mathrm{nM}$ of purified PNPase. The reaction was performed for 2 minutes at $25{ }^{\circ} \mathrm{C}$. The RNA was analyzed by ionexchange chromatography, as described above (Figure 10). The $15 \mathrm{mer}$ poly(A) RNA runs as a discrete peak (Figure 28A). However, the retention times displayed an enormous variability. This could be attributed to the room temperature, since the column was not temperature-regulated. The retention times showed a linear correlation with the room temperature (not shown). Furthermore, the temperature also affected the elution spectra. For this reason, some of the 
curves in Figure 28 were automatically smoothed, for presentation purposes. The analysis of the integral was, however, performed in the original spectra. To obtain the percentage of degradation, the integral of each peak was calculated and compared to the control spectrum.

\section{Activity at different concentrations of $\mathrm{Mg}^{2+}$}

The enzyme requires a divalent cation to be active. Although the enzyme is also active in the presence of $\mathrm{Mn}^{2+}$ (not shown), only the dependence on $\mathrm{Mg}^{2+}$ was studied. For this, several concentrations of $\mathrm{MgCl}_{2}$ were applied to the reaction described above, and the enzyme was allowed to react for 2 minutes. The activity of the enzyme at concentrations 1, 2, 510 , and 100 $\mathrm{mM}$ is displayed (Figure 28). However, reactions with lower concentrations of $\mathrm{MgCl}_{2}$ (100, 200 and $500 \mu \mathrm{M}$ ) were performed, where the enzyme showed no degradation activity (not shown).

\section{A}
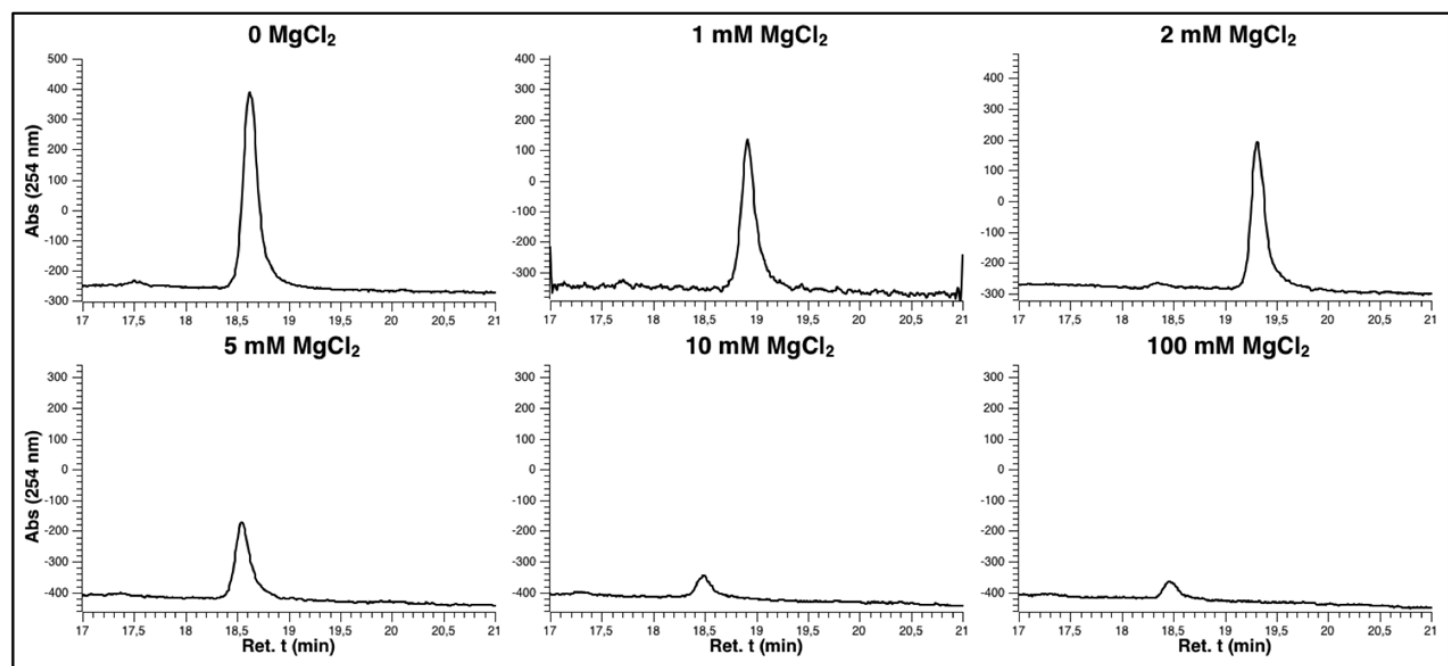

B

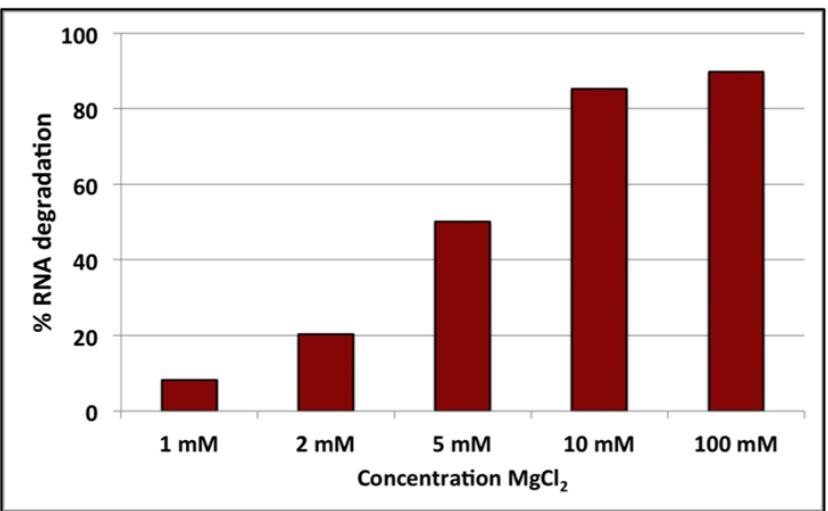

Figure 28. Degradation of RNA by PNPase with different concentrations of $\mathbf{M g C l}_{\mathbf{2}}$. The activity of PNPase in vitro on a 15 mer poly(A) RNA molecule was assayed, by it incubating with the enzyme, magnesium, and Pi, for 2 minutes at $25^{\circ} \mathrm{C}$. Different concentrations of magnesium were applied to the reaction (A). When the reaction was stopped, it was injected to and HPLC ion-exchange chromatography column. The peaks corresponding to the RNA were integrated and compared to the reaction mix without magnesium (B). 


\section{Effects of several metabolites and proteins on the in vitro degradation activity of PNPase}

The effect of several metabolites on the degradation activity of PNPase in vitro was studied. The activity of PNPase form E. coli is enhanced by c-di-GMP in the range from 0.1 to $10 \mu \mathrm{M}$ (Tuckerman et al., 2011). To assay the effect of cyclic nucleotides, $5 \mu \mathrm{M}$ of c-di-AMP or c-di-GMP were added to the reaction mix. The assay was performed for 2 minutes in the conditions described above. However, no difference could be seen in this conditions compared to the enzyme in the absence of cyclic nucleotides. Furthermore, the effect of citrate was assayed, since it was seen that it had an effect on the activity of the PNPase from E. coli (Nurmohamed et al., 2011). Citrate in different concentrations was added to the reaction $(1,5$, and $10 \mathrm{mM})$. The degradation activity of PNPase was reduced with increasing concentrations of citrate. However, repeating the experiment with $\mathrm{Mg}$-citrate at the same concentrations revealed no difference in the degradation activity of PNPase. Thus, it can be assumed that, in the first experiment, citrate is chelating the magnesium available for the reaction, consequently reducing the degradation activity of PNPase, as was seen before (Figure 28). Furthermore, since PNPase has been proposed to be part of the RNA degradosome, the effect of the glycolytic enzymes enolase and PfkA on the activity of PNPase was assayed in vitro. For this purpose, the enzymes were added to the reaction mix, and a control was performed in which only PNPase was present. PNPase has been shown to be a trimer, PfkA a tetramer, and enolase an octamer. For this reason, the enzymes were added in a ration of 3:8 and 3:4 of PNPase to enolase and PfkA, respectively. However, in these conditions, no effect could be seen on the degradation activity of PNPase.

\subsubsection{Conclusions}

PNPase oligomerizes as a trimer, where both PH domains of each protomer organize in a ring structure, leaving a central channel for the entrance of RNA. The active site is located in the second PH domain. Furthermore, PNPase activity is sensitive to concentrations of magnesium as expected, showing higher degradation activity at 10-100 mM. The enzyme is not active at concentrations of magnesium lower than $1 \mathrm{mM}$. Moreover, the degradation activity of PNPase is not affected in vitro by citrate, c-di-AMP, c-di-GMP, enolase or PfkA. 


\section{Discussion}

\subsection{The RNA degradosome of $B$. subtilis, does it exist?}

The regulation of the gene expression is of major importance for the organisms to adapt to the changing environmental conditions. In bacteria, this control occurs mainly by regulating the transcription initiation, stability, and degradation of the mRNAs by the joint work of RNases and associated proteins. It is common that these proteins organize in complexes, the RNA degradosomes, to improve the regulation of the pathways. The degradosomes of several organisms have been extensively studied to unravel the collaboration of the enzymes within these pathways. In B. subtilis, the existence of such a complex was hypothesized, following up the discovery of several in vivo interactions between RNases, RNA-related proteins, and glycolytic enzymes. Although these interactions were performed in artificial conditions such as bacterial two-hybrid or in the presence of a crosslinker, several could be reproduced in vitro and in vivo. However, the complex could not be purified as a whole, raising the question of whether this complex exists in vivo or not.

In this work the sub-cellular localization of each of the members of this putative RNA degradosome by fluorescence microscopy has been analyzed. As has been shown, the fusion of proteins to tags such as GFP can affect the activity, interactions, and localization of the proteins. For this reason, the viability of the protein fusions has been studied, by comparing them to deletion mutants to confirm that the proteins preserved the wild type characteristics. Since these fusions were introduced in the chromosome in the original locus, no additional copy of the enzymes is available. This has proven that the strains that harboured the fusions are viable, showing a wild-type phenotype (Figure 11 and Figure 13). RNase J2, however, does not cause a phenotype when absent, but it strongly interacts in vivo with its paralogue RNase J1 (Figure 12). The fact that both enzymes exhibit a similar localization is, then, enough to assume the RNase J2GFP fusion is viable.

RNase $\mathrm{Y}$, the central endonuclease of the RNA degradosome, is encoded by rny (ymdA), the first gene of a bicistronic operon with $y m d B$. For this reason, the fusion of RNase $Y$ to GFP was introduced in the amyE gene, and was expressed under the control of a xylose-inducible promoter, keeping a second copy of RNase $\mathrm{Y}$ in its native locus. However, RNase $\mathrm{Y}$ is a membranebound protein, and its membrane localization has been confirmed in several independent studies. The experiments presented here are in execellent agreement with these observations, and the localization of RNase $Y$ perfectly corresponds to that of Nile Red, a membrane-specific stain (Figure 14). Moreover, it can be observed higher fluorescence intensity at the cell septa. In a 
recent study, RNase $Y$ was found to interact with the dynamin-like protein DynA, which also localizes to the division septa (Bürmann et al., 2012). In E. coli, the central endoribonuclease of the RNA degradosome is also a membrane-associated protein. Furthermore, it was shown that RhIB, the RNA helicase associated to the RNA degradosome, localizes to the membrane, depending on its interaction with RNase E (Strahl et al., 2015). However, the results presented here show that CshA, the RNA helicase associated to the $B$. subtilis RNA degradosome, is localized to the cytoplasm (Figure 16), as had been reported before (Weber et al., 2001). CshA localizes around the nucleoid, in the area where ribosomes are located. Furthermore, the paralogous RNases J1 and J2 show a similar localization to CshA. It was shown before that the localization of ribosomes is dependent on active transcription, since treating the cells with the inhibitor rifampicin, results in relaxation of the nucleoid a delocalization of the ribosomal fraction. This phenomenon can be observed for CshA, RNase J1 and RNase J2 (Figure 17), suggesting that the localization of these proteins depends on the presence of RNA. Interestingly, in E. coli the RNase E also delocalizes in response to rifampicin treatment (Strahl et al., 2015); such a delocalization, however, was not observed for RNase $Y$ in $B$. subtilis (data not shown). This difference may be caused by the different attachment of the two RNases to the membrane: RNase $E$ is membraneattached via an amphipathic helix (Khemici et al., 2008), whereas RNase $\mathrm{Y}$ is inserted to the membrane via a trans-membrane helix (Lehnik-Habrink et al., 2011a). It is interesting to note that, in E. coli, the major fraction of the RNA helicase RhIB localizes to the membrane via RNase E, even though the protein is also engaged in the cytoplasmic complex with PNPase (Lin and Lin-Chao, 2005; Strahl et al., 2015). In B. subtilis, the major fractions of the exoribonucleases and the RNA helicase CshA are clearly not associated to the membrane, i. e. these major fractions do not interact with RNase $\mathrm{Y}$.

The analysis of the localization of PNPase, the $3^{\prime}-5^{\prime}$ exonuclease associated to the degradosome, showed that the protein is evenly distributed throughout the cytoplasm and not excluded from the nucleoid (Figure 15). It is tempting to speculate that the differential localization of polynucleotide phosphorylase as compared to the other exoribonucleases, $\mathrm{J} 1$ and $\mathrm{J} 2$, and the helicase CshA, is related to the fact that PNPase also exerts functions that are not related to RNA degradation: PNPase does also bind single-stranded DNA and participates in DNA repair (Cardenas et al., 2009; Cardenas et al., 2011).

Furthermore, the glycolytic enzymes, enolase and PfkA, are located to the cytoplasm, where they are evenly distributed (Figure 15). Interestingly, enolase shows a different localization at $28^{\circ} \mathrm{C}$ than at $37^{\circ} \mathrm{C}$. Although it is always localized to the cytoplasm, at $37^{\circ} \mathrm{C}$ bright spots at the cell poles appear in some cells. Polar localization of enolase has been reported before, and was shown 
to depend on phosphorylation of the enzyme on a tyrosine residue by the protein tyrosine kinase, PtkA (Jers et al., 2010).

At a glance, these observations contradict previous reports on the interactions between the proteins involved in RNA degradation. However, there are several independent in vivo and in vitro reports that confirm the binary interactions of the potential RNA degradosome enzymes strongly suggesting that these interactions are real (Commichau et al., 2009; Lehnik-Habrink et al., 2010; Lehnik-Habrink et al., 2011a; Newman et al., 2012; Salvo et al., 2016). All potential degradosome proteins are likely to be very abundant proteins as has been shown for PNPase, PfkA, or Eno (Eymann et al., 2004). This hypothesis is supported by the fact that the genes encoding the degradosome proteins all belong to the most strongly expressed genes in B. subtilis (Nicolas et al., 2012). Thus, these abundant proteins may be present at multiple places in the cell, and they may serve multiple functions. Indeed, it has been shown that polynucleotide phosphorylase and the RNA helicase RhIB of E. coli are part of two distinct complexes: the two proteins form a complex in the cytoplasm, and they are also part of the membrane-attached RNA degradosome (Lin and LinChao, 2005; Strahl et al., 2015). Similarly, enolase is not only part of the degradosome but also a cytoplasmic glycolytic enzyme. Thus, it is important to study the relative localization of the proteins in the different compartments. Given the clear evidence for the multiple binary proteinprotein interactions on one hand, and the lack of purification of the B. subtilis RNA degradosome on the other, it is tempting to speculate that these interactions are rather transient, and may not always involve all components. Possibly, the RNA degrading enzymes engage in a variety of different interactions to achieve specificity in RNA degradation and processing. Indeed, it has recently been shown that the glycolytic enzyme glyceraldehyde 3-phosphate dehydrogenase (GapA) form a complex with RNase $\mathrm{Y}$ and RNase J1 to modulate J1 activity. This study also revealed that only a minor fraction of GapA (1 - 2\%) interacts with RNase J1 and RNase Y (Gimpel and Brantl, 2016). Interestingly, this interaction of a minor part of the total GapA population in the cell correlates perfectly with the fact that GapA is a cytoplasmic protein, even though a part of the protein is found associated to the membrane (Meile et al., 2006; Hahne et al., 2008).

All in all, the existence of an RNA degradosome seems plausible under certain conditions and in a transient manner; however, it does not seem to be the major state of the proteins that we have investigated.

\subsection{RNases $\mathrm{J} 1$ and $\mathrm{J} 2$ : their complex in vivo}

RNase J1 is a $5^{\prime}-3^{\prime}$ exoribonuclease that also possesses endoribonuclease activity, and it is encoded by the $r n j A$ gene. Although it is not essential, the deletion of $r n j A$ severely affects the 
division, competence, and resistance to antibiotics, besides altering the cell morphology. RNase J1 has a paralogue in $B$. subtilis encoded by the $r n j B$ gene. The deletion of $r n j B$ does not cause as severe a phenotype as the deletion of rnjA. Furthermore, RNase J2 has endonuclease activity, but only very weak exonuclease activity. Both proteins interact in vivo and in vitro, in a complex that modifies the specificity of the individual proteins. Although the proteins have been extensively studied, the relevance of the existence of the two paralogues, as well as the oligomerization state in vivo is still unknown. Furthermore, it is known that RNase J1 and RNase $\mathrm{J} 2$ can self-interact in vitro to form homodimers that seem more stable than the heterodimers. Moreover, it is known that the C-terminal domain of RNase J1 is necessary for its self-interaction and activity. It has been speculated that this C-terminal domain is also the dimer interface of the heterodimer. However, the importance of this domain has not been studied in vivo. Moreover, it is not known what the real state of the proteins in vivo is. Furthermore, although the localization of the proteins has been studied, little is known about the subcellular localization of each of the paralogues in the absence of the other. In this work, the oligomerization state of the proteins has been studied in vivo, emphasizing the importance of the C-terminal domain of RNase $\mathrm{J} 2$ for this complex formation. Furthermore, the localization of RNase J1 and J2 was analyzed by fluorescence microscopy, in combination with the deletion of the $r n j B$ and $r n j A$ genes, respectively.

As has been already demonstrated, the paralogous RNases J1 and J2 interact in vivo (Figure 12 and Figure 18). The truncation of the C-terminal domain of RNase J2, however, impedes the interaction of RNases J1 and J2 (Figure 18). Furthermore, RNase J1 and J2 oligomerize in vivo as dimers and tetramers. It had been proposed that the proteins would associate in homodimers that would interact to form a heterotetramer (Newman et al., 2011). However, the fact that the analysis of the fraction of a pull-down assay shows that both dimers and tetramers contain both RNases J1 and J2 implies that the proteins form heterodimers in vivo (Figure 19 lanes 1 and 3). Nonetheless, RNase J1 can also-self-interact in the absence of RNase J2, forming both dimers and tetramers (Figure 19A lane 2). However, in the absence of RNA, RNase J1 is only able to form dimers (Figure 20A lanes 2 and 3 ). It is tempting to speculate that the tetramers form upon binding to RNA. Moreover, RNase J2 can also self-interact in the absence of RNase J1 to form dimers (Figure 20A lane 5). Interestingly, in the absence of RNA, the homodimers seem to be more stable than the heterodimers, which dissociate to their monomeric state (Figure 20A lanes 1 and 4). This raises the question of why and how are the heterodimers forming in the cell, and not the homodimers. Therefore, an experiment should be performed as in Figure 20, where the cells are not treated with RNase A. This experiment could not be performed due to time restrictions. 
Furthermore, it would be interesting to see if RNase J2, in the absence of RNase $\mathrm{J} 1$, is also able to for tetramers, and if indeed the tetramers form upong binding to RNA.

The localization of RNase $\mathrm{J} 1$ and $\mathrm{J} 2$ has been analyzed in vivo. RNase $\mathrm{J} 1$ and $\mathrm{J} 2$ localize surrounding the nucleoid, where the ribosomal and RNA fractions are found. Furthermore, the localization is dependent on transcription, since a rifampicin treatment results in spreading of both proteins in the cytoplasm (Figure 17). Upon truncation of the C-terminal domain of RNase J2 or deletion of the $r n j B$ gene, the localization of RNase J1 remains the same (Figure 22A). This is not surprising, since RNase $\mathrm{J} 1$ is able to form dimers and tetramers when it does not interact with RNase J2. However, the absence of RNase J1 affects the localization of RNase J2, which localizes to spots that are spread within the cell (Figure 22B). It can be speculated from this localization that its interaction of RNase J1 is necessary for its normal localization. This would imply, however, that RNase J2 cannot interact with RNA by itself. However, the localization of ribosomes and, by extension, of RNA is not known in an rnjA deletion mutant. It is possible that the RNA also localizes in discreet spots in the aforementioned deletion strain. Nonetheless, the localization of the nucleoid has been studied in an RNase J1 deletion mutant and, although some cells were anucleate, the nucleoid was still visibly condensed (Hunt et al., 2006). Consequently, it can be assumed that the RNA would not be localized to spots in the cell, but still surrounding the nucleoid and occupying the rest of the cytoplasm. Thus, it would be interesting to observe the effect of rifampicin on the localization of RNase J2 as well as the localization of ribosomes in the absence of RNase J1. Also, it would be interesting to know the effect of the deletion of RNase J1 on the localization of the truncated RNase $\mathrm{J} 2$, which is not in spots, but evenly disperse in the cytoplasm. Another hypothesis is, however, that, in the absence of RNase J1, RNase J2 interacts with other proteins, which are localized in this spotty pattern. This could easily be analyzed by a pull-down of RNase J2 as decribed above, but in the absence of RNase J1.

An interesting observation is that, upon deletion of RNase J2 in the presence of RNase J1-GFP, the cell morphology resembles that of the deletion of RNase J1: elongated, curly, and thickened. However, neither the deletion of $r n j B$, nor the fusion of GFP to RNase J1 seem to provoke such a strong phenotype. Indeed, the RNase J1-GFP shows a wild type phenotype (Figure 11B), and the deletion of RNase $\mathrm{J} 2$ induces the formation of only some long cells (Figure 21). It can be hypothesized that the fusion of RNase J1 to GFP hinders the activity of RNase J1 or its oligomerization capabilities slightly, but it can be recovered by the presence of RNase $\mathrm{J} 2$. Moreover, the same can be observed in the strain where RNase J1 is fused to GFP and the Cterminal domain of RNase $\mathrm{J} 2$ is truncated.

Interestingly, the analysis of the cell extracts from different strains has shown that the truncation of the C-terminal domain of RNase $\mathrm{J} 2$ results in an increased amount of RNase J2 
protein. This could have several interpretations. First, the full-length protein could have a reduced stability in comparison to the truncated RNase $\mathrm{J} 2$, or the shortened mRNA has increased stability. Second, RNase J2 might be regulating its own expression; the truncated RNase J2 does not oligomerize and has, most likely, no activity, since the phenotype of the deletion of $r n j B$ and the deletion of the C-terminal domain of RNase J2 are similar (see Figure 21). Moreover, the deletion of RNase J1 results in an increased amount of RNase J2 (Figure 20B lanes 3 and 4). This contradicts a recent publication, which finds no evidence of increased levels of RNase $J 2$ in the absence of RNase J1. However, these experiments were performed with a depletion mutant and not a complete deletion (Jamalli et al., 2014). Nonetheless, the pull-down experiment revealed that several proteins that bind unspecifically to the column (like PycA) were also increased in the absence of RNase J1 (not shown), suggesting that it might be a more general effect from the deletion of a very important RNase.

All in all, it has been shown that RNase $\mathrm{J} 1$ and $\mathrm{J} 2$ interact in vivo in heterodimers and heterotetramers, but that the proteins can self-interact in the absence of the other. However, RNase J1 is not affected in its localization by the absence of RNase J2, while RNase J2 is in the absence of RNase J1. Furthermore, it can be speculated that the tetramers are formed upon interaction with RNA, and that RNase $\mathrm{J} 2$ cannot bind RNA on its own. Moreover, the fusion of RNase J1 to GFP seems to slightly affect the activity or interactions of the protein, although this can be rescued by the presence of full-length RNase J2.

\subsection{The degradation activity of PNPase in vitro}

Polyribonucleoride phosphorylase is a very well known enzyme that was discovered in the 1950s. It was the first enzyme discovered to be able to polymerize RNA from nucleotides. It catalyzes the reversible reaction of the phosphorolytic degradation of RNA molecules in vivo. Although its major activity in the cell seems to be the degradative activity, it has been shown that it can also polymerize in vivo. In E. coli, the enzyme is regulated by several metabolites and second messengers like ATP, c-di-GMP and citrate. Concentrations in the mM range of ATP inhibit both phosphorolytic and polymerizing activity (Del Favero et al., 2008). The second messenger cdi-GMP activates both activities; $10 \mu \mathrm{M}$ increases 40 -fold the phosphorolytic activity, while concentrations as low as $0.1 \mu \mathrm{M}$ can accelerate poly(A) synthesis (Tuckerman et al., 2011). Moreover, citrate also affects both activities of PNPase, both in vivo and in vitro (Nurmohamed et al., 2011). In addition, it has been shown that it is part of a complex that involves other RNArelated proteins and the glycolytic enzyme enolase. In $B$. subtilis, the enzyme has been also proposed to be part of complex that includes RNA-related proteins and the glycolytic enzymes 
enolase and phosphofructokinase (PFK or PfkA). However, little is known of the regulation of PNPase in the latter organism. In this work, the activity of PNPase on a short poly(A) RNA fragment was analyzed in vitro at $25^{\circ} \mathrm{C}$, and the effect of several putative effectors was assayed. It has been observed that the enzyme is able to polymerize and degrade this short fragment in vitro (not shown), however, the optimized reaction conditions were only obtained for the degradation activity. Furthermore, the PNPase is active in the presence of magnesium and manganese ions (not shown). The results here presented show that the enzyme is active at a wide range of magnesium concentrations, with the activity increasing with increasing amounts of the ion (Figure 28). Interestingly, the enzyme is not inhibited by concentrations of the ion as high as $100 \mathrm{mM}$. Preliminary studies also show, that the acitivity of the enzyme also increases with increasing amounts of inorganic phosphate, from $1 \mathrm{~mm}$ to $50 \mathrm{~mm}$. It was shown that the concentration of $\mathrm{Pi}$ in vivo in E. coli is $30 \mathrm{~mm}$ (Andoh et al., 1963), meaning that the enzyme most likely exerts its degradative function in vivo.

In addition, the study of several effectors on the phosphorolytic activity of PNPase shows that the regulation of this enzyme might differ from that of the PNPase from E. coli. The second messenger c-di-GMP seems to not affect the degradation activity of PNPase. A similar second messenger, c-di-AMP, is essential in B. subtilis and not present in E. coli (Gundlach et al., 2015). However, it also does not affect the phosphorolytic activity of PNPase in the conditions tested. An experiment in which increasing concentrations of citrate were added to the reaction of PNPase $(1,5$, and $10 \mathrm{~mm})$ showed that the degradation activity of PNPase was inhibited by $10 \mathrm{~mm}$ of citrate. This had already been shown for E. coli. However, addition of magnesium citrate at the same concentration showed no effect on the activity. This could be explained by the coordination of the magnesium ions present in the medium by citrate, which was present in the same concentration as magnesium. This would reduce the amount of magnesium ions available for the enzyme and, thus, reducing the percentage of degradation of PNPase. It would be interesting to assay the effect of citrate in the presence of manganese as a cofactor of PNPase, since it was shown that, for the E. coli PNPase, citrate does not inhibit the enzyme in the presence of manganese. This experiment could not be performed due to time restrictions.

PNPase has been related to enolase and phosphofructokinase, since they have been involved in the same the degradation complex. It was interesting to study whether these moonlighting enzymes could alter the activity of PNPase in vitro. The results are showing, however, that this is not the case in these conditions.

Polynucleotide phsphorylase is a very conserved enzyme and it is present in all three domains of life. The PNPases of $E$. coli and B. subtilis share a high percentage of identity and similarity. However, it seems that the regulation of these enzymes, as well as their relevance in vivo is not 
comparable. The result here presented show that the degradation acivity of PNPase is not regulated in the same way as its homologue from E. coli. Nonetheless, further analyses have to be made, including the effect of these metabolites and enzymes on the polymerization activity of PNPase. 


\section{Bibliography}

Ait-Bara, S., Carpousis, A.J., and Quentin, Y. (2014) RNase E in the $\gamma$-Proteobacteria: conservation of intrinsically disordered noncatalytic region and molecular evolution of microdomains. $\mathrm{Mol}$ Genet Genomics 290: 847-862.

Ando, Y., and Nakamura, K. (2006) Bacillus subtilis DEAD protein YdbR possesses ATPase, RNA binding, and RNA unwinding activities. Biosci Biotechnol Biochem 70: 1606-1615.

Andoh, T., Natori, S., and Mizuno, D. (1963) The degradation of E. coli Messenger RNA by polynucleotide phosphorylase. J Biochem 54: 477-479.

Apirion, D. (1978) Isolation, genetic mapping and some characterization of a mutation in Escherichia coli that affects the processing of ribonucleic acid. Genetics 90: 659-671.

Aravind, L., and Koonin, E. V. (1998) The HD domain defines a new superfamily of metaldependent phosphohydrolases. Trends Biochem Sci 23: 469-472.

Aravind, L., and Koonin, E. V. (2001) A natural classification of ribonucleases. Methods Enzymol 341: 3-28.

Arens, J. (2015) Structural analysis of different Bacillus subtilis RNA degrading enzymes and of the diadenylatcyclase. Georg-August Univeristät Göttingen.

Arraiano, C.M., Andrade, J.M., Domingues, S., Guinote, I.B., Malecki, M., Matos, R.G., et al. (2010) The critical role of RNA processing and degradation in the control of gene expression. FEMS Microbiol Rev 34: 883-923.

Awano, N., Inouye, M., and Phadtare, S. (2008) RNase activity of polynucleotide phosphorylase is critical at low temperature in Escherichia coli and is complemented by RNase II. J Bacteriol 190: 5924-5933.

Babitzke, P., and Kushner, S.R. (1991) The Ams (altered mRNA stability) protein and ribonuclease E are encoded by the same structural gene of Escherichia coli. Proc Natl Acad Sci U S A 88: 1-5.

Bandyra, K.J., Bouvier, M., Carpousis, A.J., and Luisi, B.F. (2013) The social fabric of the RNA degradosome. Biochim Biophys Acta - Gene Regul Mech 1829: 514-522.

Bechhofer, D.H. (2011) Bacillus subtilis mRNA decay: new parts in the toolkit. Wiley Interdiscip Rev RNA 2: 387-394.

Bechhofer, D.H., and Wang, W. (1998) Decay of ermC mRNA in a polynucleotide phosphorylase mutant of Bacillus subtilis. J Bacteriol 180: 5968-5977.

Beckering, C.L., Steil, L., Weber, M.H.W., Völker, U., and Marahiel, M.A. (2002) Genomewide transcriptional analysis of the cold shock response in Bacillus subtilis. J Bacteriol 184: 63956402.

Belasco, J.G., and Higgins, C.F. (1988) Mechanisms of mRNA decay in bacteria: a perspective. Gene 72: 15-23. 
Bermúdez-Cruz, R.M., Ramírez, F., Kameyama-Kawabe, L., and Montañez, C. (2005) Conserved domains in polynucleotide phosphorylase among eubacteria. Biochimie 87: 737-745.

Bernstein, J. a, Lin, P.-H., Cohen, S.N., and Lin-Chao, S. (2004) Global analysis of Escherichia coli RNA degradosome function using DNA microarrays. Proc Natl Acad Sci U S A 101: 2758-2763.

Blötz, C. (2015) Structural and functional characterization of RNase J2 from Bacillus subtilis. Georg-August Universität Göttingen.

Bouvet, P., and Belasco, J.G. (1992) Control of RNase E-mediated RNA degradation by 5'-terminal base pairing in E. coli. Nature 360: 488-491.

Bouvier, M., and Carpousis, A.J. (2011) A tale of two mRNA degradation pathways mediated by RNase E. Mol Microbiol 82: 1305-1310.

Bradford, M.M. (1976) A rapid and sensitive method for the quantitation of microgram quantities of protein utilizing the principle of protein-dye binding. Anal Biochem 72: 248-254.

Braun, F., Hajnsdorf, E., and Regnier, P. (1996) Polynucleotide phosphorylase is required for the rapid degradation of the RNase E-processed rpsO mRNA of Escherichia coli devoid of its 3' hairpin. Mol Microbiol 19: 997-1005.

Briani, F., Carzaniga, T., and Dehò, G. (2016) Regulation and functions of bacterial PNPase. Wiley Interdiscip Rev RNA 7: 241-258.

Briani, F., Favero, M. Del, Capizzuto, R., Consonni, C., Zangrossi, S., Greco, C., et al. (2007) Genetic analysis of polynucleotide phosphorylase structure and functions. Biochimie 89: 145-157.

Britton, R.A., Wen, T., Schaefer, L., Pellegrini, O., Uicker, W.C., Mathy, N., et al. (2007) Maturation of the $5^{\prime}$ end of Bacillus subtilis 16S rRNA by the essential ribonuclease YkqC/RNase J1. Mol Microbiol 63: 127-138.

Bürmann, F., Sawant, P., and Bramkamp, M. (2012) Identification of interaction partners of the dynamin-like protein DynA from Bacillus subtilis. Commun Integr Biol 5: 362-369.

Callaghan, A.J., Aurikko, J.P., Ilag, L.L., Günter Grossmann, J., Chandran, V., Kühnel, K., et al. (2004) Studies of the RNA degradosome-organizing domain of the Escherichia coli ribonuclease RNase E. J Mol Biol 340: 965-979.

Callaghan, A.J., Marcaida, M.J., Stead, J.A., McDowall, K.J., Scott, W.G., and Luisi, B.F. (2005a) Structure of Escherichia coli RNase E catalytic domain and implications for RNA turnover. Nature 437: 1187-1191.

Callaghan, A.J., Redko, Y., Murphy, L.M., Grossmann, J.G., Yates, D., Garman, E., et al. (2005b) 'ZnLink': A metal-sharing interface that organizes the quaternary structure and catalytic site of the endoribonuclease, RNase E. Biochemistry 44: 4667-4675.

Callebaut, I., Moshous, D., Mornon, J.-P., and Villartay, J.-P. de (2002) Metallo-beta-lactamase fold within nucleic acids processing enzymes: the beta-CASP family. Nucleic Acids Res 30: 35923601. 
Campos-Guillén, J., Bralley, P., Jones, G.H., Bechhofer, D.H., and Olmedo-Alvarez, G. (2005) Addition of poly $(\mathrm{A})$ and heteropolymeric $3^{\prime}$ ends in Bacillus subtilis wild-type and polynucleotide phosphorylase-deficient strains. J Bacteriol 187: 4698-4706.

Cardenas, P.P., Carrasco, B., Sanchez, H., Deikus, G., Bechhofer, D.H., and Alonso, J.C. (2009) Bacillus subtilis polynucleotide phosphorylase 3'-to-5' DNase activity is involved in DNA repair. Nucleic Acids Res 37: 4157-4169.

Cardenas, P.P., Carzaniga, T., Zangrossi, S., Briani, F., Garcia-Tirado, E., Dehò, G., et al. (2011) Polynucleotide phosphorylase exonuclease and polymerase activities on single-stranded DNA ends are modulated by RecN, SsbA and RecA proteins. Nucleic Acids Res 39: 9250-9261.

Carpousis, A.J. (2002) The Escherichia coli RNA degradosome: structure, function and relationship in other ribonucleolytic multienzyme complexes. Biochem Soc Trans 30: 150-155.

Carpousis, A.J. (2007) The RNA Degradosome of Escherichia coli : An mRNA-degrading machine assembled on RNase E. Annu Rev Microbio/ 61: 71-87.

Carpousis, A.J., Houwe, G. Van, Ehretsmann, C., and Krisch, H.M. (1994) Copurification of E. coli RNAase $E$ and PNPase: Evidence for a specific association between two enzymes important in RNA processing and degradation. Cell 76: 889-900.

Carpousis, A.J., Khemici, V., and Poljak, L. (2008) Chapter 10 Assaying DEAD-box RNA helicases and their role in mRNA degradation in Escherichia coli. Methods Enzymol 447: 183-197.

Cascante-Estepa, N. (2014) Carbon metabolism and RNA processing in Bacillus subtilis. GeorgAugust Universität Göttingen.

Cascante-Estepa, N., Gunka, K., and Stülke, J. (2016) Localization of components of the RNAdegrading machine in Bacillus subtilis. Front Microbiol 7: 1492.

Chalfie, M., Tu, Y., Euskirchen, G., W. W. Ward, and Prasher, D.C. (1994) Green fluorescent protein as a marker for gene expression. Science (80- ) 263: 802-805.

Chandran, V., and Luisi, B.F. (2006) Recognition of enolase in the Escherichia coli RNA degradosome. J Mol Biol 358: 8-15.

Chandran, V., Poljak, L., Vanzo, N.F., Leroy, A., Miguel, R.N., Fernandez-Recio, J., et al. (2007) Recognition and cooperation between the ATP-dependent RNA helicase RhIB and ribonuclease RNase E. J Mol Biol 367: 113-132.

Cheng, Z.F., and Deutscher, M.P. (2003) Quality control of ribosomal RNA mediated by polynucleotide phosphorylase and RNase R. Proc Natl Acad Sci U S A 100: 6388-6393.

Clouet-d'Orval, B.B., Phung, D.K., Langendijk-Genevaux, P.S., and Quentin, Y. (2015) Universal RNA-degrading enzymes in Archaea: Prevalence, activities and functions of beta-CASP ribonucleases. Biochimie 118: 279-285.

Coburn, G.A., Miao, X., Briant, D.J., and Mackie, G.A. (1999) Reconstitution of a minimal RNA degradosome demonstrates functional coordination between a $3^{\prime}$ exonuclease and a DEADbox RNA helicase. Genes Dev 13: 2594-2603. 
Collins, J.A., Irnov, I., Baker, S., and Winkler, W.C. (2007) Mechanism of mRNA destabilization by the glmS ribozyme. Genes Dev 21: 3356-3368.

Commichau, F.M., Pietack, N., and Stülke, J. (2013) Essential genes in Bacillus subtilis: a reevaluation after ten years. Mol Biosyst 9: 1068-1075.

Commichau, F.M., Rothe, F.M., Herzberg, C., Wagner, E., Hellwig, D., Lehnik-Habrink, M., et al. (2009) Novel activities of glycolytic enzymes in Bacillus subtilis: interactions with essential proteins involved in mRNA processing. Mol Cell Proteomics 8: 1350-1360.

Condon, C. (2007) Maturation and degradation of RNA in bacteria. Curr Opin Microbiol 10: 271278.

Condon, C. (2010) What is the role of RNase J in mRNA turnover? RNA Biol 7: 316-321.

Condon, C., and Bechhofer, D.H. (2011) Regulated RNA stability in the Gram positives. Curr Opin Microbiol 14: 148-154.

Daou-Chabo, R., Mathy, N., Bénard, L., and Condon, C. (2009) Ribosomes initiating translation of the hbs mRNA protect it from 5'-to-3' exoribonucleolytic degradation by RNase J1. Mol Microbiol 71: 1538-1550.

Deikus, G., and Bechhofer, D.H. (2007) Initiation of decay of Bacillus subtilis trp leader RNA. J Biol Chem 282: 20238-20244.

Deikus, G., and Bechhofer, D.H. (2011) 5' End-independent RNase J1 endonuclease cleavage of Bacillus subtilis model RNA. J Biol Chem 286: 34932-34940.

Deikus, G., Condon, C., and Bechhofer, D.H. (2008) Role of Bacillus subtilis RNase J1 endonuclease and 5'-exonuclease activities in trp leader RNA turnover. J Biol Chem 283: 17158-17167.

Deutscher, M.P. (2009) Maturation and degradation of ribosomal RNA in bacteria. Prog Mol Biol Trans/ Sci 85: 369-391.

Deutscher, M.P. (2015) Twenty years of bacterial RNases and RNA processing: how we've matured. RNA 21: 597-600.

Deutscher, M.P., and Reuven, N.B. (1991) Enzymatic basis for hydrolytic versus phosphorolytic mRNA degradation in Escherichia coli and Bacillus subtilis. Proc Natl Acad Sci U S A 88: 32773280.

DiChiara, J.M., Liu, B., Figaro, S., Condon, C., and Bechhofer, D.H. (2016) Mapping of internal monophosphate $5^{\prime}$ ends of Bacillus subtilis messenger RNAs and ribosomal RNAs in wild-type and ribonuclease-mutant strains. Nucleic Acids Res 44: 3373-3389.

Diethmaier, C., Pietack, N., Gunka, K., Wrede, C., Lehnik-Habrink, M., Herzberg, C., et al. (2011) A novel factor controlling bistability in Bacillus subtilis: The YmdB protein affects flagellin expression and biofilm formation. J Bacteriol 193: 5997-6007.

Domínguez-Malfavón, L., Islas, L.D., Luisi, B.F., García-Villegas, R., and García-Mena, J. (2013) The assembly and distribution in vivo of the Escherichia coli RNA degradosome. Biochimie 95: 2034-2041. 
Dominski, Z., Carpousis, A.J., and Clouet-d'Orval, B. (2013) Emergence of the $\beta$-CASP ribonucleases: Highly conserved and ubiquitous metallo-enzymes involved in messenger RNA maturation and degradation. Biochim Biophys Acta - Gene Regul Mech 1829: 532-551.

Dorléans, A., Li De La Sierra-Gallay, I., Piton, J., Zig, L., Gilet, L., Putzer, H., and Condon, C. (2011) Molecular basis for the recognition and cleavage of RNA by the bifunctional 5'-3' exo/endoribonuclease RNase J. Structure 19: 1252-1261.

Durand, S., Gilet, L., Bessiè Res, P., Nicolas, P., and Condon, C.N. (2012) Three Essential Ribonucleases-RNase $\mathrm{Y}, \mathrm{J} 1$, and III-Control the Abundance of a Majority of Bacillus subtilis mRNAs. PLoS Genet 8: e1002520.

Errington, J. (2003) Dynamic proteins and a cytoskeleton in bacteria. Nat Cell Biol 5: 175-178.

Even, S., Pellegrini, O., Zig, L., Labas, V., Vinh, J., Bréchemmier-Baey, D., et al. (2005) Ribonucleases J1 and J2: Two novel endoribonucleases in B. subtilis with functional homology to E. coli RNase E. Nucleic Acids Res 33: 2141-2152.

Eymann, C., Dreisbach, A., Albrecht, D., Bernhardt, J., Becher, D., Gentner, S., et al. (2004) A comprehensive proteome map of growing Bacillus subtilis cells. Proteomics 4: 2849-2876.

Farr, G.A., Oussenko, I.A., and Bechhofer, D.H. (1999) Protection against 3'-to-5' RNA decay in Bacillus subtilis. J Bacteriol 181: 7323-7330.

Favero, M. Del, Mazzantini, E., Briani, F., Zangrossi, S., Tortora, P., and Dehò, G. (2008) Regulation of Escherichia coli polynucleotide phosphorylase by ATP. J Biol Chem 283: 27355-27359.

Figaro, S., Durand, S., Gilet, L., Cayet, N., Sachse, M., and Condon, C. (2013) Bacillus subtilis mutants with knockouts of the genes encoding ribonucleases RNase $\mathrm{Y}$ and RNase J1 are viable, with major defects in cell morphology, sporulation, and competence. $J$ Bacteriol 195: 23402348.

Gamba, P., Jonker, M.J., and Hamoen, L.W. (2015) A novel feedback loop that controls bimodal expression of genetic competence. PLoS Genet 11: e1005047.

Gimpel, M., and Brantl, S. (2016) Dual-function sRNA encoded peptide SR1P modulates moonlighting activity of $B$. subtilis GapA. RNA Biol 6286: 1-11.

Górna, M.W., Carpousis, A.J., and Luisi, B.F. (2012) From conformational chaos to robust regulation: the structure and function of the multi-enzyme RNA degradosome. $Q$ Rev Biophys 45: 105-145.

Górna, M.W., Pietras, Z., Tsai, Y.-C., Callaghan, A.J., Hernández, H., Robinson, C. V, and Luisi, B.F. (2010) The regulatory protein RraA modulates RNA-binding and helicase activities of the $E$. coli RNA degradosome. RNA 16: 553-562.

Guérout-Fleury, A.M., Shazand, K., Frandsen, N., and Stragier, P. (1995) Antibiotic-resistance cassettes for Bacillus subtilis. Gene 167: 335-336.

Gundlach, J., Mehne, F.M.P., Herzberg, C., Kampf, J., Valerius, O., Kaever, V., and Stülke, J. (2015) An essential poison: Synthesis and degradation of cyclic di-AMP in Bacillus subtilis. $J$ Bacteriol 197: 3265-3274. 
Gunka, K., Stannek, L., Care, R.A., and Commichau, F.M. (2013) Selection-driven accumulation of suppressor mutants in Bacillus subtilis: The apparent high mutation frequency of the cryptic $\operatorname{gud} B$ gene and the rapid clonal expansion of $\operatorname{gud} B+$ suppressors are due to growth under selection. PLoS One 8: e66120.

Hahne, H., Wolff, S., Hecker, M., and Becher, D. (2008) From complementarity to comprehensiveness - Targeting the membrane proteome of growing Bacillus subtilis by divergent approaches. Proteomics 8: 4123-4136.

Hardwick, S.W., Gubbey, T., Hug, I., Jenal, U., and Luisi, B.F. (2012) Crystal structure of Caulobacter crescentus polynucleotide phosphorylase reveals a mechanism of RNA substrate channelling and RNA degradosome assembly. Open Biol 2: 120028.

Hardwick, S.W., and Luisi, B.F. (2013) Rarely at rest: RNA helicases and their busy contributions to RNA degradation, regulation and quality control. RNA Biol 10: 56-70.

Hartmann, R.K., Gößringer, M., Späth, B., Fischer, S., and Marchfelder, A. (2009) The making of tRNAs and more - RNase P and tRNase Z. Prog Mol Biol Trans/ Sci 85: 319-368.

Herzberg, C., Weidinger, L.A.F., Dörrbecker, B., Hübner, S., Stülke, J., and Commichau, F.M. (2007) SPINE: A method for the rapid detection and analysis of protein-protein interactions in vivo. Proteomics 7: 4032-4035.

Hui, M.P., Foley, P.L., and Belasco, J.G. (2014) Messenger RNA degradation in bacterial Cells. Annu Rev Genet 48: 537-559.

Hunger, K., Beckering, C.L., Wiegeshoff, F., Graumann, P.L., and Marahiel, M.A. (2006) Coldinduced putative DEAD box RNA helicases CshA and CshB are essential for cold adaptation and interact with cold shock protein B in Bacillus subtilis. J Bacteriol 188: 240-248.

Hunt, A., Rawlins, J.P., Thomaides, H.B., and Errington, J. (2006) Functional analysis of 11 putative essential genes in Bacillus subtilis. Microbiology 152: 2895-2907.

Jahn, N., and Brantl, S. (2016) Heat-shock-induced refolding entails rapid degradation of bsrG toxin mRNA by RNases Y and J1. Microbiology 162: 590-599.

Jamalli, A., Hébert, A., Zig, L., and Putzer, H. (2014) Control of expression of the RNases J1 and J2 in Bacillus subtilis. J Bacteriol 196: 318-324.

Jarrige, A.-C., Bré Chemier-Baey, D., Mathy, N., Lie Duché, O., and Portier, C. (2002) Mutational analysis of polynucleotide phosphorylase from Escherichia coli. J Mol Biol 321: 397-409.

Jarvis, E.D., Widom, R.L., LaFauci, G., Setoguchi, Y., Richter, I.R., and Rudner, R. (1988) Chromosomal organization of rRNA operons in Bacillus subtilis. Genetics 120: 625-635.

Jers, C., Pedersen, M.M., Paspaliari, D.K., Schütz, W., Johnsson, C., Soufi, B., et al. (2010) Bacillus subtilis BY-kinase PtkA controls enzyme activity and localization of its protein substrates. Mol Microbiol 77: 287-299.

Kaberdin, V.R., and Lin-Chao, S. (2009) Unraveling new roles for minor components of the E. coli RNA degradosome. RNA Biol 6: 402-405. 
Kalman, M., Murphy, H., and Cashel, M. (1991) rh/B, a new Escherichia coli K-12 gene with an RNA helicase-like protein sequence motif, one of at least five such possible genes in a prokaryote. New Biol 3: 886-895.

Kawai, Y., Asai, K., and Errington, J. (2009) Partial functional redundancy of MreB isoforms, MreB, $\mathrm{Mbl}$ and MreBHp in cell morphogenesis of Bacillus subtilis. Mol Microbiol 73: 719-731.

Khemici, V., Poljak, L., Luisi, B.F., and Carpousis, A.J. (2008) The RNase E of Escherichia coli is a membrane-binding protein. Mol Microbiol 70: 799-813.

Khemici, V., Poljak, L., Toesca, I., and Carpousis, A.J. (2005) Evidence in vivo that the DEAD-box RNA helicase RhIB facilitates the degradation of ribosome-free mRNA by RNase E. Proc Natl Acad Sci U S A 102: 6913-6018.

Khemici, V., Prados, J., Linder, P., and Redder, P. (2015) Decay-initiating endoribonucleolytic cleavage by RNase $Y$ is kept under tight control via sequence preference and sub-cellular localisation. PLoS Genet 11: e1005577.

Kobayashi, K., Ehrlich, S.D., Albertini, A., Amati, G., Andersen, K.K., Arnaud, M., et al. (2003) Essential Bacillus subtilis genes. Proc Natl Acad Sci U S A 100: 4678-4683.

Koslover, D.J., Callaghan, A.J., Marcaida, M.J., Garman, E.F., Martick, M., Scott, W.G., and Luisi, B.F. (2008) The crystal structure of the Escherichia coli RNase E apoprotein and a mechanism for RNA degradation. Structure 16: 1238-1244.

Kühnel, K., and Luisi, B.F. (2001) Crystal structure of the Escherichia coli RNA degradosome component enolase. J Mol Biol 313: 583-592.

Kunst, F., Ogasawara, N., Moszer, I., Albertini, A.M., Alloni, G., Azevedo, V., et al. (1997) The complete genome sequence of the Gram-positive bacterium Bacillus subtilis. Nature 390: 249256.

Laalami, S., Bessières, P., Rocca, A., Zig, L., Nicolas, P., and Putzer, H. (2013) Bacillus subtilis RNase $Y$ activity in vivo analysed by tiling microarrays. PLoS One 8: e54062.

Laalami, S., Zig, L., and Putzer, H. (2014) Initiation of mRNA decay in bacteria. Cell Mol Life Sci 71: 1799-1828.

Laemmli, U.K. (1970) Cleavage of structural proteins during the assembly of the head of bacteriophage T4. Nature 227: 680-685.

Lehnik-Habrink, M. (2011) An mRNA degradation complex in Bacillus subtilis. Georg-August Universität Göttingen.

Lehnik-Habrink, M., Lewis, R.J., Mäder, U., and Stülke, J. (2012) RNA degradation in Bacillus subtilis: An interplay of essential endo- and exoribonucleases. Mol Microbiol 84: 1005-1017.

Lehnik-Habrink, M., Newman, J., Rothe, F.M., Solovyova, A.S., Rodrigues, C., Herzberg, C., et al. (2011a) RNase $Y$ in Bacillus subtilis: A natively disordered protein that is the functional equivalent of RNase E from Escherichia coli. J Bacteriol 193: 5431-5441. 
Lehnik-Habrink, M., Pförtner, H., Rempeters, L., Pietack, N., Herzberg, C., and Stülke, J. (2010) The RNA degradosome in Bacillus subtilis: Identification of CshA as the major RNA helicase in the multiprotein complex. Mol Microbiol 77: 958-971.

Lehnik-Habrink, M., Rempeters, L., Kovács, Á.T., Wrede, C., Baierlein, C., Krebber, H., et al. (2013) DEAD-box RNA helicases in Bacillus subtilis have multiple functions and act independently from each other. J Bacteriol 195: 534-544.

Lehnik-Habrink, M., Schaffer, M., Mäder, U., Diethmaier, C., Herzberg, C., and Stülke, J. (2011b) RNA processing in Bacillus subtilis: Identification of targets of the essential RNase Y. Mol Microbiol 81: 1459-1473.

Leroy, A., Vanzo, N.F., Sousa, S., Dreyfus, M., and Carpousis, A.J. (2002) Function in Escherichia coli of the non-catalytic part of RNase E: Role in the degradation of ribosome-free mRNA. Mol Microbiol 45: 1231-1243.

Lewis, P.J., Thaker, S.D., and Errington, J. (2000) Compartmentalization of transcription and translation in Bacillus subtilis. EMBO J 19: 710-718.

Leyva-Vazquez, M.A., and Setlow, P. (1994) Cloning and nucleotide sequences of the genes encoding triose phosphate isomerase, phosphoglycerate mutase, and enolase from Bacillus subtilis. J Bacteriol 176: 3903-3910.

Li de la Sierra-Gallay, I., Zig, L., Jamalli, A., and Putzer, H. (2008) Structural insights into the dual activity of RNase J. Nat Struct Mol Biol 15: 206-212.

Lin, P.-H., and Lin-Chao, S. (2005) RhlB helicase rather than enolase is the beta-subunit of the Escherichia coli polynucleotide phosphorylase (PNPase)-exoribonucleolytic complex. Proc Natl Acad Sci U S A 102: 16590-16595.

Liou, G.G., Chang, H.Y., Lin, C.S., and Lin-Chao, S. (2002) DEAD-box RhIB RNA helicase physically associates with exoribonuclease PNPase to degrade double-stranded RNA independent of the degradosome-assembling region of RNase E. J Biol Chem 277: 41157-41162.

Liou, G.G., Jane, W.N., Cohen, S.N., Lin, N.S., and Lin-Chao, S. (2001) RNA degradosomes exist in vivo in Escherichia coli as multicomponent complexes associated with the cytoplasmic membrane via the N-terminal region of ribonuclease E. Proc Natl Acad Sci U S A 98: 63-68.

Littauer, U.Z., and Grunberg-Manago, M. (1999) Polynucleotide Phosphorylase. John Wiley \& Sons, Inc., Hoboken, NJ, USA.

Liu, B., Deikus, G., Bree, A., Durand, S., Kearns, D.B., and Bechhofer, D.H. (2014) Global analysis of mRNA decay intermediates in Bacillus subtilis wild-type and polynucleotide phosphorylasedeletion strains. Mol Microbiol 94: 41-55.

Loughney, K., Lund, E., and Dahlberg, J.E. (1982) tRNA genes are found between the 16S and 23S rRNA genes in Bacillus subtilis. Nucleic Acids Res 10: 1607-1624.

Lu, F., and Taghbalout, A. (2014) The Escherichia coli major exoribonuclease RNase II is a component of the RNA degradosome. Biosci Rep 34: e00166.

Luttinger, A., Hahn, J., and Dubnau, D. (1996) Polynucleotide phosphorylase is necessary for competence development in Bacillus subtilis. Mol Microbiol 19: 343-356. 
Mackie, G.A. (1998) Ribonuclease E is a 5'-end-dependent endonuclease. Nature 395: 720-723.

Mäder, U., Zig, L., Kretschmer, J., Homuth, G., and Putzer, H. (2008) mRNA processing by RNases $\mathrm{J} 1$ and $\mathrm{J} 2$ affects Bacillus subtilis gene expression on a global scale. Mol Microbiol 70: 183-196.

Marcaida, M.J., DePristo, M.A., Chandran, V., Carpousis, A.J., and Luisi, B.F. (2006) The RNA degradosome: Life in the fast lane of adaptive molecular evolution. Trends Biochem Sci 31: 359-365.

Margolin, W. (2012) The price of tags in protein localization studies. J Bacteriol 194: 6369-6371.

Mascarenhas, J., Weber, M.H.W., and Graumann, P.L. (2001) Specific polar localization of ribosomes in Bacillus subtilis depends on active transcription. EMBO Rep 2: 685-689.

Mathy, N., Bénard, L., Pellegrini, O., Daou, R., Wen, T., and Condon, C. (2007) 5'-to-3' exoribonuclease activity in bacteria: Role of RNase J1 in rRNA maturation and $5^{\prime}$ stability of mRNA. Cell 129: 681-692.

Mathy, N., Hébert, A., Mervelet, P., Bénard, L., Dorléans, A., Li de la Sierra-Gallay, I., et al. (2010) Bacillus subtilis ribonucleases $\mathrm{J} 1$ and $\mathrm{J} 2$ form a complex with altered enzyme behaviour. $\mathrm{Mol}$ Microbiol 75: 489-498.

Matus-Ortega, M.E., Regonesi, M.E., Piña-Escobedo, A., Tortora, P., Dehò, G., and García-Mena, J. (2007) The KH and S1 domains of Escherichia coli polynucleotide phosphorylase are necessary for autoregulation and growth at low temperature. Biochim Biophys Acta - Gene Struct Expr 1769: 194-203.

Mauri, P., and Dehò, G. (2008) Chapter 6: A proteomic approach to the analysis of RNA degradosome composition in Escherichia coli. Methods Enzymol 447: 99-117.

Meile, J.-C.C., Wu, L.J., Ehrlich, S.D., Errington, J., and Noirot, P. (2006) Systematic localisation of proteins fused to the green fluorescent protein in Bacillus subtilis: Identification of new proteins at the DNA replication factory. Proteomics 6: 2135-2146.

Meinken, C., Blencke, H.M., Ludwig, H., and Stülke, J. (2003) Expression of the glycolytic gapA operon in Bacillus subtilis: Differential syntheses of proteins encoded by the operon. Microbiology 149: 751-761.

Meyer, F.M., Gerwig, J., Hammer, E., Herzberg, C., Commichau, F.M., Völker, U., and Stülke, J. (2011) Physical interactions between tricarboxylic acid cycle enzymes in Bacillus subtilis: Evidence for a metabolon. Metab Eng 13: 18-27.

Miczak, A., Kaberdin, V.R., Wei, C., and Lin-Chao, S. (1996) Proteins associated with RNase E in a multicomponent ribonucleolytic complex. Proc Natl Acad Sci U S A 93: 3865-3869.

Mitra, S., Hue, K., and Bechhofer, D.H. (1996) In vitro processing activity of Bacillus subtilis polynucleotide phosphorylase. Mol Microbiol 19: 329-342.

Miyawaki, A. (2011) Proteins on the move: Insights gained from fluorescent protein technologies. Nat Rev Mol Cell Biol 12: 656-668. 
Mohanty, B.K., and Kushner, S.R. (2000) Polynucleotide phosphorylase functions both as a 3' right-arrow 5' exonuclease and a poly(A) polymerase in Escherichia coli. Proc Natl Acad Sci U S A 97: 11966-11971.

Mohanty, B.K., and Kushner, S.R. (2010) Bacterial/archaeal/organellar polyadenylation. Wiley Interdiscip Rev RNA 2: 256-276.

Mohanty, B.K., and Kushner, S.R. (2016) Regulation of mRNA decay in bacteria. Annu Rev Microbiol 70: 25-44.

Morita, T., Kawamoto, H., Mizota, T., Inada, T., and Aiba, H. (2004) Enolase in the RNA degradosome plays a crucial role in the rapid decay of glucose transporter mRNA in the response to phosphosugar stress in Escherichia coli. Mol Microbiol 54: 1063-1075.

Mudd, E.A., Krisch, H.M., and Higgins, C.F. (1990) RNase E, an endoribonuclease, has a general role in the chemical decay of Escherichia coli mRNA: Evidence that rne and ams are the same genetic locus. Mol Microbiol 4: 2127-2135.

Müller, P., Jahn, N., Ring, C., Maiwald, C., Neubert, R., Meißner, C., and Brantl, S. (2016) A multistress responsive type I toxin-antitoxin system: bsrE/SR5 from the $B$. subtilis chromosome. RNA Biol 6286: 1-13.

Muñoz-Márquez, M.E., and Ponce-Rivas, E. (2010) Effect of pfkA chromosomal interruption on growth, sporulation, and production of organic acids in Bacillus subtilis. J Basic Microbiol 50: 232-240.

Newman, J.A., Hewitt, L., Rodrigues, C., Solovyova, A., Harwood, C.R., and Lewis, R.J. (2011) Unusual, dual endo- and exonuclease activity in the degradosome explained by crystal structure analysis of RNase J1. Structure 19: 1241-1251.

Newman, J.A., Hewitt, L., Rodrigues, C., Solovyova, A.S., Harwood, C.R., and Lewis, R.J. (2012) Dissection of the network of interactions that links RNA processing with glycolysis in the Bacillus subtilis degradosome. J Mol Biol 416: 121-136.

Nicolas, P., Mäder, U., Dervyn, E., Rochat, T., Leduc, A., Pigeonneau, N., et al. (2012) Conditiondependent transcriptome reveals high-level regulatory architecture in Bacillus subtilis. Science (80- ) 335: 1103-1106.

Niepmann, M. and Zheng, J, (2006) Discontinuous native protein gel electrophoresis: pros and cons. Expert Rev Proteomics 4: 355-361.

Noone, D., Salzberg, L.I., Botella, E., Bäsell, K., Becher, D., Antelmann, H., and Devine, K.M. (2014) A highly unstable transcript makes CwIO D,L-endopeptidase expression responsive to growth conditions in Bacillus subtilis. J Bacteriol 196: 237-247.

Nurmohamed, S., Vaidialingam, B., Callaghan, A.J., and Luisi, B.F. (2009) Crystal structure of Escherichia coli polynucleotide phosphorylase core bound to RNase E, RNA and manganese: Implications for catalytic mechanism and RNA degradosome assembly. J Mol Biol 389: 17-33.

Nurmohamed, S., Vincent, H.A., Titman, C.M., Chandran, V., Pears, M.R., Du, D., et al. (2011) Polynucleotide phosphorylase activity may be modulated by metabolites in Escherichia coli. $J$ Biol Chem 286: 14315-14323. 
Oliva, M.A., Halbedel, S., Freund, S.M., Dutow, P., Leonard, T.A., Veprintsev, D.B., et al. (2010) Features critical for membrane binding revealed by DivIVA crystal structure. EMBO J 29: 19882001.

Ow, M.C., and Kushner, S.R. (2002) Initiation of tRNA maturation by RNase $E$ is essential for cell viability in E. coli. Genes Dev 16: 1102-1115.

Pei, X.Y., Bralley, P., Jones, G.H., and Luisi, B.F. (2015) Linkage of catalysis and 5' end recognition in ribonuclease RNase J. Nucleic Acids Res 43: 8066-8076.

Pietack, N. (2010) Investigation of glycolysis in Bacillus subtilis. Georg-August Universität Göttingen.

Pietack, N., Becher, D., Schmidl, S.R., Saier, M.H., Hecker, M., Commichau, F.M., and Stülke, J. (2010) In vitro phosphorylation of key metabolic enzymes from Bacillus subtilis: PrkC phosphorylates enzymes from different branches of basic metabolism. I Mol Microbiol Biotechnol 18: 129-140.

Pietras, Z., Hardwick, S.W., Swiezewski, S., and Luisi, B.F. (2013) Potential regulatory interactions of Escherichia coli RraA protein with DEAD-box helicases. J Biol Chem 288: 31919-31929.

Portier, C. (1975a) Quaternary structure of Escherichia coli polynucleotide phosphorylase: New evidence for a trimeric structure. FEBS Lett 50: 79-81.

Portier, C. (1975b) Quaternary structure of polynucleotide phosphorylase from Escherichia coli: Evidence of a complex between two types of polypeptide chains. Eur J Biochem 582: 573-582.

Py, B., Higgins, C.F., Krisch, H.M., and Carpousis, a J. (1996) A DEAD-box RNA helicase in the Escherichia coli RNA degradosome. Nature 381: 169-172.

Rath, D., Mangoli, S.H., Pagedar, A.R., and Jawali, N. (2012) Involvement of pnp in survival of UV radiation in Escherichia coli K-12. Microbiology 158: 1196-1205.

Redder, P., and Linder, P. (2012) Chapter 17: DEAD-box RNA helicases in Gram-positive RNA decay. Methods Enzymol 511: 369-383.

Redko, Y., Aubert, S., Stachowicz, A., Lenormand, P., Namane, A., Darfeuille, F., et al. (2013) A minimal bacterial RNase J-based degradosome is associated with translating ribosomes. Nucleic Acids Res 41: 288-301.

Regonesi, M.E., Favero, M. Del, Basilico, F., Briani, F., Benazzi, L., Tortora, P., et al. (2006) Analysis of the Escherichia coli RNA degradosome composition by a proteomic approach. Biochimie 88: 151-161.

Roy, M.K., and Apirion, D. (1983) Purification and properties of ribonuclease E, an RNA-processing enzyme from Escherichia coli. Biochim Biophys Acta 747: 200-208.

Salvo, E., Alabi, S., Liu, B., Schlessinger, A., and Bechhofer, D.H. (2016) Interaction of Bacillus subtilis polynucleotide phosphorylase and RNase $Y$ : Structural mapping and effect on mRNA turnover. J Biol Chem 291: 6655-6663.

Sambrook, J.; Fritsch, E. F. and Maniatis, T. (1989) Molecular cloning: A laboratory manual. 2nd Edition. Cold Spring Harb Lab Press. 
Sanger, F., Nicklen, S., and Coulson, A.R. (1977) DNA sequencing with chain-terminating inhibitors. Proc Natl Acad Sci U S A 74: 5463-5467.

Sarkar, B., Cao, G.-J., and Sarkar, N. (1997) Identification of two poly(A) polymerases in Bacillus subtilis. Biochem Mol Biol Int Pages 41: 1045-1050.

Sarkar, N. (1997) Polyadenylation of mRNA in prokaryotes. Annu Rev Biochem 66: 173-197.

Sekiguchi, M., and Cohen, S.S. (1963) The selective degradation of phage-induced ribonucleic acid by polynucleotide phosphorylase. J Biol Chem 238: 349-356.

Shahbabian, K., Jamalli, A., Zig, L., and Putzer, H. (2009) RNase Y, a novel endoribonuclease, initiates riboswitch turnover in Bacillus subtilis. EMBO J 28: 3523-3533.

Shapiro, L., and Losick, R. (2000) Dynamic spatial regulation in the bacterial cell. Cell 100: 89-98.

Shi, Z., Yang, W.-Z., Lin-Chao, S., Chak, K.-F., and Yuan, H.S. (2008) Crystal structure of Escherichia coli PNPase: central channel residues are involved in processive RNA degradation. RNA 14: 2361-2371.

Spring, T.G., and Wold, F. (1971) The purification and characterization of Escherichia coli enolase. 246(22): 6797-6802.

Stewart, C., Wilson, F.E., and Bott, K.F. (1982) Detailed physical mapping of the ribosomal RNA genes of Bacillus subtilis. Elsevier Biomed Press 19: 153-162.

Stickney, L.M., Hankins, J.S., Miao, X., and Mackie, G.A. (2005) Function of the conserved S1 and $\mathrm{KH}$ domains in polynucleotide phosphorylase. J Bacteriol 187: 7214-7221.

Strahl, H., Bürmann, F., and Hamoen, L.W. (2014) The actin homologue MreB organizes the bacterial cell membrane. Nat Commun 5: 1-11.

Strahl, H., Turlan, C., Khalid, S., Bond, P.P.J., Kebalo, J.-M.M., Peyron, P., et al. (2015) Membrane recognition and dynamics of the RNA degradosome. PLoS Genet 11: 1-23.

Symmons, M.F., Jones, G.H., and Luisi, B.F. (2000) A duplicated fold is the structural basis for polynucleotide phosphorylase catalytic activity, processivity, and regulation. Structure 8: 1215-1226.

Symmons, M.F., Williams, M.G., Luisi, B.F., Jones, G.H., and Carpousis, A.J. (2002) Running rings around RNA: A superfamily of phosphate-dependent RNases. Trends Biochem Sci 27: 11-18.

Taraseviciene, L., Bjork, G.R., and Uhlin, B.E. (1995) Evidence for an RNA binding region in the Escherichia coli processing endoribonuclease RNase E. J Biol Chem 270: 26391-26398.

Taraseviciene, L., Miczak, A., and Apirion, D. (1991) The gene specifying RNase E (rne) and a gene affecting mRNA stability (ams) are the same gene. Mol Microbiol 5: 851-855.

Tseng, Y.-T., Chiou, N.-T., Gogiraju, R., and Lin-Chao, S. (2015) The protein interaction of RNA helicase B (RhIB) and polynucleotide Phosphorylase (PNPase) contributes to the homeostatic control of cysteine in Escherichia coli. J Biol Chem 290: 29953-29963. 
Tuckerman, J.R., Gonzalez, G., and Gilles-Gonzalez, M.A. (2011) Cyclic di-GMP activation of polynucleotide phosphorylase signal-dependent RNA processing. J Mol Biol 407: 633-639.

Vanzo, N.F., Li, Y.S., Py, B., Blum, E., Higgins, C.F., Raynal, L.C., et al. (1998) Ribonuclease E organizes the protein interactions in the Escherichia coli RNA degradosome. Genes Dev 12: 2770-2781.

Wach, A. (1996) PCR-synthesis of marker cassettes with long flanking homology regions for gene disruptions in S. cerevisiae. Yeast 12: 259-265.

Wade, H.E., and Lovett, S. (1961) Polynucleotide phosphorylase in ribosomes from Escherichia coli. Biochem J 81: 319-328.

Wang, W., and Bechhofer, D.H. (1996) Properties of a Bacillus subtilis polynucleotide phosphorylase deletion strain. J Bacteriol 178: 2375-2382.

Waters, S.M., Zeigler, D.R., and Nicholson, W.L. (2015) Experimental evolution of enhanced growth by Bacillus subtilis at low atmospheric pressure: Genomic changes revealed by wholegenome sequencing. Appl Environ Microbiol 81: 7525-7532.

Weber, M.H.W., Volkov, A. V., Fricke, I., Marahiel, M.A., and Graumann, P.L. (2001) Localization of cold shock proteins to cytosolic spaces surrounding nucleoids in Bacillus subtilis depends on active transcription. J Bacteriol 183: 6435-6443.

Weiss, W., Weiland, F., and Görg, A. (2009) Protein detection and quantitation technologies for gel-based proteome analysis. Methods Mol Biol 564: 59-82.

Wilusz, C.J., and Wilusz, J. (2004) Bringing the role of mRNA decay in the control of gene expression into focus. Trends Genet 20: 491-497.

Worrall, J.A.R., Górna, M., Crump, N.T., Phillips, L.G., Tuck, A.C., Price, A.J., et al. (2008) Reconstitution and analysis of the multienzyme Escherichia coli RNA degradosome. $J \mathrm{Mol} \mathrm{Biol}$ 382: 870-883.

Worrall, J.A.R., Howe, F.S., McKay, A.R., Robinson, C. V, and Luisi, B.F. (2007) Allosteric activation of the ATPase activity of the Escherichia coli RhIB RNA helicase. J Biol Chem 283: 5567-5576.

Wu, J., Jiang, Z., Liu, M., Gong, X., Wu, S., Burns, C.M., and Li, Z. (2009) Polynucleotide phosphorylase protects Escherichia coli against oxidative stress. Biochemistry 48: 2012-2020.

Xu, F., and Cohen, S.N. (1995) RNA degradation in Escherichia coli regulated by 3' adenylation and 5' phosphorylation. Nature 374: 180-183.

Yao, S., Blaustein, J.B., and Bechhofer, D.H. (2008) Erythromycin-induced ribosome stalling and RNase J1-mediated mRNA processing in Bacillus subtilis. Mol Microbiol 69: 1439-1449.

Yao, S., Sharp, J.S., and Bechhofer, D.H. (2009) Bacillus subtilis RNase J1 endonuclease and 5' exonuclease activities in the turnover of DeltaermC mRNA. RNA 15: 2331-2339.

Yehudai-Resheff, S., Hirsh, M., and Schuster, G. (2001) Polynucleotide phosphorylase functions as both an exonuclease and a poly(A) polymerase in spinach chloroplasts. Mol Cell Biol 21: 54085416. 
Zhao, Y., Lu, M., Zhang, H., Hu, J., Zhou, C., Xu, Q., et al. (2015) Structural insights into catalysis and dimerization enhanced exonuclease activity of RNase J. Nucleic Acids Res 43: 5550-5559.

Zweers, J.C., Wiegert, T., and Dijl, J.M. Van (2009) Stress-responsive systems set specific limits to the overproduction of membrane proteins in Bacillus subtilis. Appl Environ Microbiol 75: 73567364. 


\section{Appendix}

\subsection{Bacterial strains}

Table 20. Bacterial strains used in this work

\begin{tabular}{|c|c|c|}
\hline Strain & Genotype & Reference \\
\hline \multicolumn{3}{|l|}{ E. coli } \\
\hline $\mathrm{DH} 5 \alpha$ & $\begin{array}{l}\text { F- endA1 glnV44 thi-1 recA1 relA1 gyrA96 deoR } \\
\text { nupG } \Phi 80 d \text { lacZ } \triangle M 15 \triangle(\text { lacZYA-argF)U169, } \\
\text { hsdR17 }\left(r_{K}^{-} m_{K}^{+}\right), \lambda-\end{array}$ & Sambrook et al., 1989 \\
\hline \multicolumn{3}{|c|}{ B. subtilis } \\
\hline 168 & $\operatorname{trpC2}$ & Laboratory collection \\
\hline BSB1 & $168 \operatorname{trp}^{+}$ & Nicolas et al., 2012 \\
\hline CCB434 & W168 $\Delta r n j A:: s p e c$ & Figaro et al., 2013 \\
\hline GP594 & $\operatorname{trpC2} \Delta$ eno::cat & Commichau et al., 2013 \\
\hline GP1034 & $\operatorname{trpC2}$ rnjA-Strep-spec & Lehnik-Habrink, 2011 \\
\hline GP1035 & $\operatorname{trpC2} \Delta \operatorname{csh} A:: a p h A 3$ & Lehnik-Habrink et al., 2013 \\
\hline GP1042 & $\operatorname{trpC2}$ rnjA-Strep-cat & Lehnik-Habrink, 2011 \\
\hline GP1048 & $\operatorname{trp} C 2$ rnjA-Strep-cat rnjB-3xFLAG-spec & Lehnik-Habrink, 2011 \\
\hline GP1075 & $\operatorname{trpC2} r n j A-3 x F L A G-a p h A 3$ & Lehnik-Habrink, 2011 \\
\hline GP1291 & $\operatorname{trpC} \Delta r n j B:: c a t$ & Blötz, 2015 \\
\hline GP1684 & $\operatorname{trpC2}$ amyE::(Pxyl-rny-mSFgfpV206K-spec) & $\begin{array}{l}\text { pGP1449 } \rightarrow 168 \\
\text { Cascante-Estepa et al., } 2016\end{array}$ \\
\hline GP1687 & $\operatorname{trpC2} r n j B$-Strep-aphA3 & $\mathrm{LFH} \rightarrow 168$ \\
\hline GP1694 & trpC2 amyE::(Pxyl-mSFgfpV206K-rnjA-spec) & $\begin{array}{l}\text { pGP2802 } \rightarrow 168 \\
\text { Cascante-Estepa et al., } 2016\end{array}$ \\
\hline
\end{tabular}




\begin{tabular}{|c|c|c|}
\hline GP1695 & $\operatorname{trpC2}$ amyE::(Pxyl-mSFgfpV206K-rnjB-spec) & $\begin{array}{l}\text { pGP2803 } \rightarrow 168 \\
\text { Cascante-Estepa et al., } 2016\end{array}$ \\
\hline GP1698 & $\operatorname{trpC2}$ pnpA-gfpA206K-spec & $\begin{array}{l}\text { pGP2806 } \rightarrow 168 \\
\text { Cascante-Estepa et al., } 2016\end{array}$ \\
\hline GP1699 & $\operatorname{trpC2}$ rnjB-gfpA206K-spec & $\begin{array}{l}\text { pGP2807 } \rightarrow 168 \\
\text { Cascante-Estepa et al., } 2016\end{array}$ \\
\hline GP1700 & $\operatorname{trpC2}$ eno-gfpA206K-spec & $\begin{array}{l}\text { pGP2808 } \rightarrow 168 \\
\text { Cascante-Estepa et al., } 2016\end{array}$ \\
\hline GP1720 & $\operatorname{trpC2} p f k A-g f p A 206 K-s p e c$ & $\begin{array}{l}\text { pGP2810 } \rightarrow 168 \\
\text { Cascante-Estepa et al., } 2016\end{array}$ \\
\hline GP1721 & $\operatorname{trpC2}$ cshA-gfpA206K-spec & $\begin{array}{l}\text { pGP2811 } \rightarrow 168 \\
\text { Cascante-Estepa et al., } 2016\end{array}$ \\
\hline GP1722 & $\operatorname{trpC2}$ rnjA-gfpA206K-spec & $\begin{array}{l}\text { pGP2812 } \rightarrow 168 \\
\text { Cascante-Estepa et al., } 2016\end{array}$ \\
\hline GP1723 & $\operatorname{trpC2}$ rnjA-Strep-spec $\Delta r n j B:: c a t$ & GP1291 $\rightarrow$ GP1034 \\
\hline GP1724 & $\operatorname{trpC2}$ rnjB-Strep-spec & pGP2816 $\rightarrow 168$ \\
\hline GP1731 & $\operatorname{trpC2}$ rnjB-Strep-spec rnjA-3xFLAG-aphA3 & GP1724 $\rightarrow$ GP1075 \\
\hline GP1732 & $\operatorname{trpC2}$ rnjB- $\triangle$ Cter::cat & $\mathrm{LFH} \rightarrow 168$ \\
\hline GP1733 & $\operatorname{trpC2}$ rnjB- $\Delta$ Cter-gfpA206K-spec & pGP2818 $\rightarrow 168$ \\
\hline GP1734 & $\operatorname{trpC2}$ rnjA-gfpA206K-spec rnjB-ACter::cat & GP1732 $\rightarrow$ GP1722 \\
\hline GP1736 & $\operatorname{trpC2}$ rnjA-Strep-spec rnjB- $\Delta$ Cter::cat & GP1732 $\rightarrow$ GP1034 \\
\hline GP1737 & $\operatorname{trpC2}$ rnjB- $\Delta C$ ter-Strep-spec & pGP1827 $\rightarrow 168$ \\
\hline GP1740 & $\operatorname{trpC2}$ rnjA-Strep-cat rnjB- $\Delta C$ Cter-3xFLAG-spec & pGP2821 $\rightarrow$ GP1042 \\
\hline GP1741 & $\operatorname{trp} C 2$ rnjB- $\Delta$ Cter-Strep-spec rnjA-3xFLAG-aphA3 & GP1737 $\rightarrow$ GP1075 \\
\hline GP1744 & BSB1 $\triangle p f k A:: a p h A 3$ & $\mathrm{LFH} \rightarrow \mathrm{BSB} 1$ \\
\hline GP1747 & $\operatorname{trpC2} \Delta p f k A:: a p h A 3$ & $\begin{array}{l}\text { LFH } \rightarrow 168 \\
\text { Cascante-Estepa et al., } 2016\end{array}$ \\
\hline GP1748 & $\operatorname{trpC2} \Delta p n p A:: a p h A 3$ & $\begin{array}{l}\text { LFH } \rightarrow 168 \\
\text { Cascante-Estepa et al., } 2016\end{array}$ \\
\hline
\end{tabular}




\begin{tabular}{lll}
\hline GP1749 & trpC2 rnjB-gfpA206K-aphA3 & LFH $\rightarrow 168$ \\
GP1750 & trpC2 rnjB-gfpA206K-aphA3 $\Delta r n j A:: s p e c$ & GP2502 $\rightarrow$ GP1749 \\
GP2317 & trpC2 rnjA-gfpA206K-spec $\Delta r n j B:: c a t$ & GP1291 $\rightarrow$ GP1722 \\
GP2318 & trpC2 rnjB-Strep-aphA3 $\Delta r n j A:: s p e c$ & GP2502 $\rightarrow$ GP1687 \\
GP2502 & $\operatorname{trpC~} \Delta$ rnjA::spec & CCB434 $\rightarrow$ 168 \\
& & Cascante-Estepa et al., 2016 \\
\hline
\end{tabular}

${ }^{a}$ Arrows indicate construction by transformation.

\subsection{Plasmids}

Table 21. Plasmids used in this work

\begin{tabular}{|c|c|c|c|}
\hline Plasmid & Relevant Characteristics & Primers & Reference \\
\hline pBP43 & pUS19-gfpA206K & ML220/ML221 & Cascante-Estepa et al., 2016 \\
\hline pDG780 & Amplification of aphA3 cassette & - & Guérout-Fleury et al., 1995 \\
\hline pGEM-cat & Amplification of $\mathrm{cm}^{R}$ cassette & - & Guérout-Fleury et al., 1995 \\
\hline pGP393 & $\mathrm{His}_{6}-p f k A$ & - & Pietack, 2010 \\
\hline pGP563 & $\mathrm{His}_{6}$-eno & - & Pietack et al., 2010 \\
\hline pGP838 & $\mathrm{His}_{6}-p n p A$ & - & Pietack, 2010 \\
\hline pGP1331 & C-terminal 3xFLAG tag & - & Lehnik-Habrink et al., 2010 \\
\hline pGP1389 & C-terminal Strep tag & - & Lehnik-Habrink et al., 2011a \\
\hline pGP1449 & pHJS105-rny & $\begin{array}{l}\text { NC51/NC52 } \\
\text { NC53/NC54 }\end{array}$ & Cascante-Estepa et al., 2016 \\
\hline pGP2802 & pHJS105-rnjA & NC63/NC64 & Cascante-Estepa et al., 2016 \\
\hline pGP2803 & pHJS105-rnjB & NC65/NC2 & Cascante-Estepa et al., 2016 \\
\hline pGP2806 & pBP43-pnpA & ML91/ML92 & Cascante-Estepa et al., 2016 \\
\hline
\end{tabular}




\begin{tabular}{llll}
\hline pGP2807 & pBP43-rnjB & ML173/ML174 & Cascante-Estepa et al., 2016 \\
pGP2808 & pBP43-eno & FR86/FR90 & Cascante-Estepa et al., 2016 \\
pGP2810 & pBP43-pfkA & ML56/ML57 & Cascante-Estepa et al., 2016 \\
pGP2811 & pBP43-cshA & ML11/ML12 & Cascante-Estepa et al., 2016 \\
pGP2812 & pBP43-rnjA & ML58/ML59 & Cascante-Estepa et al., 2016 \\
pGP2816 & pGP1389-rnjB & ML173/ML174 & This work \\
pGP2817 & pGP1389-rnjB- 4 Cter & NC78/NC79 & This work \\
pGP2818 & pBP43-rnjB- $\Delta C$ Cter & NC78/NC79 & This work \\
pGP2821 & pGP1331-rnjB- 4 Cter & NC78/NC79 & This work \\
pHJS105 & amyE::(Pxyl-mSFgfpV206K spec) & - & Gamba et al., 2015 \\
\hline
\end{tabular}

\subsection{Oligonucleotides}

All the oligonucleotides were purchased from Sigma-Aldrich. Overlapping sequences are in italics; restriction sites for endonucleases are underlined

Table 22. Oligonucleotides used in this work

\begin{tabular}{lll} 
Primer & Sequence $^{\text {a }}$ & Purpose \\
\hline $\begin{array}{l}\text { cat fwd } \\
\text { (kan) }\end{array}$ & $\begin{array}{l}\text { CAGCGAACCATTTGAGGTGATAGGCGGCAAT } \\
\text { AGTTACCCTATTATCAAG }\end{array}$ & $\begin{array}{l}\text { Fwd; amplification of cat cassette } \\
\text { from pGEMcat }\end{array}$ \\
cat rev & CGATACAAATTCCTCGTAGGCGCTCGGCCAG & Rev; amplification of cat cassette \\
(kan) & CGTGGACCGGCGAGGCTAGTTACCC & from pGEMcat \\
CB21 & CGCCTACGAGGAATTTGTATCGATTGACTGAC & Fwd; down fragment LFH GP1687, \\
& TAAAGACCGGAGCT & GP1732, GP1749 \\
CB25 & TTCAGCAAGTCATTCATGCAGC & Fwd; up fragment LFH GP1687
\end{tabular}




\begin{tabular}{|c|c|c|}
\hline FR21 & CACTTAATCAGACGTGCGACATTGGCG & Fwd; check primer LFHs $r n j B$ \\
\hline FR86 & $\begin{array}{l}\text { TTTGTCGACCTTGTTTAAGTTGTAGAAAGAGT } \\
\text { TGATACCGTGG }\end{array}$ & $\begin{array}{l}\text { Rev; amplification of eno (no STOP } \\
\text { codon) for cloning into pBP43 }\end{array}$ \\
\hline FR90 & AAAGGATCCCGCTTCAAACAATCGTTGAAGC & $\begin{array}{l}\text { Fwd; amplification of eno for cloning } \\
\text { into pBP43 }\end{array}$ \\
\hline kan fwd & CAGCGAACCATTTGAGGTGATAGG & $\begin{array}{l}\text { Fwd; amplification of aphA3 cassette } \\
\text { from pDG780 }\end{array}$ \\
\hline kan rev & CGATACAAATTCCTCGTAGGCGCTCGG & $\begin{array}{l}\text { Rev; amplification of aphA3 cassette } \\
\text { from pDG780 }\end{array}$ \\
\hline ML11 & $\begin{array}{l}\text { ACAGTCGACGTAAGATTTTTTCTGGCGTCTGT } \\
\text { CACCTG }\end{array}$ & $\begin{array}{l}\text { Rev; amplification of cshA (no STOP } \\
\text { codon) for cloning into pBP43 }\end{array}$ \\
\hline ML12 & ACAGGATCCCTGGCTGAAGCTCTGAACCTTCG & $\begin{array}{l}\text { Fwd; amplification of cshA for cloning } \\
\text { into pBP43 }\end{array}$ \\
\hline ML56 & $\begin{array}{l}\text { ACAGTCGACGATAGACAGTTCTTTTGAAAGCT } \\
\text { GATACA }\end{array}$ & $\begin{array}{l}\text { Rev; amplification of } p f k A \text { (no STOP } \\
\text { codon) for cloning into } \mathrm{pBP} 43\end{array}$ \\
\hline ML57 & ACAGGATCCGTGGAGACGGTTCCTATATGG & $\begin{array}{l}\text { Fwd; amplification of } p f k A \text { for cloning } \\
\text { into pBP43 }\end{array}$ \\
\hline ML58 & ACAGTCGACAACCTCCATAATGATCGGCAGG & $\begin{array}{l}\text { Rev; amplification of } r n j A \text { (no STOP } \\
\text { codon) for cloning into pBP43 }\end{array}$ \\
\hline ML59 & ACAGGATCCCGAACAATCAACCAGCTGTATCG & $\begin{array}{l}\text { Fwd; amplification of } r n j A \text { for cloning } \\
\text { into pBP43 }\end{array}$ \\
\hline ML91 & $\begin{array}{l}\text { 5'-CCTATCACCTCAAATGGTTCGCTGTTATCA } \\
\text { CTTGTCGTCATCGTCTTTGTAG }\end{array}$ & $\begin{array}{l}\text { Rev; amplification of } p n p A \text { (no STOP } \\
\text { codon) for cloning into pBP43 }\end{array}$ \\
\hline ML92 & $\begin{array}{l}\text { ACAGGATCCGCTCGGAGATATGGACTTTAAA } \\
\mathrm{G}\end{array}$ & $\begin{array}{l}\text { Fwd; amplification of } p n p A \text { for } \\
\text { cloning into pBP43 }\end{array}$ \\
\hline ML94 & $\begin{array}{l}\text { CCTATCACCTCAAATGGTTCGCTGAGCTATTAT } \\
\text { CATTTTTTCGAACTGCGG }\end{array}$ & $\begin{array}{l}\text { Rev; down fragment LFH GP1687 } \\
\text { (from GP1724) }\end{array}$ \\
\hline ML149 & AAAAGCTCATTCAAAAATCGCTGAAG & Fwd; up fragment LFH GP1749 \\
\hline ML173 & $\begin{array}{l}\text { ACAGTCGACTACTTCCATAATAATTGGGATGA } \\
\text { TCATCG }\end{array}$ & $\begin{array}{l}\text { Rev; amplification of } r n j B \text { (no STOP } \\
\text { codon) for cloning into pBP43 }\end{array}$ \\
\hline
\end{tabular}




\begin{tabular}{|c|c|c|}
\hline ML174 & $\begin{array}{l}\text { ACAGGATCCCTCATTTACTCTAAAACAGTAGA } \\
\text { TCTTC }\end{array}$ & $\begin{array}{l}\text { Fwd; amplification of } r n j B \text { for cloning } \\
\text { into pBP43 }\end{array}$ \\
\hline ML220 & $\begin{array}{l}\text { ATAAAGCTTATGAGTAAAGGAGAAGAACTTTT } \\
\text { СACTG }\end{array}$ & Fwd; amplification of $g f p$ from $\mathrm{pSH} 3$ \\
\hline ML221 & $\begin{array}{l}\text { ATAAAGCTTTTATTTGTATAGTTCATCCATGCC } \\
\text { ATGTG }\end{array}$ & Rev; amplification of $g f p$ from $\mathrm{pSH} 3$ \\
\hline NC1 & $\begin{array}{l}\text { AAAGGATCCTTGAAAAAGAAAAATACAGAA } \\
\text { AACGTTAGAATTATCGCCC }\end{array}$ & Fwd; up fragment LFH GP1732 \\
\hline NC2 & $\begin{array}{l}\text { TTTAAGCTTTTATACTTCCATAATAATTGGGAT } \\
\text { GATCATCGGTTTAC }\end{array}$ & $\begin{array}{l}\text { Rev; amplification of } r n j B \text { for cloning } \\
\text { into pHJS105 }\end{array}$ \\
\hline NC51 & $\begin{array}{l}\text { AAACCTAGGATGACCCCAATTATGATGGTTCT } \\
\text { CA }\end{array}$ & $\begin{array}{l}\text { Fwd; amplification of } r n y \text { for cloning } \\
\text { into pHJS105 }\end{array}$ \\
\hline NC52 & TTTGGATCCTTTTGCATACTCTACGGCTCGA & $\begin{array}{l}\text { Rev; amplification of } r n y \text { (no STOP } \\
\text { codon) for cloning into pHJS105 }\end{array}$ \\
\hline NC53 & $\begin{array}{l}\text { AAAGGATCCGGCTCAGGAAGCGGTATGGGTA } \\
\text { CCCTGCAGATGAG }\end{array}$ & $\begin{array}{l}\text { Fwd; amplification of } g f p \text { from } \\
\text { pHJS105 }\end{array}$ \\
\hline NC54 & $\begin{array}{l}\text { TTTGCGGCCGCTTATTTGTAGAGCTCATCCAT } \\
\text { GCCA }\end{array}$ & $\begin{array}{l}\text { Rev; amplification of } g f p \text { from } \\
\text { pHJS105 (with STOP codon) }\end{array}$ \\
\hline NC63 & $\begin{array}{l}\text { AAAGGATCCAAATGAAATTTGTAAAAAATGAT } \\
\text { CAGACTG }\end{array}$ & $\begin{array}{l}\text { Fwd; amplification of rnjA for cloning } \\
\text { into pHJS105 }\end{array}$ \\
\hline NC64 & $\begin{array}{l}\text { TTTAAGCTTTTAAACCTCCATAATGATCGGCA } \\
\mathrm{G}\end{array}$ & $\begin{array}{l}\text { Rev; amplification of } r n j A \text { for cloning } \\
\text { into pHJS105 }\end{array}$ \\
\hline NC65 & $\begin{array}{l}\text { AAAGGATCCAAATGAAAAAGAAAAATACAGA } \\
\text { AAACGTTAG }\end{array}$ & $\begin{array}{l}\text { Fwd; amplification of } r n j B \text { for cloning } \\
\text { into pHJS105 }\end{array}$ \\
\hline NC78 & ACAGTCGACATCACCGACACCTAAACCATCA & $\begin{array}{l}\text { Rev; amplification of } r n j B \text { (w/o C-ter } \\
\text { domain) for cloning into pGP1389 (w/o } \\
\text { STOP) }\end{array}$ \\
\hline NC79 & ACAGGATCCTCAATCTGTCCTGCAGCTGG & $\begin{array}{l}\text { Fwd; amplification of } r n j B \text { (w/o C-ter) } \\
\text { cloning into pGP1389 }\end{array}$ \\
\hline NC80 & $\begin{array}{l}\text { CCTATCACCTCAAATGGTTCGCTGTTAATCAC } \\
\text { CGACACCTAAACCATCA }\end{array}$ & Rev; up fragment LFH GP1732 \\
\hline NC107 & AATTTGAAGCCGTGGGACCG & Fwd; up fragment LFH GP1747 \\
\hline
\end{tabular}




\begin{tabular}{|c|c|c|}
\hline NC108 & $\begin{array}{l}\text { CCGGTGATATTCTCATTTTAGCCATTCTCCATT } \\
\text { CACCTCAGCAACATA }\end{array}$ & Rev; up fragment LFH GP1747 \\
\hline NC109 & $\begin{array}{l}\text { TATTATATTTTACTGGATGAATTGTTTTAGTGT } \\
\text { ACAGCTGAAGGCTGAAGAT }\end{array}$ & Fwd; down fragment LFH GP1747 \\
\hline NC110 & GCATGATCGCATCTGTTCCG & Rev; down fragment LFH GP1747 \\
\hline NC111 & ATGGCTAAAATGAGAATATCACCGGA & $\begin{array}{l}\text { Fwd; amplification of aphA3 (from } \\
\text { pDG780) }\end{array}$ \\
\hline NC112 & CTAAAACAATTCATCCAGTAAAATATAATA & $\begin{array}{l}\text { Rev; amplification of aphA3 (from } \\
\text { pDG780) }\end{array}$ \\
\hline NC113 & ATCTGGCCGATGTGGATTGC & Fwd; sequencing in aphA3 \\
\hline NC114 & AGATGTTGCTGTCTCCCAGG & Rev; sequencing in aphA3 \\
\hline NC115 & TCCGATATGGATCTAAGTGCGG & Fwd; sequencing GP1747 \\
\hline NC116 & TGCATTGTTTGAACTGCTTCAACC & Rev; sequencing GP1747 \\
\hline NC126 & $\begin{array}{l}\text { CCGGTGATATTCTCATTTTAGCCATACAATTAC } \\
\text { GAACTCCTCTCTTCG }\end{array}$ & Rev; up fragment LFH GP1748 \\
\hline NC127 & ATCGGGTTTCCGACAGCGA & Fwd; up fragment LFH GP1748 \\
\hline NC128 & $\begin{array}{l}\text { TATTATATTTTACTGGATGAATTGTTTTAGATG } \\
\text { AAAACATAAAAGGAGCCTGGG }\end{array}$ & Fwd; down fragment LFH GP1748 \\
\hline NC129 & СCATTATGTATCTTGCTTAACACTC & Rev; down fragment LFH GP1748 \\
\hline NC130 & ATTAAAGGAATTGTCATTCATGGTG & Fwd; sequencing GP1748 \\
\hline NC131 & GTTCAGTGACTGTTCCAAGCG & Rev; sequencing GP1748 \\
\hline NC132 & $\begin{array}{l}\text { TCAAATGGTTCGCTGGGTTTATCTTATTTGTA } \\
\text { GAGCTCATCCATGCCAT }\end{array}$ & Rev; up fragment LFH GP1749 \\
\hline
\end{tabular}




\begin{tabular}{lll}
\hline NC133 & CGGTGAAATGTCCGGATGC & Rev; sequencing GP1749 \\
& & \\
NC135 & $\begin{array}{l}\text { TGGAGCCACCCGCAGTTCGAAAAATGATAAA } \\
\text { GAAAAGAGGAAGGAATAATAAATGG }\end{array}$ & $\begin{array}{l}\text { Fwd; amplification of aphA3 cassette } \\
\text { from pDG780 }\end{array}$ \\
& AGCTCCGGTCTTAGTCAGTCACTAGGTACTA & $\begin{array}{l}\text { Rev; amplification of aphA3 cassette } \\
\text { from pDG780 }\end{array}$ \\
& AAACAATTCATCCAG & Rev; down fragment LFH GP1749, \\
SHU12 & GCTCATGTGCGCTTGTCTCTTG & GP1732, GP1687
\end{tabular}

anderlined bases indicate restriction sites. Italic indicates homology regions.

\subsection{Materials}

\subsubsection{Chemicals}

$\begin{array}{ll}\text { Acetic acid } & \text { ChemSolute } \\ \text { Acryl-:Bisacrylamide } & \text { Roth } \\ \text { C-di-AMP } & \text { Biolog } \\ \text { Agar } & \text { Roth } \\ \text { Agarose } & \text { PEQLAB } \\ \text { AgNO }_{3} & \text { Roth } \\ \text { Ammonium peroxydisulfate } & \text { Roth } \\ \text { Ampicillin } & \text { Roth } \\ \text { Bromophenol blue } & \text { Riedel-de Haën } \\ \text { BSA } & \text { AppliChem } \\ \text { Casamino acids (CAA) } & \text { Oxoid } \\ \text { CaCl }{ }_{2} \text { 2 } \mathrm{H}_{2} \mathrm{O} & \text { Roth } \\ \text { Casamino acids } & \text { Roth } \\ \text { CDP-Star } & \text { Roche } \\ \text { Chloramphenicol } & \text { Serva } \\ \text { Coomassie Brilliant Blue, G-250 } & \text { Roth } \\ \text { DAPI } & \text { AppliChem } \\ D \text {-desthiobiotin } & \text { IBA }\end{array}$




\begin{tabular}{|c|c|}
\hline DMSO & Roth \\
\hline dNTPs & Thermo Scientific \\
\hline Ethanol & VWR Prolabo chemicals \\
\hline Ethidium bromide & Roth \\
\hline Ferric ammonium citrate (CAF) & Fluka \\
\hline Formaldehyde & Roth \\
\hline$D-(+)$-Glucose & AppliChem \\
\hline L-glutamic acid & Roth \\
\hline Glycerol & Roth \\
\hline Glycine & AppliChem \\
\hline c-di-GMP & Biolog \\
\hline HDGreen Plus DNA stain & Intas \\
\hline HEPES & Roth \\
\hline Imidazole & Sigma-Aldrich \\
\hline IPTG & PEQLAB \\
\hline Isopropyl $\beta$-D-1-thiogalactopyranoside & Sigma-Aldrich \\
\hline Kanamycin & AppliChem \\
\hline $\mathrm{KCl}$ & Roth \\
\hline $\mathrm{KH}_{2} \mathrm{PO}_{4}$ & Roth \\
\hline $\mathrm{K}_{2} \mathrm{HPO}_{4} \cdot 3 \mathrm{H}_{2} \mathrm{O}$ & Roth \\
\hline $\mathrm{KOH}$ & Roth \\
\hline$\lambda$-DNA & Thermo Scientific \\
\hline$\beta$-mercaptoethanol & Roth \\
\hline Methanol & VWR Chemicals \\
\hline $\mathrm{MgCl}_{2} \cdot 3 \mathrm{H}_{2} \mathrm{O}$ & Roth \\
\hline $\mathrm{MgSO}_{4} \cdot 7 \mathrm{H}_{2} \mathrm{O}$ & Roth \\
\hline $\mathrm{MnCl}_{2} \cdot 4 \mathrm{H}_{2} \mathrm{O}$ & Roth \\
\hline $\mathrm{Na}_{3}$-citrate & AppliChem \\
\hline $\mathrm{NaCl}$ & Roth \\
\hline $\mathrm{Na}_{2} \mathrm{CO}_{3}$ & Roth \\
\hline
\end{tabular}




\begin{tabular}{ll}
$\mathrm{Na}_{2}-\mathrm{EDTA} \cdot 2 \mathrm{H}_{2} \mathrm{O}$ & Roth \\
$\left(\mathrm{NH}_{4}\right)_{2} \mathrm{SO}_{4}$ & Fluka \\
$\mathrm{NaOH}$ & Roth \\
$\mathrm{Na}_{2} \mathrm{~S}_{2} \mathrm{O}_{3} \cdot 5 \mathrm{H}_{2} \mathrm{O}$ & Merck \\
$\mathrm{Nile}$ Red & Slgma-Aldrich \\
$\mathrm{Ni}{ }^{2+}-\mathrm{NTA}$ Sepharose & IBA \\
Nutrient broth & Roth \\
PIPES disodium salt & Serva \\
Poly(A) 15 mer RNA & Slgma-Aldrich \\
Rifampicin & Sigma \\
Sodium dodecyl sulfate (SDS) & Roth \\
Spectinomycin & Sigma Life Sciences \\
Strep-Tactin Sepharose & IBA \\
$D$-(+)-Sucrose & AppliChem \\
Tetramethylethylenediamine & Roth \\
Tris & Roth \\
Tryptone & Roth \\
L-Tryptophan & Applichem \\
Tween-20 & Sigma-Aldrich \\
Yeast extract & Oxoid \\
Xylene cyanol & Merck \\
\hline &
\end{tabular}

\subsubsection{Auxiliary material}

$\begin{array}{ll}\text { Centrifuge cups } & \text { Beckmann } \\ \text { Cuvettes (microlitre, plastic) } & \text { Greiner } \\ \text { Eppendorf tubes } & \text { Greiner } \\ \text { Falcon tubes } & \text { Sarstedt } \\ \text { Glas beads } 0.1 \mathrm{~mm} & \text { Roth } \\ \text { Glas pipettes } & \text { Brad }\end{array}$


Micropipettes

(2.5; 20; 200; $1000 \mu \mathrm{l}$ and $5 \mathrm{ml})$

Eppendorf

PageRulerTM Plus Protein Ladder

Thermo Scientific

Petri dishes

Greiner

Pipette tips

Greiner

Poly-prep chromatography columns

BioRad

PVDF membrane

BioRad

Vivaspin ${ }^{\circledR}$ turbo 15

Sartorius

\subsubsection{Instrumentation}

\begin{tabular}{ll} 
ÄKTAprime plus & GE Healthcare \\
Autoclave LTA 2×3x4 & Zirbus Technology \\
AxioCam MRm & Zeiss \\
Axiolmager M2 Microscope & Zeiss \\
Axioskop 40 Microscope & Zeiss \\
BioLC DNA Pac PA200 4x50 mm Guard & Dionex \\
BioLC DNA Pac PA200 4x250 mm & Dionex \\
Centrifuge Heraeus FRESCO 21 & Thermo Scientific \\
Centrifuge Heraeus Megafuge 16R & Thermo Scientific \\
Centrifuge Sorvall RC 6+ & Thermo Scientific \\
Centrifuge Sorvall WX Ultraseries & Thermo Scientific \\
Chrom. Data System LC-NetII/ADC & Jasco \\
Degasser DG-2080-53 & Jasco \\
ECPlan-NEOFLUAR 100X/1.3 & Zeiss \\
Filterset 2 & AHF Analysentechnik \\
Filterset 38 BP470/40, FT495, BP525/50 & Zeiss \\
Filterset 43 BP545/25, FT570, BP605/70 & Zeiss \\
Filterset 49 G365, FT395, BP445/50 & Zeiss \\
French pressure cell press & Thermo Scientific \\
Horizontal shaker 3006 & GFL \\
\hline
\end{tabular}


HPLC Pump PU-2080Plus

Ice machine MF 36

Incubator Heraeus

Incubator shaker Innova ${ }^{\circledR} 44$ series

Labcycler

Magnetic stirrer KMO 2 basic

Mini PROTEAN ${ }^{\circledR}$ System

Molecular Imager ${ }^{\circledR}$ Gel Doc ${ }^{\text {TMXR+ }}$

NanoDrop ND-1000

pH-meter Calimatic 766

Plan Neofluar 100x/1.30

Plan Neofluar 40x/0.75

Power Pac Basic ${ }^{\mathrm{TM}}$

Press machine

Scale CP22025

Ultrospec 2100 pro spectroph.

UV Detector UV-2075Plus

Sterile bench HERA safe KS12

HiLoad 16/600 Superdex 200 pg

ThermoStat Plus

Tyssue Lyser II

Vortex

Water desalination plant
Jasco

Scotsman

Thermo Scientific

Eppendorf

SensoQuest

IKA-Werke

BioRad

BioRad

PeqLab Biotechnologie

Knick

Zeiss

Zeiss

BioRad

G. Heinemann

Sartorius

Amersham Biosciences

Jasco

Thermo Scientific

GE Healthcare

Eppendorf

QIAGEN

Schütt Labortechnik

Millipore

\subsubsection{Commercial systems}

DNeasy ${ }^{\circledR}$ Blood \& Tissue Kit

NucleoSpin ${ }^{\circledR}$ Plasmid

peqGOLD Bacterial DNA kit

QIAquick ${ }^{\circledR}$ PCR purification Kit

Roti $^{\circledR}$-Quant
QIAGEN

Macherey-Nagel

PEQLAB

QIAGEN

Roth 
6.4.5. Enzymes and antibodies

$\begin{array}{ll}\text { Alkaline phosphatase (AP) } & \text { Thermo Scientific } \\ \text { DNase I } & \text { Roche } \\ \text { Phusion DNA polymerase } & \text { Thermo Scientific } \\ \text { RNase A } & \text { Roche } \\ \text { Restriction enzymes } & \text { Thermo Scientific } \\ \text { T4-DNA ligase } & \text { Thermo Scientific } \\ \text { Anti-Strep antibody } & \text { PromoKine } \\ \text { Anti-FLAG antibody } & \text { Sigma-Aldrich } \\ \text { Anti-GapA antibody } & \text { Meinken et al., } 2003 \\ \text { Anti-Rabbit IgG } & \text { Promega }\end{array}$

\subsection{Websites and software}

\subsubsection{Websites}

\begin{tabular}{lll}
\hline URL & Provider & Usage \\
\hline $\begin{array}{l}\text { http://biotools.nubic.northwester } \\
\text { n.edu/OligoCalc.html }\end{array}$ & Northwestern University, USA & $\begin{array}{l}\text { Calculation of } \\
\text { oligonucleotide } \\
\text { properties }\end{array}$ \\
http://www.ncbi.nIm.nih.gov/pub & National Institutes of & Literature \\
med & Health, Bethesda, USA & \\
http://subtiwiki.uni-goettingen.de & General Microbiology, University & B. subtilis knowledge \\
& of Göttingen & \\
http://www.wikipedia.org & Wikimedia Foundation, Inc. & General knowledge \\
http://www.rcsb.org/pdb/home/h & Reasearch Collaboratory for & Protein structures \\
ome.do & Structural Bioinformatics (RCSB) & \\
http://www.expasy.org & Swiss Institute of Bioinformatics & Protein properties \\
& (SIB) & predictor \\
\hline
\end{tabular}




\subsubsection{Software}

\begin{tabular}{lll}
\hline Program & Provider & Usage \\
\hline AxioVision Rel. 4.7 & Zeiss & Image uptake \\
AxioVision Rel. 4.8 & Zeiss & Image uptake \\
Borwin 1.50 & Jasco & Spectra analysis \\
ChemDraw 14 & PerkinElmer Informatics & Chemical scheme \\
ChemoStar Imager & Intas & Image processing \\
Geneious 7.0.2 & Biomatters Ltd & Bioinformatics \\
Image J 1.49p & NIH & Image processing \\
ImageLab ${ }^{\text {TM Software }}$ & BioRad & Image processing \\
Mendeley Desktop 1.17.6 & PDFTron ${ }^{\text {TM }}$ Systems Inc. & References \\
Microsoft Office 2010 & Microsoft Inc. & Data processing \\
PrimeView Evaluation & GE Healthcare & Spectra analysis \\
PyMOL ${ }^{\text {TM }}$ 1.7 & Schrödinger & Protein structures \\
SciDAVis 1.D009 & scidavis.sourceforge.net & Plotting \\
\hline
\end{tabular}

\subsection{List of abbreviations}

$\begin{array}{ll}\%(v / v) & \% \text { (volume/volume) } \\ \%(w / v) & \% \text { (weight/volume) } \\ \text { ADP } & \text { adenosine diphosphate } \\ a m p & \text { ampicillin } \\ \text { AP } & \text { alkaline phosphatase } \\ \text { APS } & \text { ammonium peroxodisulfate } \\ \text { ATP } & \text { adenosine triphosphate } \\ \text { B2H } & \text { bacterial two-hybrid assay } \\ \text { bp } & \text { base pair } \\ \text { BSA } & \text { Bovine serum albumin } \\ \text { CAA } & \text { casamino acids } \\ \text { CAF } & \text { ferric ammonium citrate } \\ \text { cat } / \mathrm{cm}^{R} & \text { chloramphenicol }\end{array}$




\begin{tabular}{|c|c|}
\hline DAPI & 4',6-diamino-2-fenilindol \\
\hline $\mathrm{dH}_{2} \mathrm{O}$ & deionized water \\
\hline DMSO & dimethylsulfoxide \\
\hline DNA & deoxyribonucleic acid \\
\hline DNase & DNA nuclease \\
\hline dNTP & deoxyribonucleoside triphosphate \\
\hline EDTA & ethylendiaminetetraacetic acid \\
\hline et al. & et alia \\
\hline FA & formaldehyde \\
\hline FD & fast digest \\
\hline fwd & forward \\
\hline GFP & green fluorescent protein \\
\hline HPLC & High-Performance Liquid Chromatography \\
\hline IPTG & isopropyl- $6-D$-thiogalactopyranoside \\
\hline kan/aphA3 & kanamycin \\
\hline LB & Luria-Bertani \\
\hline LFH & long-flanking homology \\
\hline mRNA & messenger RNA \\
\hline $\mathrm{NIH}$ & National Institutes of Health \\
\hline $\mathrm{Ni}^{2+}-\mathrm{NTA}$ & nickel-nitrilotriacetic acid \\
\hline NTP & nucleoside triphosphate \\
\hline OD & optical density \\
\hline PAGE & polyacrylamide gel electrophoresis \\
\hline PCR & polymerase chain reaction \\
\hline PFK/PfkA & phosphofructokinase \\
\hline $\mathrm{Pi}$ & inorganic phosphate \\
\hline PIPES & piperazine- $N, N^{\prime}$-bis(2-ethanesulfonic acid) \\
\hline PVDF & polyvinylidene fluoride \\
\hline rev & reverse \\
\hline RNA & ribonucleic acid \\
\hline
\end{tabular}




$\begin{array}{ll}\text { RNase } & \text { ribonuclease } \\ \text { rRNA } & \text { ribosomal RNA } \\ \text { tRNA } & \text { tranfer RNA } \\ \text { RT } & \text { room temperature } \\ \text { SEC } & \text { size-exclusion chromatography } \\ \text { SDS } & \text { sodium dodecylsulfate } \\ \text { SP } & \text { sporulation } \\ \text { spec/spc } & \text { spectinomycin } \\ \text { SPINE } & \text { Strep Protein INteraction Experiment } \\ \text { TAE } & \text { Tris acetic EDTA } \\ \text { TBS } & \text { Tris buffer saline } \\ \text { TEMED } & \text { tetramethylethylenediamine } \\ \text { Tris } & \text { tris-(hydroxymethyl)-aminomethane } \\ U & \text { units } \\ \text { WT } & \text { wild-type }\end{array}$




\section{Curriculum vitae}

\section{PERSONAL INFORMATION}

Name: Nora Cascante Estepa

Date of birth: August 17th 1989

Place of birth: Soria (Spain)

Nationality: Spanish

\section{EDUCATION AND TRAINING}

\section{9/13-02/17 Ph.D. in Molecular Biology}

Georg-August University Göttingen, Göttingen (Germany).

Title of thesis: Localization and Function of RNases in Bacillus subtilis. Department of General Microbiology, Institute for Genetics and Microbiology. Supervisor: Prof. Dr. Jörg Stülke.

\section{9/12-03/13 M.Sc. in Molecular Biology}

Georg-August University Göttingen, Göttingen (Germany).

Title of thesis: Carbon metabolism and RNA processing in Bacillus subtilis. Department of General Microbiology, Institute for Genetics and Microbiology. Supervisor: Prof. Dr. Jörg Stülke.

\section{0/11-06/12 M.Sc. in Genetics and Cell Biology}

Autonomous University of Madrid (UAM), University of Alcalá (UAH) and Complutense University of Madrid (UCM), Madrid (Spain).

Title of thesis: "Reprogramación de la actividad mitocondrial en condiciones de hipoxia: regulación de la proteína NDUFA4." (Reprogramming of mitochondrial activity in hypoxia: regulation of protein NDUFA4). Department of Immunology. Supervisor: Manuel Ortiz de Landázuri

\section{0/07-09/11 Licenciatura en Bioquímica (B.Sc. in Biochemistry)}

Autonomous University of Madrid (UAM), Madrid (Spain)

Final degree project (B.Sc. Thesis): "Reprogramación de la actividad mitocondrial vía hipoxia: regulación de las proteínas NDUFA4L2 y NDUFA4." (Reprogramming of mitochondrial activity via hypoxia: regulation of the proteins NDUFA4L2 and NDUFA4). Department of Immunology, La Princesa University Hospital, Madrid. Supervisor: Dr. Manuel Ortiz de Landázuri

\section{PUBLICATIONS}

Cascante-Estepa N., Gunka K. and Stülke J. (2016) Localization of Components of the RNA-Degrading Machine in Bacillus subtilis. Front. Microbiol. 7: 1492. 